University of Louisville

ThinkIR: The University of Louisville's Institutional Repository

$6-2013$

\title{
Using discrete event simulation to improve the patient care process in the emergency department of a rural Kentucky hospital.
}

Molly Cassaro Jones

University of Louisville

Follow this and additional works at: https://ir.library.louisville.edu/etd

Part of the Operations Research, Systems Engineering and Industrial Engineering Commons

\section{Recommended Citation}

Jones, Molly Cassaro, "Using discrete event simulation to improve the patient care process in the emergency department of a rural Kentucky hospital." (2013). Electronic Theses and Dissertations. Paper 709.

https://doi.org/10.18297/etd/709

This Master's Thesis is brought to you for free and open access by ThinkIR: The University of Louisville's Institutional Repository. It has been accepted for inclusion in Electronic Theses and Dissertations by an authorized administrator of ThinkIR: The University of Louisville's Institutional Repository. This title appears here courtesy of the author, who has retained all other copyrights. For more information, please contact thinkir@louisville.edu. 


\author{
By \\ Molly Cassaro Jones \\ B.S., University of Louisville, 1982 \\ J.D., University of Louisville, 1985

\begin{abstract}
A Thesis
Submitted to the Faculty of the University of Louisville

J. B. Speed School of Engineering as Partial Fulfillment of the Requirements for the Professional Degree
\end{abstract}

\title{
MASTER OF ENGINEERING
}

Department of Industrial Engineering 


\section{USING SIMULATION TECHNIQUES TO IMPROVE THE PATIENT CARE PROCESS IN THE EMERGENCY DEPARTMENT OF A RURAL KENTUCKY HOSPITAL}

Submitted by:

Molly Cassaro Jones

A Thesis Approved on:

(Date)

by the Following Reading and Examination Committee:

Dr. Gerald W. Evans, Thesis Director

Dr. William Biles

Dr. Adel S. Elmaghraby 


\section{ACKNOWLEDGEMENTS}

I must begin by thanking my parents, Dr. Michael A. Cassaro and Catherine O. Cassaro for their encouragement and enthusiasm of this endeavor. They have instilled in me a love of academia; both its processes and its outcomes, and for that I am forever grateful.

To the Emergency Department Hospital employees, I extend sincere appreciation for their unending support in this project, and their sincere enthusiasm for beneficial information to be gained by this project. In addition, I'd like to thank the Emergency Department physicians for their input and interest in the project. Without the willingness of the employees and the physicians to be under the microscope, and to be continually accommodating in information gathering, this project would not have been possible.

I thank the staff in my office of Inspire Medical, Inc. for their patience as I focused on this project, at times leaving them to function without my assistance.

I am forever grateful to Dr. Gerald Evans, my thesis advisor, for his guidance, support, and patience throughout this project. In addition, I would like to thank my committee members, Dr. William Biles and Dr. Adel Elmaghraby for their participation on this Thesis.

Special thanks to my husband Jeff and my children, Jeffrey, Jack, Matt, Pete and Michelle, for their unending patience in this long project. I dedicate this Thesis to my children, as they are each currently studying engineering; may they love academia for its processes and outcomes. 


\begin{abstract}
The patient care process of a rural Kentucky hospital is a complex process that must be flexible in order to deal with a large variety of patient needs and a fluctuating patient volume where all patients are unscheduled. A simulation model of an average month in the emergency department was built using the Arena Simulation package. Methods for creating a simulation using Arena are included in this work. Statistics were generated from a number of different sources to create an accurate representation of the model.

The Hospital reporting shows a need to improve on two quality measures being tracked, the length of time a patient is in the emergency department from entry to completion of care, and the number of patients who leave without being seen by the physician (most often due to the length of their waiting room time prior to the initiation of care). Due to the complex nature of the emergency department and its impact by other departments of the Hospital as well as outside factors such as patient demand, the ability to quantify an expected gain from a change to the facility or to a process can be difficult to establish. A simulation model will allow for experiments on the system to be created and observed, thus enabling the Hospital to identify the best opportunities for improvement.

Experiments included in this work show changes to the emergency department facility by adding an additional patient treatment bed, and changing a policy regarding transfer of a patient from the emergency department to inpatient care in the Hospital. Both experiments show improvement in quality measures, with reduced waiting room times, fewer patients who leave without being seen by the physician, and an overall reduction in the length of stay from entry to completion of care in the ED.

In the creation of the simulation model, an objective was to develop a model that could be used to guide decision through its flexibility and statistical reliability. The model can be used to test a variety of physical or procedural changes to the emergency department, as well as to test to the impacts of increased patient volume.
\end{abstract}




\section{TABLE OF CONTENTS}

APPROVAL PAGE

ACKNOWLEDGEMENTS

ABSTRACT V v

LIST OF TABLES viii

LIST OF FIGURES $\quad$ ix

I. INTRODUCTION 1

A. Emergency Medicine in Kentucky 4

B. Emergency Medicine in Rural Kentucky 7

C. The Hospital Under Study $\quad 8$

II. REVIEW OF LITERATURE 12

$\begin{array}{ll}\text { III. RESOURCES AND TOOLS } & 18\end{array}$

$\begin{array}{lr}\text { A. Time Study Tools } & 18\end{array}$

$\begin{array}{lr}\text { B. Staff Support } & 18\end{array}$

C. Flow Chart Software 19

D. Simulation Software 19

IV. MODELING THE EMERGENCY DEPARTMENT 20

A. Formulate the Problem 22

B. Understand the System 23

C. Establish Clear Goals 25

D. Formulate the Model Representation 26

E. Data Collection 28

F. Translate into Modeling Software 35

G. Model Verification $\quad 52$

H. Model Validation $\quad 55$

I. Designing Experiments 56

$\begin{array}{lll}\text { V. RESULTS } & 60\end{array}$

$\begin{array}{ll}\text { A. Present Model } & 60\end{array}$

B. Model Modifications 62 
C. Analysis of Models Using the Paired-t Test 65

VI. CONCLUSION 70

VII. RECOMMENDATIONS 71

$\begin{array}{ll}\text { APPENDIX I } & 74\end{array}$

$\begin{array}{ll}\text { APPENDIX II } & 76\end{array}$

$\begin{array}{ll}\text { APPENDIX III } & 84\end{array}$

$\begin{array}{ll}\text { APPENDIX IV } & 87\end{array}$

$\begin{array}{ll}\text { APPENDIX V } & 89\end{array}$

$\begin{array}{ll}\text { APPENDIX VI } & 91\end{array}$

$\begin{array}{ll}\text { APPENDIX VII } & 93\end{array}$

$\begin{array}{ll}\text { APPENDIX VIII } & 95\end{array}$

$\begin{array}{ll}\text { REFERENCES } & 97\end{array}$ 


\section{LIST OF TABLES}

4.1 Patient Classifications For Arena ${ }^{\circledR}$ Simulation Model

4.2 Personnel Resources Available to Regional Hospital ED

4.3 Procedures and Durations for Events in ED Simulation Model

4.4 Number of Nurses Available for use in ED Simulation Model

4.5 Comparison of Patient Length of Stay Data Using Hospital Reporting and From Simulation Model Results (Units are in hours)

4.6 LWBS Data Comparison

5.1 Present Model Simulation Output Results

5.2 Comparison of Model Results

5.3 Comparison of Quality Measures for Present Model and Five Bed Model

5.4 Comparison of Quality Measures for Present Model and Admit Policy Model

5.5 Comparison of Quality Measures for Present Model and Five Bed Plus Admit Policy Model

A.3 ED Patient Care Tasks

A.4 Time Study Data Collection Template

A.5 Completed Time Study Data Collection Form

A.6 Acuity Level Descriptions

A.7 Monthly ED Census, X-Rays, and Admitted Patients Counts 


\section{LIST OF FIGURES}

1.1 Thirteen Year Trend of Annual Emergency Department Visits in Kentucky 1

1.2 Annual ED Patient Visits, in Millions 5

1.3 Annual Patient Volume at Regional Hospital $\quad 9$

1.4 Regional Hospital ED Floor Plan 11

4.1 Flow Chart of ED Patient Care Process 24

4.2 New Patient Arrivals by Hour of Day 33

4.3 Full Image of Hospital ED Arena ${ }^{\circledR}$ Simulation 35

4.4 Run Setup Dialog Box 36

4.5 Arena ${ }^{\circledR}$ Spreadsheet of Resources Used in the ED Simulation Model 36

4.6 Patient Arrival Schedule 38

4.7 Entry of Entity into the ED Model and Initial Assignment of Attributes 39

4.8 Modules used to Categorize Patients, Assign Attributes and Record 40 Information

4.9 Modules Representing Sign-in, Triage and Registration Activities 41

4.10 Modules to Determine if a Bed is Available And Bed Placement 42

4.11 Modules Used to Duplicate the Entity and Retain the Duplicate for Later 43 Use

4.12 Modules Representing the Patient Care Function in the Simulated ED 44

4.13 Determining if the Trauma Bed or Other ED Bed is Available 46

4.14 Initial Process Modules Simulating Care of Trauma Patient 47

4.15 Simulated Process of Moving an ED Patient to Hallway For Completion of 48 ED Care and Assignment of Bed to Level 1 Patient

4.16 Process to Update Attributes on Duplicate Entity Representing Original Entity in ED Bed 
4.17 Representation of Nurse Discharge and Room Cleaning 50

4.18 Finding Patients Waiting Too Long For Care 50

4.19 Release of Entity From the Simulation Model 51

4.20 Animation of Hospital ED During Simulation 53

4.21 Animation of Patients in Hospital ED During Simulation 54

4.22 Animation of Patient Arrivals During Simulation 54

4.23 Animation of Bed and Staff Utilization During Simulation 54

5.1 Paired-t Test of Present Model and Five Bed Model 65

5.2 Paired-t Test of Present Model and Admit Policy Model 66

5.3 Paired-t Test of Present Model and Five Bed Plus Admit Policy Model 68

A.1 Kentucky 2010 Census Results Total Population by County 75

A.8 Larger Image of Hospital Simulation Model 96 


\section{INTRODUCTION}

Emergency Departments (ED) in Kentucky, as in the United States, continue to experience increasing patient volumes. A graphical representation of this trend in Kentucky is shown below, in Figure 1.1. This trend in ED patient visits is expected to continue, and thus ED resources need to be utilized so as to make the process run as efficiently and effectively as possible. The purpose of the research described in this thesis was to create a valid discrete event simulation model of a typical rural ED, and to use the model to test modifications to the ED physical structure and patient care processes in order to identify opportunities to improve the efficiency of patient care.

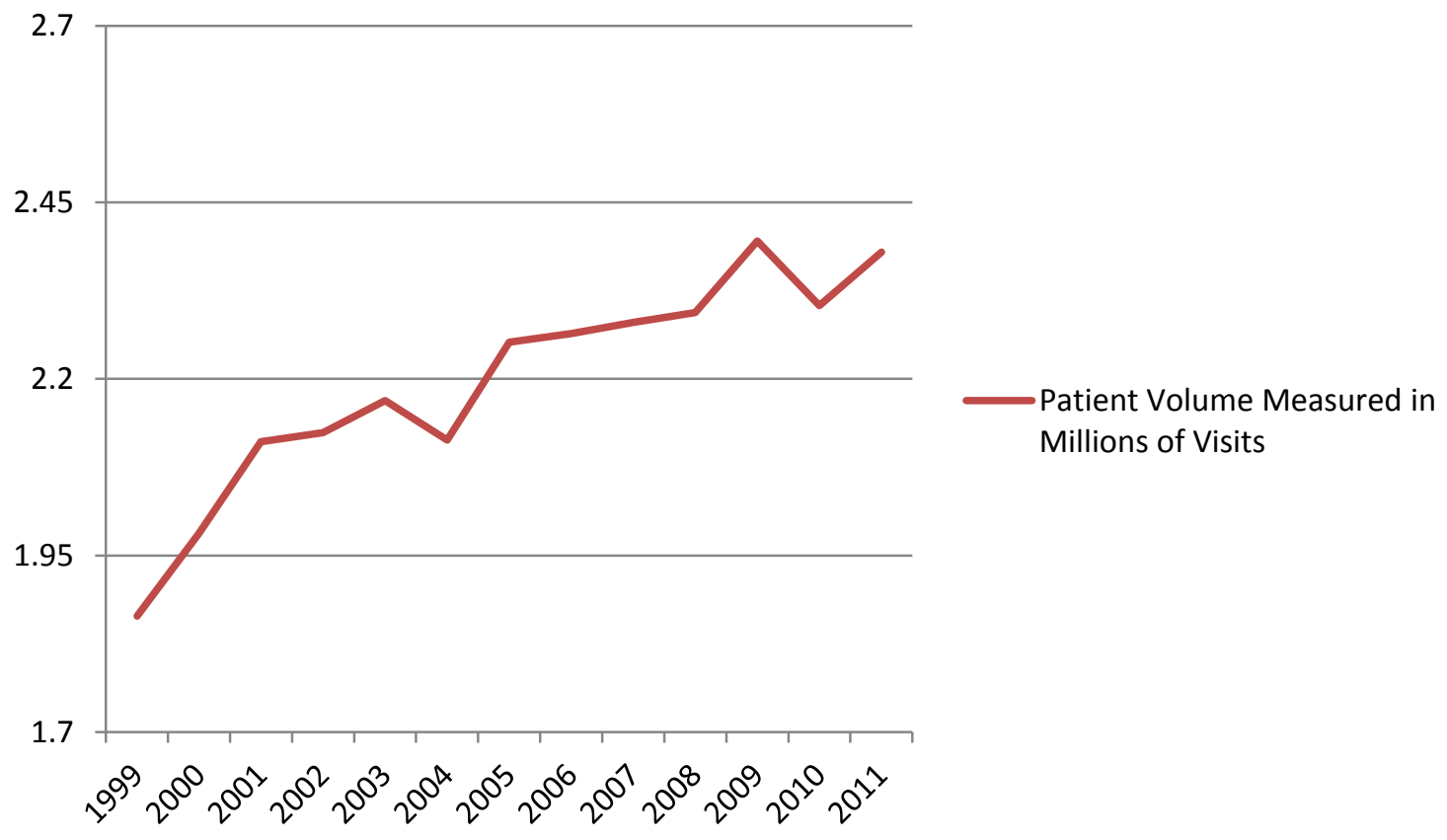

Figure 1.1 - Thirteen Year Trend of Annual Emergency Department Visits in Kentucky

This trend of increasing ED patient visits is a concern for all hospitals and contributes to a situation known as ED crowding. ED crowding occurs when the identified need for emergency care exceeds the available resources [1]. ED crowding 
leads to the inability of the ED to provide consistent, efficient and cost-effective care, while at the same time it has a negative impact on patient satisfaction and patient comes, thus leading to an increase in the potential for malpractice risk.

As the efficiency of the patient care process in the ED increases, the quality of that care can also increase. Hospitals routinely track the waiting time for patients in the $\mathrm{ED}$, and the number of patients who leave without being seen (LWBS) due to a long wait. In addition, the overall time a patient spends in the ED, from entry to the discharge, is tracked by the Hospital and of significance to the patient. Hospitals must report their measures on these statistics to the Center for Medicare \& Medicaid Services (CMS) and their accrediting agency. All of these measures correlate to the quality of care a patient will receive in the ED.

Research directed at improving ED efficiency has been conducted in the large hospital setting, where although patient capacity may be significant, it is challenged by the ever increasing number of patients seeking ED care. In contrast, this research addresses opportunities for improvement in a small rural hospital ED.

Emergency Departments in urban cities as well as those in rural areas share the same mission: to provide life saving care to patients on an immediate basis. However, their facilities and resources, including personnel and equipment, can be drastically different. In addition, the regulations that affect the hospitals can differ. These differences include:

- a rural ED is constrained in its ability to go on ambulance diversion since the next hospital may be too long an ambulance ride away for patient safety; 
- patients awaiting admission in an urban ED may be boarded in the ED if an inpatient bed is not available, however, a rural ED cannot board a patient awaiting admission, but must transfer the patient to another facility if a bed is not available;

- waiting time to transfer a patient can mean that the ED experiences a significant reduction in available beds as well as significant nurse and physician time involved in the process of transfer;

- rural ED beds are frequently used for scheduled or non-scheduled outpatient care and thus become unavailable to the ED for long periods of time each day;

- availability of laboratory work, physician specialty consultation, and radiology services can be very different;

- turn-around time for laboratory work and radiology services can be longer.

In addition to differences in facilities and resources, the patient care demands that must be met can differ significantly. Patients in the rural areas are more likely to rely on the ED for routine medical needs that in an urban setting may be more readily available in a medical office, or a clinic. Several factors contribute to this and are discussed in the next section.

Due to the differences between urban and rural EDs, process or resource modifications which improve efficiency in an urban ED may lack applicability at a rural ED. However, the results of studying a rural ED may shed light on possible improvements in other similar rural EDs. 


\section{Emergency Medicine in Kentucky}

The 2010 census recorded a population in Kentucky of 4,339,376, with $42 \%$ of its residents living in rural areas of the State. A population density map of Kentucky is shown in Figure A.1 of Appendix I. Kentucky is the 10th most rural state in the nation, and its landscape includes diverse socioeconomic settings [2]. The main industries in rural Kentucky are farming, timber and coal. Larger manufacturing companies which once existed in the rural areas have moved to locations offering lower costs for both land and labor. Those larger companies were likely to provide health insurance for their employees. With medical costs increasing, the remaining small businesses and farmers find it difficult to pay for health insurance. Much of Kentucky experiences the typical rural area characteristic of a lack of health care accessibility and affordability brought on by lack of insurance coverage for the individual, a shortage of physicians, and few health care facilities [2].

In 2011, Kentucky hospitals treated over 2.3 million patients in their emergency departments. Approximately one-half of these patient encounters occur in the emergency departments of the State's rural area hospitals [3].

Kentucky is divided into 120 counties. Kentucky has nine distinct metropolitan statistical areas, which combined include 35 of Kentucky's counties. The remaining 85 counties are considered rural areas of the state and are the locations of 65 of Kentucky's hospitals. Based on the 2010 Census, Table A.2 of Appendix II provides a listing Kentucky's nine metropolitan statistical areas, and the counties included in each area. In addition, the emergency department visits per year for the six year period from 2006 to 
2011 are shown for each of the statistical areas and for the rural counties of Kentucky.

This data was used to create the graphical representation below showing the trending increase of ED visits for all hospitals within the metropolitan statistical areas (MSA) as compared to the hospitals outside of a metropolitan statistical area (non-MSA). The total increase of ED patient visits in the rural area hospitals was greater than the increase experienced in the urban, or MSA, hospitals.

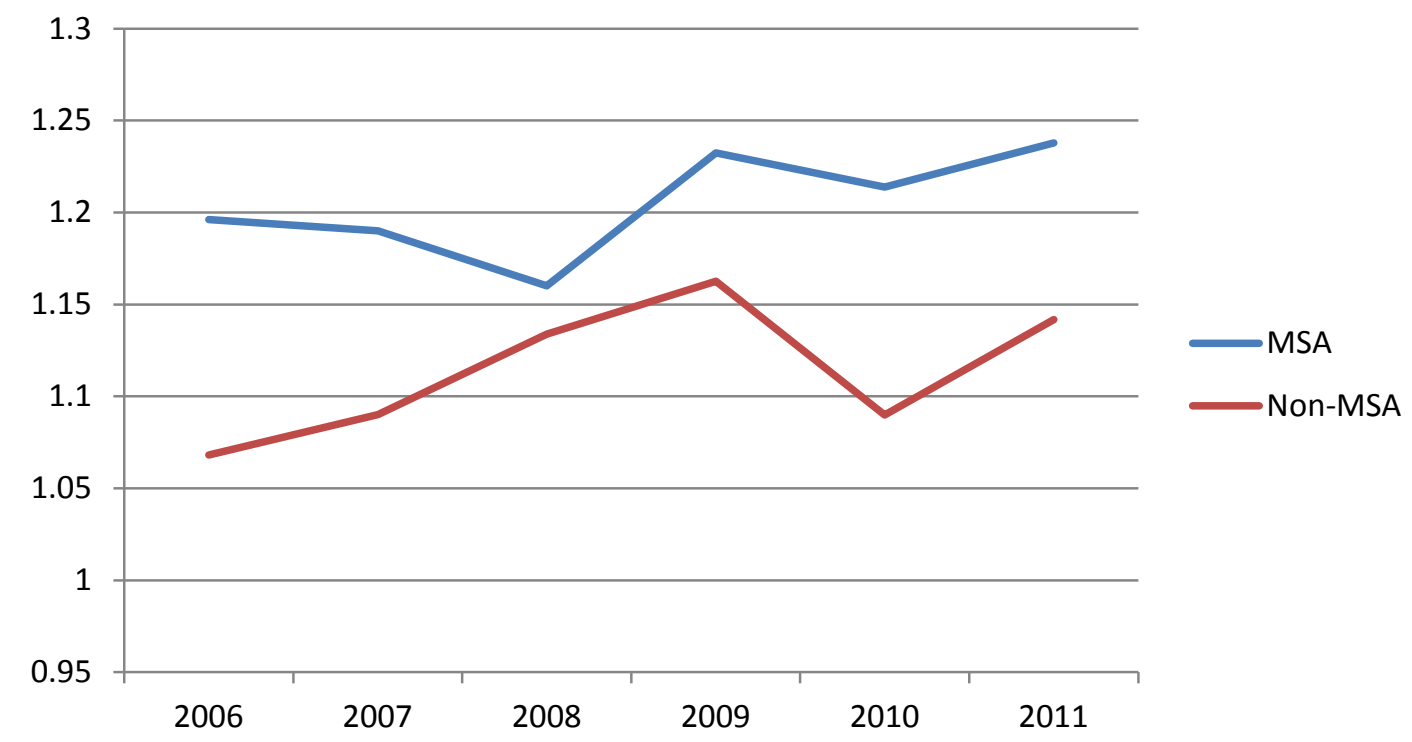

Figure 1.2 - Annual ED Patient Visits, in Millions

As the demand for medical care increases, and the number of primary care physicians and specialty trained physicians in rural areas remains low, patients are looking to the ED as the safety net for their care. The physician shortage results in long wait times for an appointment for a primary care physician and traveling long distances for care by a specialty physician. As a result, a patient's inability to get an office appointment often results in a visit to the ED where medical care can be received without an appointment. A medical condition requiring follow-up care from a specialty trained 
physician, such as a cardiologist, or orthopedic surgeon, can pose a difficult problem for a patient in the rural area where specialty trained physicians are very few, or non-existent. The inability to receive care from a specialty trained physician can result in a situation where, what would have been a routine office visit becomes an emergency, and thus a visit to the ED.

The Emergency Medical Treatment and Active Labor Act (EMTALA), was passed by Congress in 1986, and fully implemented in 1994 [4]. This Act requires that any patient presenting to a hospital seeking treatment must be provided with a medical screening examination and must be medically stable prior to discharge, regardless of their ability to pay. The Act gave all persons in the United States a legal right to emergency care, but provided no funding for this care. This federal obligation to screen or evaluate and treat as necessary, coupled with an ever worsening physician shortage in the rural areas, did not see its full effect until the late 1990's. Until this time, rural ED volumes were increasing at a slower rate. In part this is evidenced by the fact that many rural ED's did not provide physician staffing on a full time basis, and only had a physician in the ED on weekends and evenings, when local physician offices were closed. All of Kentucky's hospitals now have an in house physician around the clock. Many of Kentucky's rural EDs were constructed to serve patient demand levels based on preEMTALA conditions.

As the demand increases in the ED, the need to provide care in the most efficient manner becomes more important. The efficiency is impacted by the human resources available, including physicians, nurses trained at various levels, technicians and clerks. In addition, facility resource limitations, including floor space, and equipment can impact 
the efficiency of the ED. Further, the ED must rely on resources available from other parts of the hospital, such as the lab, x-ray, and inpatient rooms, thus creating an additional potential impact on ED efficiency. Establishing a process for patient care delivery that applies each of these resources in the most efficient manner can reduce the cost of care and at the same time increase the quality of that care. As will be explained further in the Recommendations Section of this thesis, the revenue for the hospital can also be increased.

\section{Emergency Medicine in Rural Kentucky}

A typical rural hospital ED will have four to ten patient beds. The hospital itself may have from 16 to 100 inpatient beds [5]. In most cases, ED staffing will consist of one physician on either a 12 or 24 hour schedule, in some cases a nurse practitioner or physician assistant, one to three nurses who may have overlapping shifts, and one or two technicians. A registration clerk will sign patients into the ED, and waiting room areas for patients and families may be of adequate size, or these seating areas may exist in cramped spaces, even in the hallways.

The ED physicians come from various medical specialties which can include family practice, internal medicine, pediatrics, cardiology, orthopedics, radiology, anesthesiology, general surgery, obstetrics, and many others. The rural ED physician will have to be more versatile in the care he is able to give, and many of the patients he cares for will have no primary care physician for follow-up treatment [6]. It is very unlikely that this physician will have access to specialists, within the hospital or the county, for consultation regarding a patient's care. Any consultations will be done by phone and since the physician to be consulted will be on duty at another facility, he or she will most 
likely be busy, resulting in corresponding wait times at the rural ED. There may be few other physicians in the county for support, and on occasion, the physician in the ED can be expected to provide all patient care, for all patients in the hospital, both those in the ED and those admitted and in a patient room.

\section{The Hospital Under Study}

The name of the specific hospital studied for this research will remain anonymous for privacy considerations and it will be referred to as Regional Hospital. This is a 25 bed hospital serving a county area with a population of approximately 20,000 . The hospital also serves patients residing in parts of five surrounding counties. It is a nonprofit hospital, accredited by the Joint Commission for Healthcare Organizations, and certified for Medicare and Medicaid.

The hospital facility in which the ED is located was constructed more than 20 years ago, when the ED did not provide physician staffing on a 24 hour basis as it now does, and at a time when the annual number of patients seeking care in the ED was less than one third of the current number. The square footage of the ED facility has not been increased. The ED has a total of four beds, a single triage room, a single registration counter, and a waiting room sufficient to seat approximately 20 patients and family members. ED staffing at any time will include one physician, one ED technician and one nurse with the exception of overlapping nurse shifts from 3 p.m. to 11 p.m. each week day and an additional nurse shift from 11 a.m. to 11 p.m. on Saturday and Sunday, when two nurses are in the ED. The Hospital utilizes on sight laboratory services. Radiology services available include traditional x-ray and cat scans, which are performed on site, but read by a radiologist off site. A written report from the radiology group is faxed to 
the ED. The ED can transfer patients to a hospital in Louisville, if needed for higher level care, through air ambulance. From 2001 to 2011, the annual patient volume has steadily increased from 3,572 to a current level of 9,420. Over this time frame, there has not been an increase in space, or physician staffing, and only a minimal increase in nurse and technician staffing. Figure 1.3 demonstrates this patient volume trend for Regional Hospital.

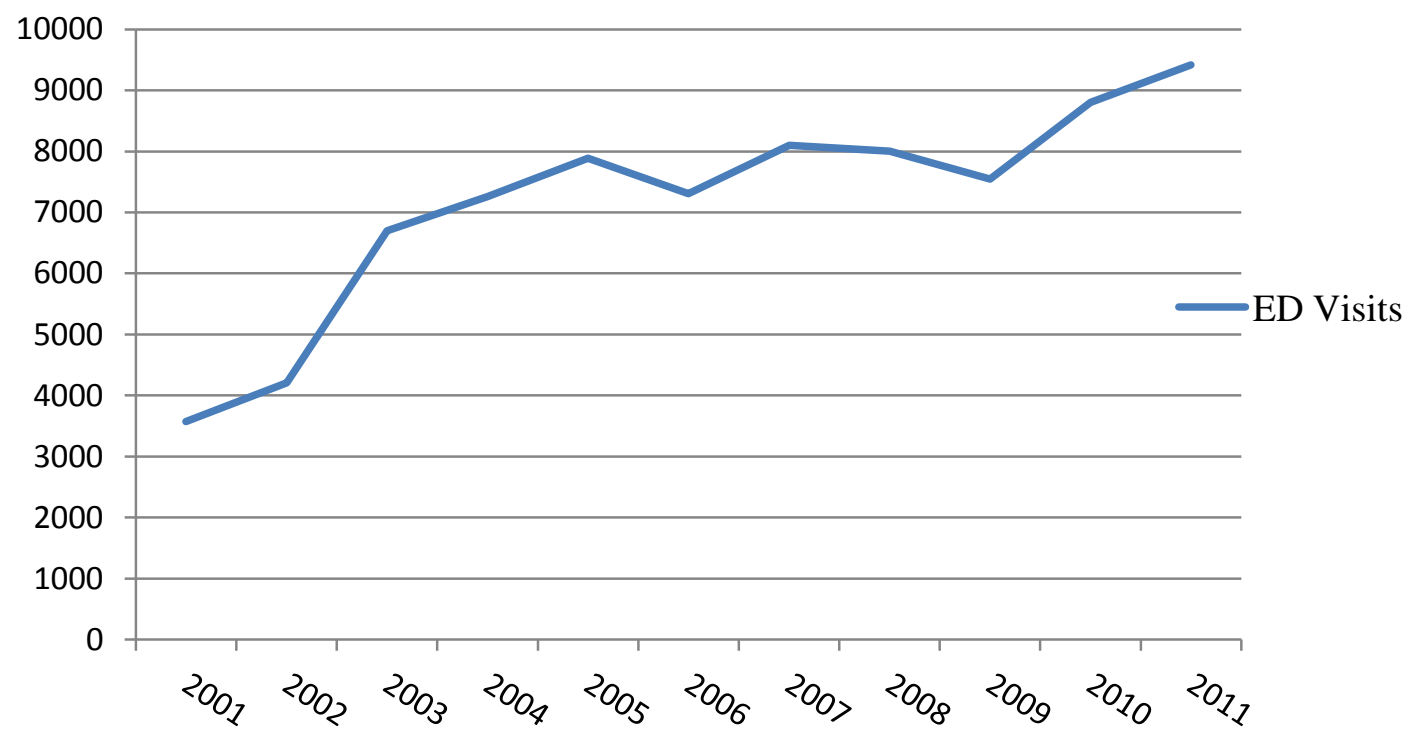

Figure 1.3 - Annual Patient Volume at Regional Hospital

Current patient wait times are long, resulting in low patient satisfaction and increasing numbers of patients who leave without being seen. The work load for ED nurses and physicians is resulting in poor job satisfaction for staff. Physicians are demanding ever increasing compensation as a result of the workload demand. There is not a commensurate increase in revenue to the hospital to provide for increased 
compensation for the staff due to several reasons, including the low reimbursement levels by government payers as well as the decreasing percentage of insured patients.

Regional Hospital is looking at the possibility of adding an additional ED treatment room. They believe they can do this by moving the nurse's break room to another area of the hospital. They are also considering the institution of a policy regarding the patients admitted to the Hospital from the ED. This new policy would require that the floor nurses transport the patient from the ED within 30 minutes of notification of the admission. Currently with no time standard attached to this patient transfer, the delay can range from 30 minutes to an hour and a half, with an expected time of 50 minutes. A simulation of the ED will allow the hospital to review the impact of either of these changes before expending resources to make facility changes or adopting protocols for policy changes. In addition a valid simulation of the ED will enable the investigation of a variety of modifications to the ED process and staffing configurations. Further, a valid simulation of this rural hospital may assist other similar rural hospitals in their investigation for improvements.

The floor plan of the ED at Regional Hospital is shown in Figure 1.4 on the following page. 


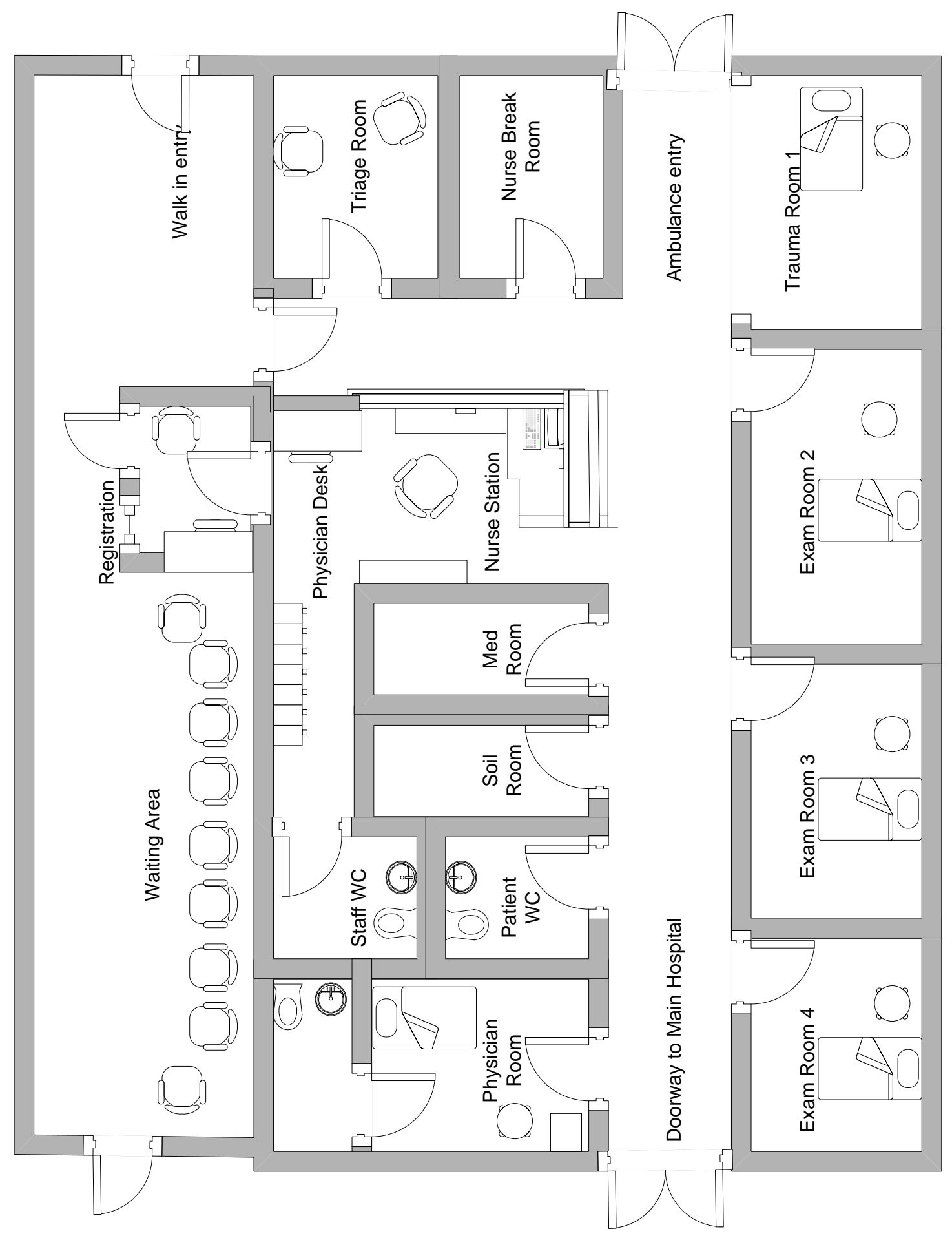

Figure 1.4 - Regional Hospital ED Floor Plan. 


\section{LITERATURE REVIEW}

The Institute of Medicine published reports in 2000 and 2001: To Err is Human [7], and Crossing the Quality Chasm [8], respectively. These reports highlighted deficiencies in the current delivery of healthcare, and they urged stakeholders to work to improve the quality and efficiency of the care process. As a result, the National Academy of Engineering collaborated with the Institute of Medicine to investigate and report on the role that systems engineering tools can play in improving health care processes [9]. From this collaboration, a recommendation was made for research that advances the application and utility of systems engineering in health care delivery with specific recommendation for the use of modeling and simulation to achieve this goal.

A review of 43 ED simulation studies reported in the literature between 1970 and 2006 presented the importance of simulation as a systems analysis tool due to its flexibility in testing scenarios, hypotheses, policy changes, and in re-engineering ideas in the healthcare settings [10]. In the studies reviewed, discrete event simulation was used to examine patient flows and the allocation of resources in the healthcare setting.

Typical scenarios tested by the models involved changes to resource availability, and process modifications. In addition, adjustments to the surrounding environment, such as incoming patient volumes and patient acuity, or increasing hospital inpatient bed availability, were tested [10].

The simulation studies provided valuable, yet somewhat general insight into the problem of ED crowding. Following the analysis of the 43 simulation studies, the authors conclude that a simulation study that can incorporate the patient perspective, can capture the patient and the healthcare providers interactions, and additionally represent 
the ED as a part of the larger hospital system, may best represent a more generalized ED model that can have applications to more than a single hospital setting [10]. Stated another way, input, throughput and output are three interdependent components of ED crowding, and all components need consideration [11].

An example of analyzing throughput from two dimensions was undertaken in a study of the effect of resource allocation against process change [12]. A two step approach was taken. In the first step, the optimal number of beds was established for the patient inflow, assuming unlimited nurses, clerks and physicians. In the second step, the mix of physicians, nurses and clerks was optimized so that the length of stay was less than 169 minutes. The simulation model was then used to test process changes such as the addition of a fast track or bedside registration, in order to maximize profit. The results provided staffing needs based on patient flow that minimized cost while ensuring a maximum length of stay was not exceeded.

There are many more examples of the modeling of changes to the ED process, or the throughput of the ED. These include: a physician triage process in place of the traditional nurse triage [13]; the addition of a fast track for patients of lesser acuity [12]; the implementation of bedside registration in place of a separate registration workstation [12]; and limiting or eliminating the boarding of patients in the ED [14].

Representing the ED as a part of the larger hospital system was demonstrated through studies in which hospital inpatient beds were added in order to reduce the incidence of ambulance diversion [11], [14]. However, when the hospital experienced a simultaneous increase in the demand for hospital inpatient beds from non-ED patients, 
thus reducing the ability to move a patient out of the ED and into the Hospital, ambulance diversion remained high [14].

An environmental factor, or an input factor, is involved when looking at the effect of ambulance diversion on ED crowding [14]. By going on ambulance diversion, the ED is reducing the potential inflow of patients, and most typically those patients arriving by ambulance will be higher acuity patients. Thus the environmental factor impacted is two dimensional: number of patients and complexity of patients [10].

Looking at only a single resource set, and without changing the process or altering environmental factors, a recent study evaluated increases to the staff of physician and clinical decision makers so as to optimize throughput with the existing non-staff resources held constant [15]. Although this may create an optimal throughput time, the cost may be prohibitive since physicians and clerical staff can represent some of the highest costs in an ED.

An important component in the creation of a valid and credible simulation model is the input data to be used [16]. The quality of the data available can influence the modeling approach and the level of detail to be included in the model. Although some steps in the ED patient care process can become standardized, the process to be applied to any particular patient will be unique from patient to patient and numerous problems can arise in collecting data to represent the ED process [10]. Issues which arose in studies contained in this review, and which were also relevant to the current work include: patient confidentiality issues, limited electronic capture of process times, the limited number of times a particular process is utilized thus limiting the availability of historical 
data, and limited information available to correlate the impact on process time based on the classification of the patient.

No single data source exists which houses all relevant ED information. Data collection methods frequently include interviews with care providers and management, on site process observations, records of historical data, review of patient charts, time and motion studies, and when available, the use of time and date stamping machines [10].

Historical data is typically relied upon for determining patient arrival times [10]. The patient's time of arrival should be documented either in a log or an electronic database. Historical data is also a good source for gaining insight on the probability of patient acuity levels [17].

Patient charts and billing records can be reviewed for collection of data regarding treatment path, ED bed time, disposal of the patient as either admit, discharge, transfer, expired in the ED, or patients who leave without being seen [17], [18], [12], [19].

Where documentation of data is not available, or is lacking in sufficient amount to provide a reliable measure, expert opinion can provide information necessary to build a credible model [20], [21]. This expert opinion can be used to provide input on both, the sequence and duration of activities in the $\mathrm{ED}[18],[13]$.

With the data gathered, various approaches have been taken in representing the data within the simulation model [13]. Patient arrivals are typically modeled as a Poisson distribution, with an intensity identified to represent various time frames; as frequently as each hour of the week [13]. Physician and nurse patient care times are often modeled using a triangular distribution [13], [21]. However in some studies, a mean treatment 
time with a normal distribution was assigned based upon the acuity level of the patient [22], [19], [17], [20].

Regardless of the distributions applied, the data gathered will present a complex relationship between the patient's need, the treatment steps to be applied, and the disposal of the patient. To address this complex relationship, there is a need to classify patients [17]. A frequent approach to patient classification in simulation studies is the use of the Emergency Severity Index (ESI) to identify a patient based upon one of five triage levels, where the level is valid for indicating the urgency of the care as well as the resource needs [10], [14], [23].

The ESI system was first developed in 1998 in response to ED crowding in order to address the need to classify patients so that the most urgent obtain treatment the soonest [23]. The Index is now in its 4 th version. In order to properly use the ESI, the triage nurse must anticipate expected resource needs such as diagnostic tests and procedures. Therefore, since resource needs are anticipated, it can be used to simulate the activities in the ED. The ESI has been found to have a moderate correlation to the difficulty of the physician's evaluation and treatment, and to nursing workload measures [10], [11], [14], [22], [21], [19].

The patient classification will have a direct impact on the modeling of the patient flow [10]. The simulation model may assign attributes to the patient based upon the patient's classification, and those attributes are used to designate the process and wait durations for the patient [14]; or a unique process path may be identified for each of the possible patient classifications [17]. 
Throughout many of the simulation studies reviewed, a reappearing solution to ED crowding was to increase available ED space, such as the addition of treatment beds [12], [11], [14]. However, the more critical resource to be examined may be the ED physician because this resource is most often the bottleneck, and thus the end result of the addition of beds is simply to move the patient queue from the waiting room to the treatment bed [10]. The simulation studies often approached the problem of ED crowding as a process related issue, and thus changes such as adding a fast track or reducing turnaround times for ancillary services were tested [10]. However, although the solution to ED crowding may be in changes to the ED processes, there is little consensus on the specific changes that can be applied with success across all EDs.

Mathematical modeling, including applications of simulation, in healthcare have appeared in the research literature since the 1950's, and the hospital settings under study have been large urban hospitals [24]. Although the studies reviewed provided insight into the manner and methods appropriate for going about the modeling of an ED, there were no examples of simulation relative to hospital patient care in a rural setting, and particularly its emergency department [25]. This is understandable when one considers that the issue of increasing patient demand, and the need for resource optimization did not become apparent in our rural hospitals until the impact of EMTALA began to be realized as discussed earlier [25]. However, these hospitals are now in need of the application of systems engineering tools in order to improving their health care processes. 


\section{RESOURCES AND TOOLS}

\section{Time Study Tools}

Traditional stop watch and paper were used for performing time studies. The time studies were used to record the times associated with staff and patient interactions, and interactions between staff. Thus, for example, the duration of a patient encounter with the registration clerk was recorded, as well as the duration of a patient encounter with the ED tech, the ED nurse, and also the ED physician. Times were tracked on a per patient visit basis, so that the various components of a patient's care were tracked from beginning to end of the visit providing a record of the sequence of events in the visit as well as a record of the duration of separately identifiable components of a visit.

\section{Staff Support}

An emergency department physician assisted in performing chart review for the purposes of obtaining information on the specific elements of the patient care process, such as x-ray, or labs, and the likelihood of various combinations of care elements within the patient care process.

\section{Spreadsheet Software}

Excel was used to create a template for collection of data during the time study, and analysis of the data gathered.

Excel was used for statistical analysis of the chart review data. Excel was also used to analyze a sample set of patient arrival data to establish expected patient arrival times. 


\section{Flow Chart Software}

Visio software was used to develop a schematic of the ED at Regional Hospital. In addition, this software was used to create a process flow diagram for patient care at the Regional Hospital ED.

\section{Simulation Software}

Rockwell Automation's Arena ${ }^{\circledR}$, software Version 12 was used to create a model of the hospital emergency department, and to test scenarios of changed circumstances, in order to identify improvements that can be made. A complete description of the model created will be discussed in the next Chapter. 


\section{MODELING THE EMERGENCY DEPARTMENT}

The Arena ${ }^{\circledR}$ software package by Rockwell Automation, [16] was used for this study. This software offers flexibility in the creation of system modeling and thus all necessary aspects of the ED can be accurately represented. In addition, the use of animation proved to be a valuable tool in quickly gaining the confidence of hospital and physician staff that the model was in fact a representation of the hospital's ED.

The following will provide information on key concepts and terms used by the Arena ${ }^{\circledR}$ software. Understanding these concepts and terms will assist in understanding the ED model created.

Key concepts used by Arena ${ }^{\circledR}$ to represent a system include entities, attributes, variables, resources and queues.

Entities are the dynamic objects in the model. They are created, flow through the model and are terminated at the end. As they flow through the model, they may change status; they may be affected by other entities, and they can change the state of the system as well as be affected by system state changes [16]. For the ED model, the entity represents a patient entering the ED for care.

An attribute is a characteristic that is attached to individual entities [16]. It will have a specific value that can differ from one entity to another. Arena ${ }^{\circledR}$ is programmed to track and record some standard attributes, but the user can create and define any entity specific characteristics needed to create a valid model. For the ED model, attributes are assigned to each entity/patient in order to define the path each entity will take through the model. These attributes include characteristics that would define the specific care a 
patient may receive in an ED. As applied to the ED model, they define the resources, or processes that will be affected by the entity, such as will x-ray or laboratory resources be utilized, how much will the physician resource be utilized, will the entity be admitted to the Hospital, transferred to another Hospital or discharged. An attribute is also used to define a priority level for the entity. This priority corresponds to a patient acuity, with more acute the patient's having a higher the priority for care.

As used in Arena ${ }^{\circledR}$, a variable is a piece of information that reflects a characteristic of the system, regardless of the entities in the system at the time [16]. There may be many variables used in a model, but each one will be unique to the system as a whole, at any time, and will be the same for all entities in the system. As with attributes, Arena ${ }^{\circledR}$ is programmed with some standard built in variables, such as a variable that tracks the current model time, or variables that track the length of each queue. But the user can create and define variables as needed to create a valid model. For the ED model, some variables defined in the system are the number of ED beds that are occupied at any time.

A resource represents things such as personnel, equipment, or space that an entity can use, consume or occupy as it moves through the system [16]. The resources are defined as a part of model creation, and their availability for use by an entity during the model run can be programmed by the user at the time the resource is defined. For the ED model, the resources are the physician, the nurses, the ED technician, the registration clerk, and the ED beds. The resource utilization is defined such that only one entity can be using or occupying the resources at any time, and additional entities needing the resource must wait. 
A queue represents the waiting entities during the model run [16]. Entities may be waiting for a resource as defined by their path through the system, or they may be waiting for a condition to occur before they can proceed to the next step in their path through the system. In Arena ${ }^{\circledR}$ each queue will have a name, which can be user defined. In addition, the queue can be created with limited or unlimited space as needed to create an accurate model. The user can also define what happens to additional entities arriving at a queue that has reached its capacity. In the ED model, the waiting room represents a queue of patients waiting for the registration clerk, or waiting for a nurse for triage, or waiting for an available bed so patient care can begin.

In the book, Simulation with Arena ${ }^{\circledR}[16]$, an outline of the key components for successfully creating a model is discussed. Although there is no "formula" for a simulation study, the most common or prevalent aspects that come up frequently are: 1) formulate the problem, 2) understand the system, 3) establish clear goals, 4) formulate the model representation, 5) collect accurate data, 6) translate into modeling software, 7) verify the model runs as intended, 8) validate the model, 9) design and run the experiments, 10) analyze results, and 11) document the report findings.

\section{Formulate the Problem}

The problem as described in the introduction section of this thesis and as regularly discussed at joint meetings of the administrative and medical staffs was the extended waiting room times for patients. This was causing high numbers for the LWBS statistic and an overall extended length of stay for the ED patients contributing to poor patient satisfaction scores. Although these discussions typically involved proposed solutions to the problem, each such proposal either lacked funding for implementation, or it lacked 
agreement among those involved that it would in fact be a solution, or both. It was suggested that a simulation model of the ED be created in order that proposed solutions could be tested without the expenditure of resources, whether they be money or staff effort in making change. Following an explanation of what to expect from a simulation model, this suggestion was approved by the hospital administrative team, and the medical staff.

\section{Understand the System}

Many people have a level of understanding regarding the functioning of an ED due to the fact that they have visited one either as a patient or with a loved one who was a patient. All participants in this research have worked directly in an ED for many years. Although this prior experience was beneficial in beginning the study with an understanding of the system, additional insight was gained from interviews with each person working in the ED, as well as interviews with other employees working in other parts of the hospital facility.

In order to gain confidence from hospital staff that the system was fully understood and appreciated, a flow chart of the general ED process was created. This flow chart is shown in Figure 4.1. 


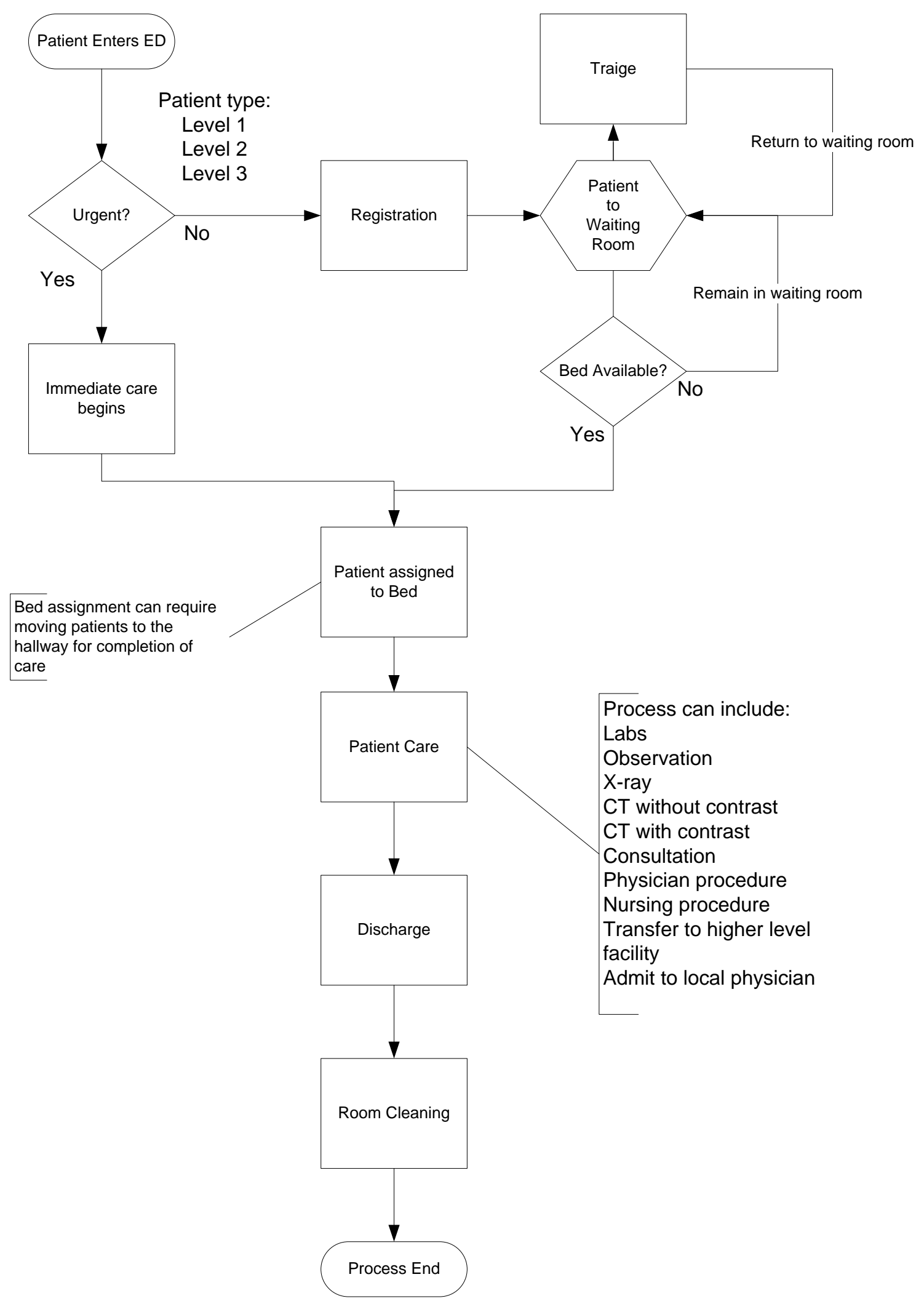

Figure 4.1 - Flow Chart of ED Patient Care Process 


\section{Establish Clear Goals}

With an understanding of modeling through the use of simulation, and a full understanding of the system to be modeled, the goals for the study were established. This process again involved meetings of the administrative and medical staffs. It was necessary that all involved were in agreement on the desired outcome of the study. After a meeting which allowed for a listing of all participants' desired goals, a follow-up meeting was help to identify and agree upon the goals which would be achievable in this initial simulation effort. The agreed upon goals were the following:

1) Create a valid simulation model representing the operations of the hospital ED as accurately as possible. The model should include an animation component in order that all staff can feel comfortable that it is a valid representation of the system.

2) The simulation model created should be created in a fashion that will allow for the testing of what-if scenarios so that many possible options for change can be tested.

3) Collect as much data from historical records or databases as possible. Where historical data is not available, data should be gathered from observation, or expert opinion.

4) Use the simulation model to test for improvement in ED efficiency. The efficiency measures to be employed are the average length of time a patient is in the ED from entry to departure, and minimizing the number of patients who leave without receiving treatment due to an excessive waiting time before they are seen by a physician. 


\section{Formulate the Model Representation}

The flowchart assisted in formulating the boundaries of the system to be modeled. As part of the patient care in the ED, the ED nurses and physicians may interact with any part of the hospital facility. For example, the laboratory may be called upon to take samples and perform testing, or the radiology department will be involved when x-rays are needed. It was agreed that including the functioning of each of these other areas would not be necessary to accurately model the ED. Delays depicting the use of another part of the hospital facility would be sufficient, and the model would be restricted to the activities occurring in the physical area designated as the ED.

It was agreed that an appropriate model would be created by constructing it so as to follow the patient through the ED. Thus, the entity moving through the model will represent an individual patient. As discussed earlier, the care a patient will receive in reality, cannot be predetermined. The particular process for treating a patient unfolds as the patient's condition is established and each step in the treatment process provides insight into the next step until care is complete. Thus, there is not a finite set of steps that can be created to define all of the possible ways to provide patient care. In order to put some definition around the patient care process in the ED, the possible different events or tasks that can be a part of patient care were identified. A description of each of these tasks is shown in Appendix III, and included with the description is a list of the resources needed to perform the task. For purposes of constructing the simulation model, the key information needed for each of these tasks are the resource needs. The specific medical procedure being performed for the benefit of the patient is not of importance, rather it's the number of procedures, or events, that will involve the patient, and the dedication of a 
resource or combination of resources that must be included. So, for example if the nurse is to draw blood from a patient, a blood drawing event is not specifically included in the model, rather there is an event that requires a nurse and it has associated with it a duration represented by a distribution. This same approach is taken for events which involve physician procedures.

The patients in the system will be divided into three types. The chart review showed that the classification designated to the patient in the billing process is a strong indication of the complexity of the care the patient received in the ED. The more complex the care provided to the patient, the more resource the patient will utilize while in the ED. For example a patient needing a simple wound cleaning with no sutures is non-complex and will entail less of the physician's time than a patient arriving due to an auto accident with multiple injuries requiring stitching and casting. Not only do these two patients differ in terms of the amount of the physician's time needed, but also in terms of the nurse's time, the need for the radiology department staff, and potentially other resources. As a practical matter, when complex care is involved for the ED patient, the physician will make numerous visits to the patient's room, as will the nurse, and the ED Tech will be called upon to assist on numerous occasions to assist the physician, the nurse, to take vital signs, or see to other comfort needs of the patient.

Table 4.1 below provides a summary description of the three types of patients that are modeled in the simulation. The probability that a new entity is assigned to one of the three classifications is shown, along with a short description of that entity. Finally, the number of physician interactions is shown. 


\begin{tabular}{|l|l|l|l|}
\hline Type & Probability & Description & Physician Interactions \\
\hline 1 & $10 \%$ & $\begin{array}{l}\text { The most emergent patient and of a complex } \\
\text { nature. These arrive by private car or } \\
\text { ambulance. They do not wait in the waiting } \\
\text { area, but are attended to immediately. }\end{array}$ & 3 to 8 \\
\hline 2 & $41 \%$ & $\begin{array}{l}\text { These are highly emergent and complex } \\
\text { patients. They may stay briefly in the } \\
\text { waiting area but will be the first patients } \\
\text { called to a bed once one is available. }\end{array}$ & 2 to 6 \\
\hline 3 & $49 \%$ & $\begin{array}{l}\text { These are patients in need of care, however } \\
\text { a long wait is not detrimental to their } \\
\text { condition. }\end{array}$ & 1 or 2 \\
\hline
\end{tabular}

Table 4.1 - Patient Classifications For Arena ${ }^{\circledR}$ Simulation Model

\section{Data Collection}

This study made use of five techniques for data collection: management interviews, first hand observation, review of a sample of patient records, annual hospital reporting, and expert opinion.

An interview with the Head of Nursing provided information regarding the personnel resources available to the Hospital ED. The ED is staffed by at least one registered nurse at all times. The nurses work on 8 or 12 shifts. In each 24 hour day, two nurses will each take a 12 hour shift. In addition, on weekdays, a nurse will assist in ED staffing by working an 8 shift. This 8 shift will overlap the end of the first nurse 12 hour shift of the day and the beginning of the second nurse 12 hour shift of the day. This scheduling scheme serves two purposes: It provides additional nursing support during times of the day in which the number of patients seeking care at the ED have been statistically higher, and it enables a smoother transition of patient care for those patients who begin care while the first shift nurse is on duty and end their care under the second shift nurse. The nurses described here are dedicated to ED patient care and do not provide care to other 
patients in the Hospital. On Saturdays and Sundays, the nurse scheduled with a shift that overlaps the first and second shift nurses is scheduled for a full 12 hour shift, due to the increased patient load on these days.

There is one physician on duty at all times in the ED. Physician shifts are 12 hours in duration. The ED physician can be called to other areas of the Hospital to provide patient care if a patient emergency exists and there is no other available physician to provide the care. The ED physician can choose to work two consecutive shifts and a room is available for resting during times there are no patients in the ED.

The ED is staffed by an ED Technician. The Technician is fully available to the $\mathrm{ED}$ and assists in maintaining the patient chart, and transporting or escorting patients to various treatment rooms or other departments of the hospital. Additionally, they will assist the physician or nurse during examinations and treatments, monitor vital signs and stock and clean the patient rooms between patients. The ED Technician is scheduled on the basis of a 12 hour shift, and there is no increase in technician staffing due to increases in patient numbers.

One Registration Clerk is scheduled at all times in the ED. This Clerk will sign-in and register all patients arriving to the ED. The Clerk will acquire all appropriate demographic and insurance information from the patient, and ensure all registration forms are completed. Due to the light workload associated with the ED patient registration function, this staff member may often be utilized by the Hospital to assist in additional paperwork and reporting activities.

The resources discussed above are listed in Table 4.2 with their corresponding shift descriptions. 


\begin{tabular}{l|c|l|l} 
Resource & Quantity & Shift Length & Frequency \\
\hline First Shift Nurse & 1 & $7 \mathrm{am}$ to 7pm & Seven days a week \\
\hline Second Shift Nurse & 1 & $7 \mathrm{pm}$ to 7am & Seven days a week \\
\hline Overlap Nurse & 1 & $3 \mathrm{pm}$ to $11 \mathrm{pm}$ & Monday to Friday \\
\hline Overlap Nurse & 1 & $11 \mathrm{am}$ to $11 \mathrm{pm}$ & Saturday and Sunday \\
\hline First Shift ED Tech & 1 & $7 \mathrm{am}$ to 7pm & Seven days a week \\
\hline Second Shift ED Tech & 1 & $7 \mathrm{pm}$ to 7am & Seven days a week \\
\hline First Shift Registration Clerk & 1 & & \\
\hline Second Shift Registration Clerk & 1 & & \\
\hline First Shift Doctor & 1 & $6 \mathrm{am}$ to 6pm & Seven days a week \\
\hline Second Shift Doctor & 1 & $6 \mathrm{pm}$ to 6am & Seven days a week
\end{tabular}

Table 4.2 - Personnel Resources Available to Regional Hospital ED

Time studies were conducted to gather first hand observations of the patient care process in the ED. These occurred on six occasions, each lasting for an eight hour period. The configuration of the ED enabled one observer, placed at the nurses' station, to track patient interactions at the registration desk, the triage room, and each of the four patient care rooms. For purposes of this study, no patient information was collected. Regardless of the medical need, only the sequence of staff encounters with the patient were recorded, along with the time duration of the encounter. Appendix IV provides a template used for the time study. A portion of a completed template is shown in Appendix V. An " $x$ " is used to designate the event, with the event start time logged in the right most column and the end time of the event logged in the left most column.

The primary outcome of the time study was to provide first hand information on actual times for various processes such as triage, registration, initial nurse patient care, initial physician care, follow-up care by the nurse and by the physician, discharge by the nurse and by the physician, and wait times for lab, or x-ray. The time study also provided an indication of the flow of resources in the patient care process. However, due to the variety of patient needs in the ED setting, the numerous approaches to addressing a 
medical need, and the impact that each patient's condition may have on the resource availability for other patients in the ED, the time study was limited in providing specific process times for all possible components of ED patient care. The more straight forward process, such as the ED technician performing a blood pressure and temperature check of a stable patient, were amply recorded. In the future, with the full implementation of electronic medical records, data on a greater number of the components of ED patient care may be available in electronic format.

The time study provided an opportunity to gain a full understanding of the process flow of the ED. Once the patient is placed in an ED bed, the typical process flow involves a nurse interaction with the patient, followed by a physician interaction and then if testing or procedures are ordered, those are performed, followed by a nurse interaction and then physician interaction. Depending on the acuity of the patient, numerous tests or procedures may be performed, and the sequence of physician and nurse interactions may be repeated numerous times. A nursing procedure or a physician procedure may be necessary resulting in a prolonged nurse or physician interaction with the patient.

To supplement the data obtained through first hand observations, a review of patient charts was undertaken. This review was performed on patient charts reflecting care in the ED for 448 patients treated in March of 2011. A physician who provides ED patient care at Regional Hospital facilitated the chart review in order that an accurate log of medical testing, ED tech care, nurse care, and physician care could be established. The chart review was performed on patient charts that had completed the hospital billing process. As a part of the billing process, an acuity level is assigned to each patient. This 
acuity level is an indication of the resources utilized in the care of the patient. The acuity level descriptions used by the Hospital are shown in Appendix VI.

The chart review did not provide information on the duration of any event in the care process, but rather was for the purpose of identifying typical steps of the care process based on the patient's acuity level.

Hospital reports were utilized to determine the monthly total number of x-ray orders, the total number of patients admitted from the ED and the number of patients transferred to another hospital. Appendix VII provides a report of the number of these events during each month of 2011, with corresponding ED patient census.

The Hospital provided a computer printout showing the patient arrival and discharge times of all patients receiving ED care from January 1, 2011 through December 31, 2011. A sample of this data was extracted to create an inter-arrival time for each hour of the day. In order to account for fluctuations in patient volumes over the year, the sample consisted of ten weeks of data, and was created by taking a full week of arrival times beginning at 12:01 a.m. on day one of the week and ending at midnight on the seventh day. Every fifth week was extracted in this manner in order to capture all parts of a month in the sample. This data was entered into Excel, and provided for a total of 1720 arrival times. Using Excel, the data was analyzed to provide the average expected number of patients arriving in an hour based on the hour of the day. The fluctuation of arrival rates based on the day of the week were not taken into consideration. A graphical representation of the patient arrival rates over a 24 hour day is shown below in Figure 4.2 . 


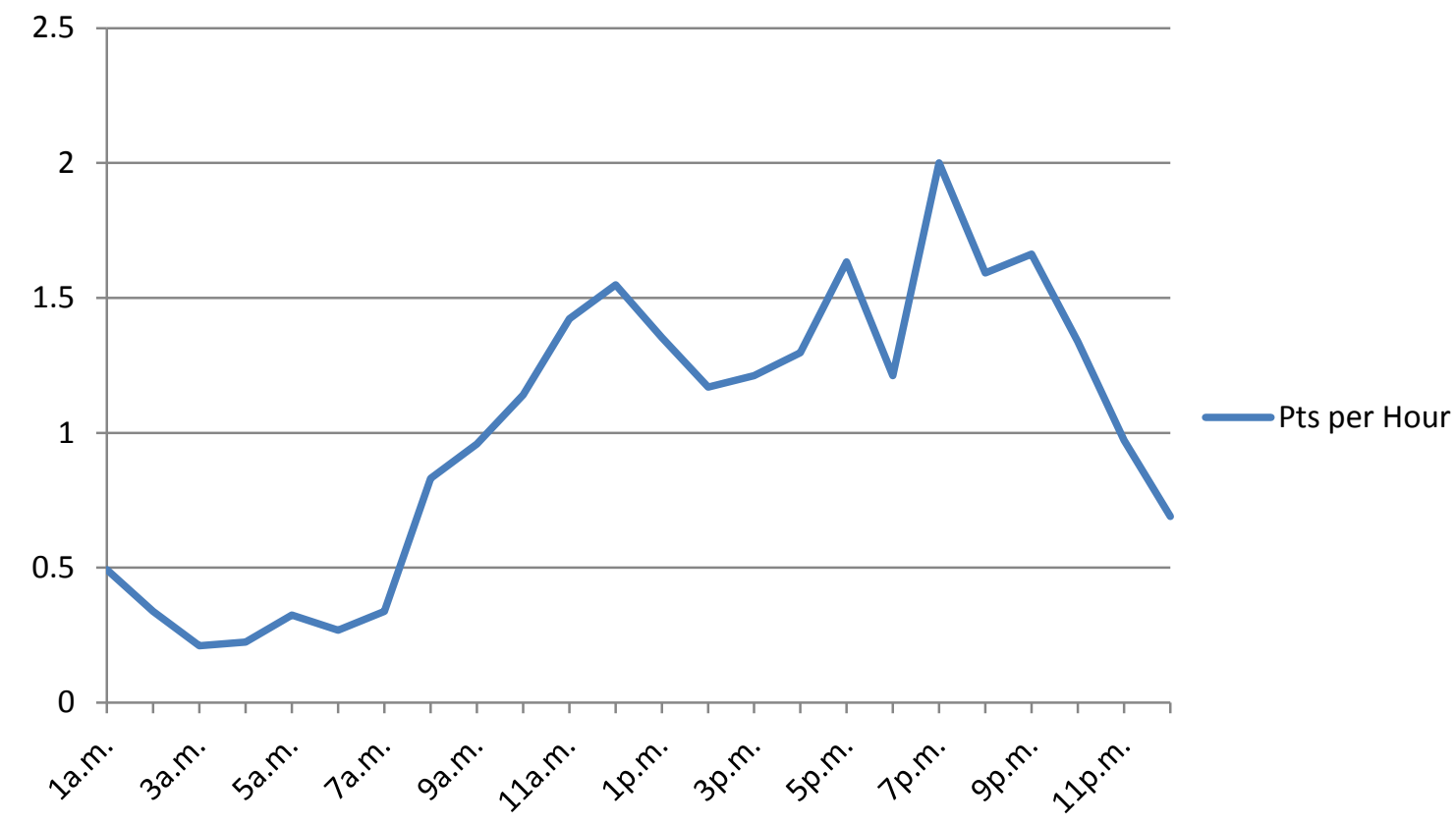

Figure 4.2 - New Patient Arrivals by Hour of Day

The information obtained from the first hand observations and the chart review was not sufficient to establish the expected duration of all events. Therefore, expert opinion was received from stakeholders for purposes of establishing the expected duration of the following activities:

1) Laboratory testing

2) Standard X-ray

3) CAT scan

4) Consultation with another physician

5) Transfer to a higher level hospital

6) Nurse procedure

7) Physician procedure 
Table 4.3 below provides a list of event descriptions and the statistical distribution of their expected duration.

\begin{tabular}{|c|c|c|}
\hline Patient Care Process & Distribution & Parameters (In Minutes) \\
\hline Patient Sign In & Triangular & $0.5,1.0,1.5$ \\
\hline Triage & Triangular & $4.0,6.0,8.0$ \\
\hline Patient Registration & Triangular & $3.0,4.0,8.0$ \\
\hline Escort to Room & Triangular & $1.0,2.0,4.0$ \\
\hline $\begin{array}{l}\text { Nurse and Tech Move Patient to } \\
\text { Hallway for Care }\end{array}$ & Triangular & $4.0,7.0,9.0$ \\
\hline Triage Critical Patient & Triangular & $4.0,6.0,8.0$ \\
\hline Physician Care Critical Patient & Triangular & $4.0,6.0,10.0$ \\
\hline Nursing Care & Triangular & $2.0,4.0,9.0$ \\
\hline Physician Care & Triangular & $3.0,4.0,8.0$ \\
\hline $\begin{array}{l}\text { Delay for Drawing Lab Before } \\
\text { XRay or CT }\end{array}$ & Triangular & $5.0,7.0,12.0$ \\
\hline Delay for Labs Drawn and Run & Triangular & $15.0,30.0,60.0$ \\
\hline X-Ray & Triangular & $10.0,18.0,30.0$ \\
\hline $\mathbf{C T}$ & Triangular & $45.0,55.0,120.0$ \\
\hline Observation & Triangular & $60,120.0,300.0$ \\
\hline Contact Admitting Physician & Triangular & $5.0,10.0,30.0$ \\
\hline $\begin{array}{l}\text { Delay for Floor Bed or } \\
\text { Transport }\end{array}$ & Triangular & $30.0,50.0,90.0$ \\
\hline Nurse Discharge & Triangular & $6.0,10.0,14.0$ \\
\hline ED Tech Clean Room & Triangular & $2.5,4.0,7.0$ \\
\hline
\end{tabular}

Table 4.3 - Procedures and Durations for Events in ED Simulation Model 
In addition, a hospital report showing the patient arrival and departure times for all ED patients presenting to the Hospital in 2011 was utilized in order to establish an historical average length of stay for ED patients. This was used to validate the model.

\section{Translate into Modeling Software}

With the goals established, the model formulated and the data collected, a simulation model could be constructed. Rockwell Automation's Arena ${ }^{\circledR}$, Version 12 software was used. Figure 4.3 presents an image of the full simulation model. The following discussion will present the components of the model as well as statistics and data utilized for the process and recourses. A larger image of the model is shown in Appendix VIII.

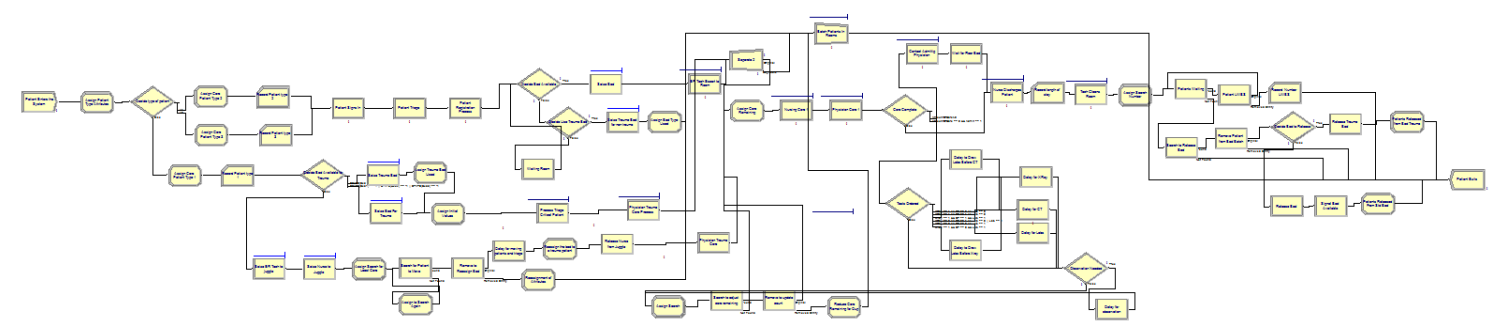

Figure 4.3- Full Image of Hospital ED Arena ${ }^{\circledR}$ Simulation

A few overall parameters were established for the model. These are specified in the Run Setup dialog box. The "Number of Replications" field was set to 100. This designates that the model will be run for 100 iterations and statistics will be gathered for each run. These multiple replications will reduce the variance and increase the reliability of the averages in the output. All statistics were initialized at the beginning of each replication. The base time units for the system were set to hours, and all expressions and 
statistics throughout the model are in terms of hours unless otherwise indicated. The model was set up to have a 48 hour warm up since the ED is always open, a warm up time would more likely simulation the ongoing nature of the ED. The system will begin to gather statistics following this warm up period. The replication length is set at 768 hours, or one, 30 day month. No terminating condition is needed since it will terminate after the lapse of 768 system hours.

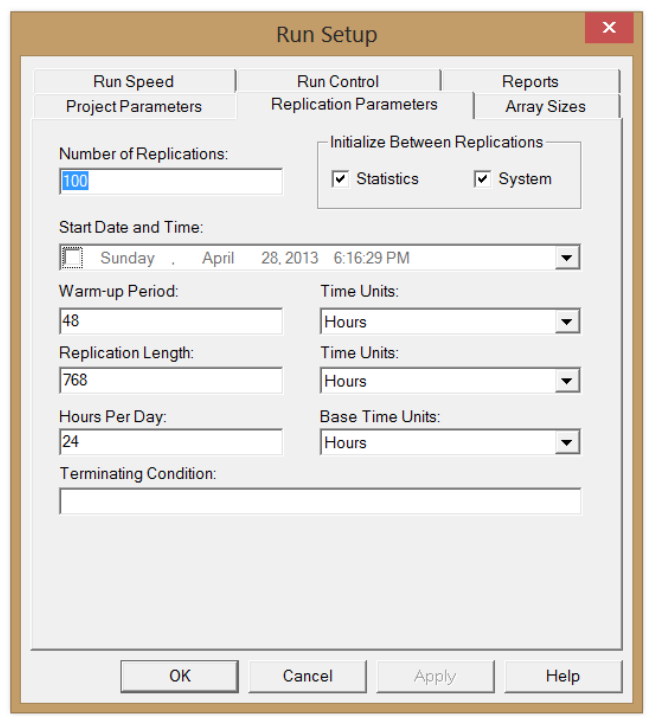

Figure 4.4 - Run Setup Dialog Box

The resources were identified in the system by entering them into the Resource spreadsheet of the Basic Process panel. Figure 4.5 shows this spreadsheet.

\begin{tabular}{|c|c|c|c|c|c|c|c|c|c|c|c|}
\hline \multirow[t]{2}{*}{ Resource } & \multicolumn{11}{|l|}{ Basic Process } \\
\hline & Name & Type & Capacity & Schedule Name & Schedule Rule & Busy / Hour & Idle / Hour & Per Use & StateSet Name & Failures & Report Statistics \\
\hline 1 & Bed1 & Fixed Capacity & 1 & 1 & Wait & 0.0 & 0.0 & 0.0 & & 0 rows & $\sqrt{V}$ \\
\hline 2 & Bed2 & Fixed Capacity & 1 & 1 & Wait & 0.0 & 0.0 & 0.0 & & 0 rows & V \\
\hline 3 & Bed3 & Fixed Capacity & 1 & 1 & Wait & 0.0 & 0.0 & 0.0 & & 0 rows & v \\
\hline 4 & Bed Trauma & Fixed Capacity & 1 & 1 & Wait & 0.0 & 0.0 & 0.0 & & 0 rows & v \\
\hline 5 & Traige Room & Fixed Capacity & 1 & 1 & Wait & 0.0 & 0.0 & 0.0 & & 0 rows & v \\
\hline 6 & Physician & Based on Schedule & Physician Schedule & Physician Schedule & Ignore & 0.0 & 0.0 & 0.0 & & 0 rows & v \\
\hline 7 & Nurse1 & Based on Schedule & nurse2 schedule & nurse2 schedule & Ignore & 0.0 & 0.0 & 0.0 & & 0 rows & V \\
\hline 8 & Nurse2 & Based on Schedule & nurse3 schedule & nurse3 schedule & Ignore & 0.0 & 0.0 & 0.0 & & 0 rows & v \\
\hline 9 & Nurse3 & Based on Schedule & nurse1 schedule & nurse1 schedule & Ignore & 0.0 & 0.0 & 0.0 & & 0 rows & V \\
\hline 10 & Registration Clerk & Fixed Capacity & 1 & 1 & Wait & 0.0 & 0.0 & 0.0 & & 0 rows & V \\
\hline 11 & ER Tech & Fixed Capacity & 1 & 1 & Wait & 0.0 & 0.0 & 0.0 & & 0 rows & v \\
\hline
\end{tabular}

Figure 4.5 - Arena ${ }^{\circledR}$ Spreadsheet of Resources Used in the ED Simulation Model 
The staff resources include, physician, nurse1, nurse 2 and nurse 3 , a registration clerk, and an ED technician. The clerk and technician have a fixed capacity of one, and the physician and nurses are available based on a schedule. The physician schedule allows for short breaks during a 24 hour shift, however, if patient care is occurring at the time for the break, the break is ignored. Breaks, for the clerk and technician, whether for meals or otherwise are assumed to occur during times patient care is not immediately needed. Using the nurse resource levels and shift scheduling information obtained from management interviews, a schedule was created for use by Arena ${ }^{\circledR}$, and is shown in the following table. For purposes of this table, time begins at 12:01a.m. on a Monday. The total hours represented is 168 , or one full week, after which the schedule repeats.

\begin{tabular}{|l|l|}
\hline$\#$ of Nurses & Duration in Hours \\
\hline 1 & 15 \\
\hline 2 & 8 \\
\hline 1 & 16 \\
\hline 2 & 8 \\
\hline 1 & 16 \\
\hline 2 & 8 \\
\hline 1 & 16 \\
\hline 2 & 8 \\
\hline 1 & 16 \\
\hline 2 & 8 \\
\hline 1 & 12 \\
\hline 2 & 12 \\
\hline 1 & 12 \\
\hline 2 & 12 \\
\hline 1 & 1 \\
\hline
\end{tabular}

Table 4.4 - Number of Nurses Available for use in ED Simulation Model 
The other resources include the triage room, three treatment beds, and one trauma bed, typically used for more severe patients. Each of these resources has a fixed capacity of one, and there is no down time considered.

One Create Module is used to bring entities / patients into the model. One patient arrives at a time, and the number of possible patients entering the ED is set to infinite. The rate at which the patients arrive is controlled by a schedule, designated "Arrival Schedule". The data, as represented above in Figure 4.2 above, was input to an Arena ${ }^{\circledR}$ spreadsheet and is show in Figure 4.6.

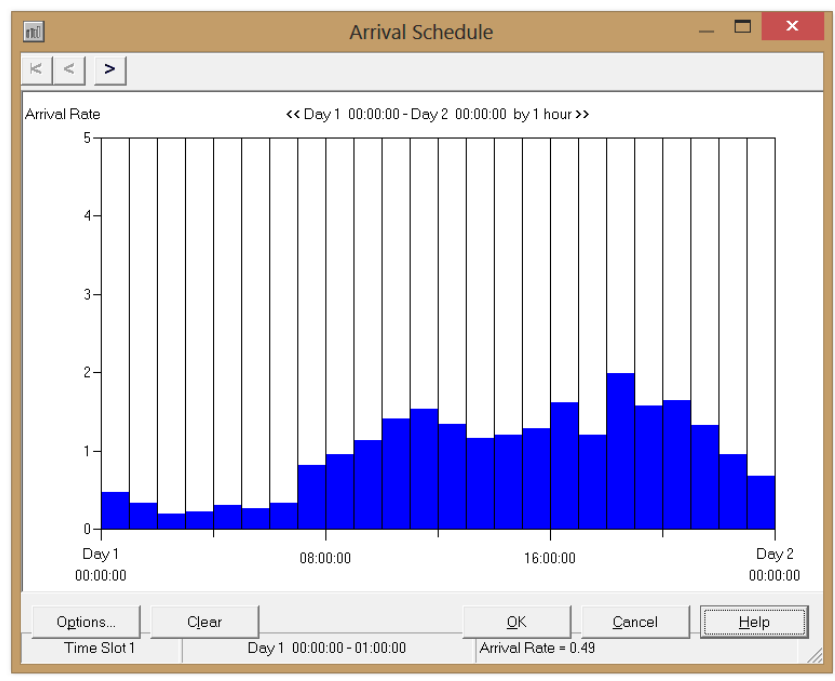

Figure 4.6 - Patient Arrival Schedule

Immediately upon entry into the system, the patient enters an Assign Module where attributes are assigned. The time the patient entered the system becomes an attribute of that patient. A variable used to count all patients entering the system is incremented by one, and then this variable is recorded as an attribute so all patients 
entering will have a unique number. Figure 4.7 shows the modules controlling the entry of a patient and the initial assignment of attributes.

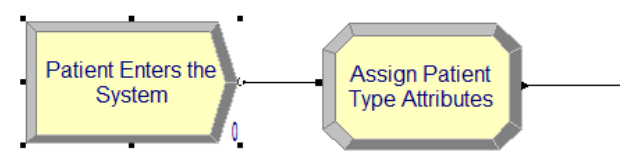

Figure 4.7 - Entry of Entity into the ED Model and Initial Assignment of Attributes

Following this initial assignment of attributes, the patients are routed for additional attribute assignments. A Decide Module is used to separate the entities into one of three types. Based upon Table 4.1 above, $10 \%$ of the entities are sent to an Assign Module for assignment of type 1 patient characteristics, $41 \%$ are sent to an Assign Module for assignment of type of 2 patient characteristics, and $49 \%$ are sent to an Assign Module for assignment of type 3 patient characteristics. In each of the three different Assign Modules the patients will be assigned additional attributes that will quantify the care the patient will receive while in the system. The care is quantified as the number of times the nurse or physician will interact with the patient, whether the patient will receive ancillary services such as labs, x-ray, or a CT scan, whether the patient will be delayed for observation in the ED, and whether the patient will be admitted to the Hospital or transferred to another hospital.

As a next step, the system records the type of each patient that has entered the system. The modules representing this decide and the assign and record events are shown in Figure 4.8 below. 


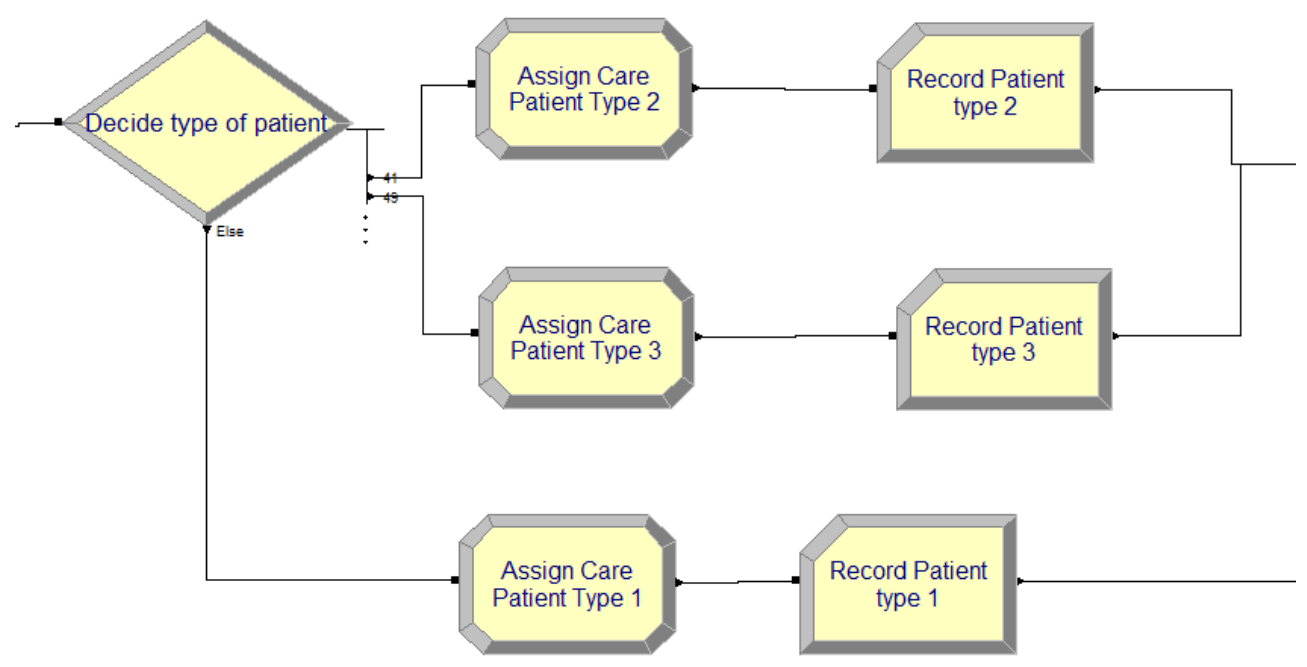

Figure 4.8 - Modules used to Categorize Patients, Assign Attributes and Record Information

At this point, the less acute patients, those designated type 2 and 3 take a different path in the system than the more acute patients of type 1 . The path for type 2 and 3 patients will be described, after which the path for type 1 will be described.

For patients of type 2 and 3, the process will be as follows: The patient will be delayed to represent the sign in process at the ED. This is a short process that does not necessitate a resource. After the sign in process, the patient will await a nurse to perform the triage function. Resources required for this event are a nurse and the triage room. The patient will then proceed to the registration clerk for registration into the ED. The modules sign-in, triage, and registration are shown in Figure 4.9 below. 


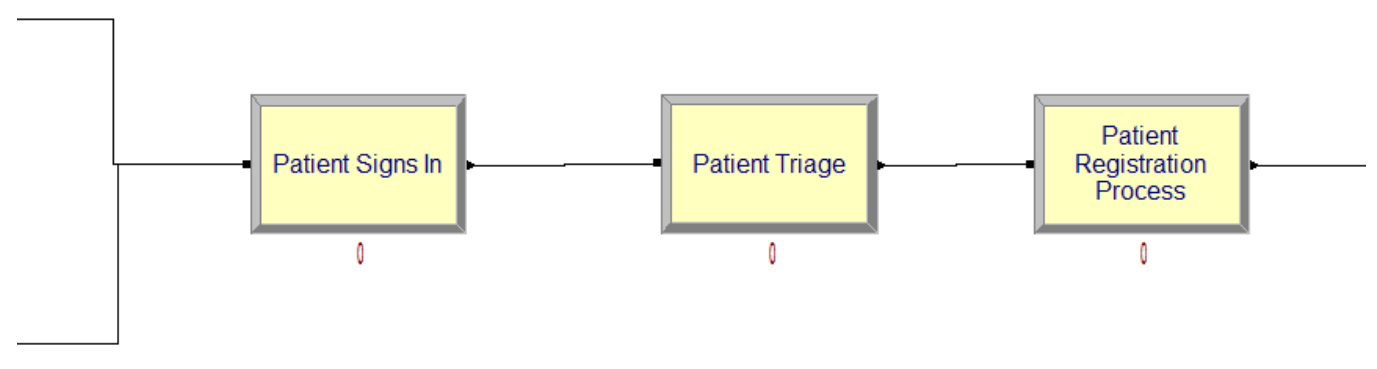

Figure 4.9 - Modules Representing Sign-in, Triage and Registration Activities

Following the registration event, the patient enters a Decide Module to determine whether a bed is available or the patient must wait in a waiting room for a bed. The system will look to see if any of the three ED beds are available. If this is a true situation, the patient will seize the bed and the ED Technician will perform the event of escorting the patient to the bed. Seizing the bed is separated from the event of the technician escorting the patient to the bed due to the fact that in reality, once a bed becomes available, the nurse will designate which waiting patient will be placed in the bed. At this point, the bed is in essence designated for a particular patient and thus for all practical purposes is no longer available. If the ED technician is busy at the time the nurse makes this decision, the bed remains designate for the patient, and the technician will be seized for escort when he or she ends the event causing the busy status.

If, following the registration event, one of the three ED beds is not available, a Decide Module is used to determine whether the bed designated for trauma patients should be utilized. This decision is based on a current practice of keeping the trauma bed available for use when a trauma patient enters the system, however to balance the need to 
reduce patient waiting time, this bed will be used for a non-trauma patient if there are more than four patients in the waiting room. Therefore, if this condition is true, and the trauma bed is idle, the patient will be placed in the trauma bed. Seizing this bed and escorting the patient occurs in the same manner as described above. An additional attribute is assigned to the patient to track that this patient is in the trauma bed. This will allow for the correct bed to be released when the patient is discharged.

If following registration, the patient is not placed in a bed, it is sent to the waiting room. The modules representing these Decide Modules, the events of seizing the beds and technician interaction, and the waiting room are shown in Figure 4.10 below.

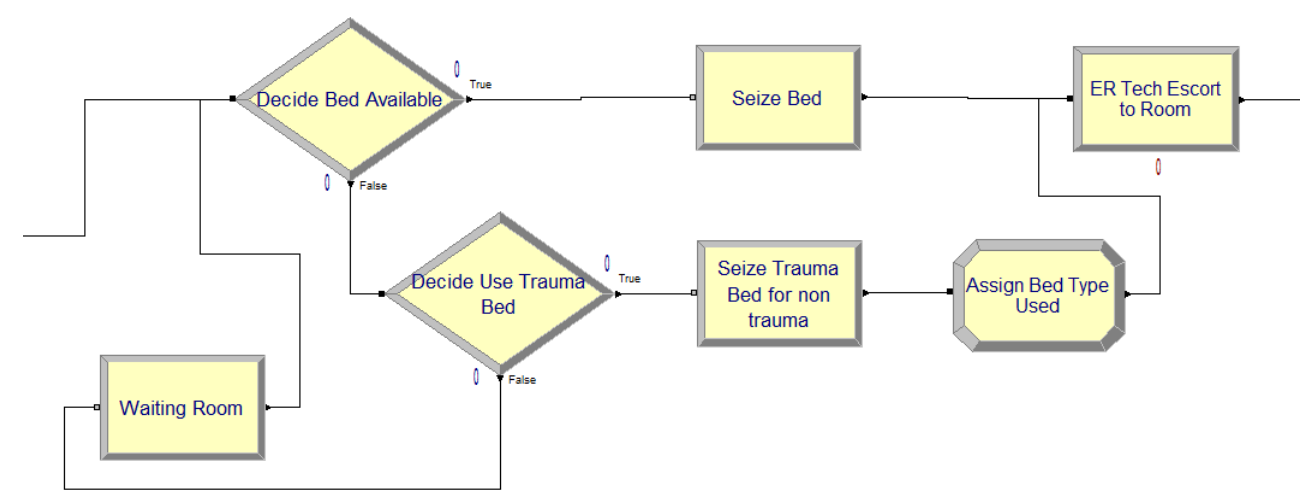

Figure 4.10 - Modules to Determine if a Bed is Available And Bed Placement

At this point in the model, in order to have information on the condition of patients in each of the beds for future use, an event occurs that causes the patient or entity to be split. This happens through the use of a Separate Module. A duplicate identical entity is created, allowing the original entity to follow one path out of the module, and the other duplicate entity to follow a different path out of the module. The duplicated entity 
moves into a module called a Batch Module. Entities in a Batch Module will remain in that module until they are released by some action of the system. The designated size of this batch has been set to a maximum limit of four. This limit is set to equal the number of beds in the ED, since this batch has been established to represent each of the patients in an ED bed, their number cannot be greater than four. As will be discussed later, patients being treated in a hallway of the ED will not be tracked through the use of a duplicate entity.

The modules representing the separating of the entity into a duplicate identical entity and the original entity/patient as well as the batch to hold the duplicate entity are shown in Figure 4.11 below.

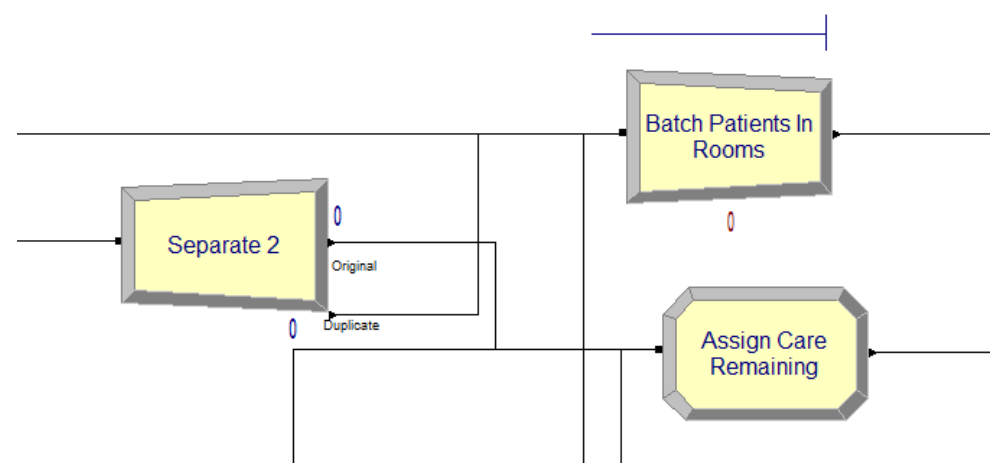

Figure 4.11 - Modules to Duplicate an Entity and Retain the Duplicate for Later Use

Now that the patient has been placed in an ED bed, the process of providing care, as represented within the model, can begin. As discussed earlier, the time study performed as a part of this research indicated that there is a typical sequence to patient care. This sequence involves a nurse interaction with the patient followed by a physician interaction, and then the performing of tests or procedures as ordered by the physician. Patient's of a higher acuity (those designated as a 1 or 2) will have more physician interactions, and more tests and procedures performed. Immediately upon entry into the 
system, each patient was assigned attributes to indicate the number of these physician and nurse interactions and the tests or procedures to be performed. The diagram below presents the portion of the simulation model that represents the ED patient care.

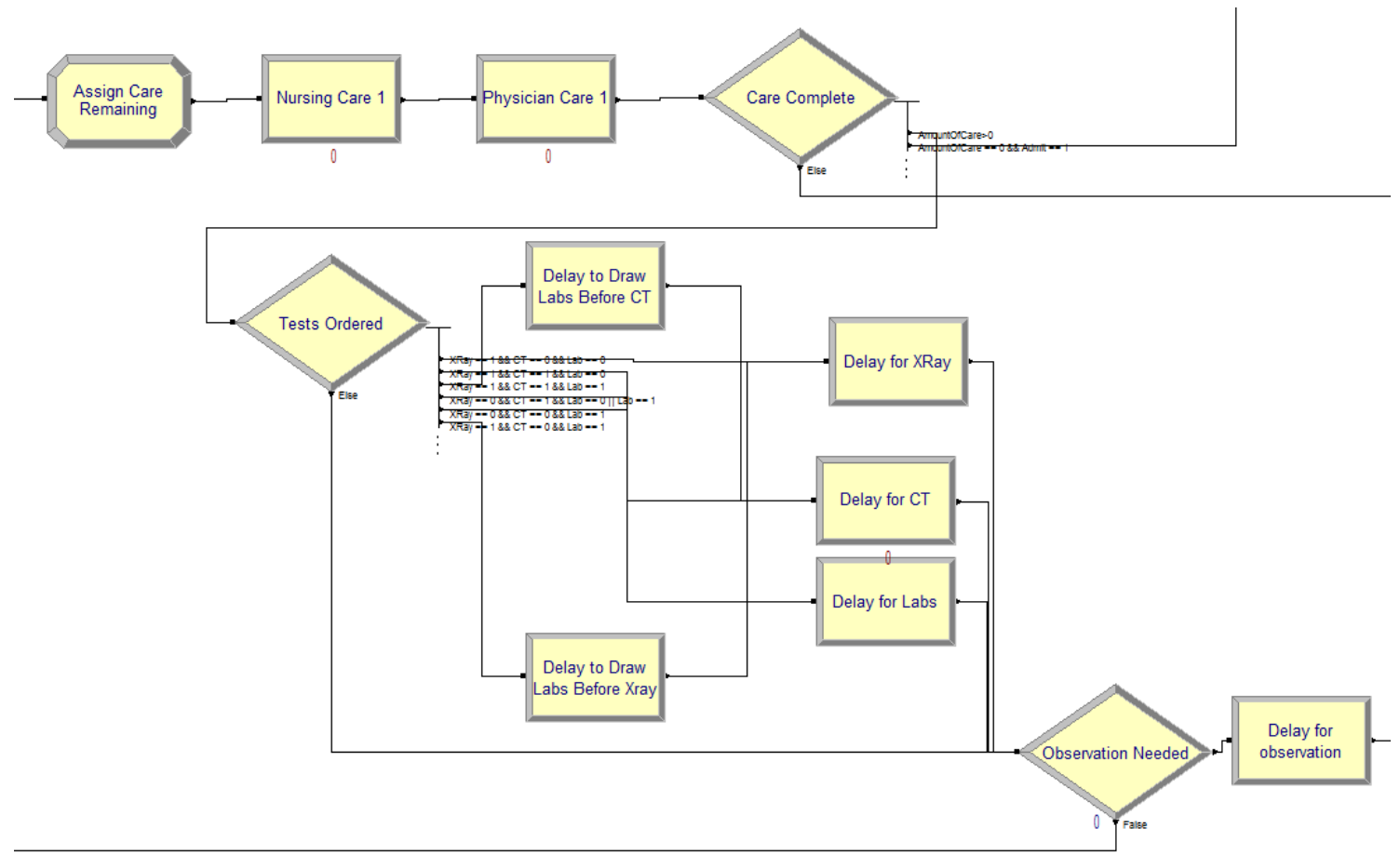

Figure 4.12 - Modules Representing the Patient Care Function in the Simulated ED

In the process presented in Figure 4.12 above, the first order of business is to modify the patient attribute used to track the number of nurse and physician interactions the patient experiences. This is achieved by incrementing that attribute by one, thus as the patient begins the first sequence of nurse and physician care, the attribute equals one. The second time there is a sequence of nurse and physician care, this attribute will equal two, and so on. 
The patient now arrives at a Process Module representing nursing care. This is followed by a Process Module representing physician care. Following the physician care, it must be determined if all patient care has been performed. This is determined based upon the attributes assigned to the patient upon entry to the system. If additional care is to be performed, the care is not complete, and the process continues to determine what additional components of care are to be performed, such as labs, x-rays, CT scan, or ED observation. This is represented by a Decision Module used to establish the combination of tests to be performed. The patient is routed differently based upon the combination of multiple tests, or the single test to be performed. Based upon the routing, the appropriate Delay Module(s) are entered by the patient, representing the wait for this care which is occurring outside the ED.

Following the sequence of decisions and process steps representing ED patient care, the patient is returned to the initial Assign Module shown in Figure 4.12 above and the attribute tracking the occurrence of nurse and physician interactions with the patient is incremented. A subsequent nursing care interaction and physician care interaction occurs and the decision is made as to whether the patient's care is compete. If it is determined that the ED care process is not complete, the sequence of events described above is again followed by the entity, and it is returned again to the initial Assign Module of Figure 4.12. If the ED care process is complete the discharge process begins. Modules representing that process will be discussed following the discussion of the simulation process representing the care of the most acute patients.

As stated earlier, shortly after entering the system the entities are categorized as one of three types to represent the acuity of the actual ED patients. The preceding was a 
discussion of the simulated care for the entities characterized as patients with acuity levels of 2 and 3 . These are the lower acuity patients than patients designated as a level 1. The following will describe the ED care simulation for entities representing patients of acuity level 1, or the patients needing the most emergent care in the ED.

Due the emergency level of the care, this level 1 entity does not follow the standard sign in and triage process. Immediately upon entry, it is determined whether there is a treatment bed available to assign to this entity. In making this determination, first the trauma bed is checked for availability. If it is available, it is seized. If it is not available, a check is made to determine if one of the other three ED beds is available, and if any one of them is available, it is seized. In either case, once a bed is seized, the next step is to assign values to attributes so that the care of the level 1 entity can be tracked. This process is represented in the simulation model using the following modules.

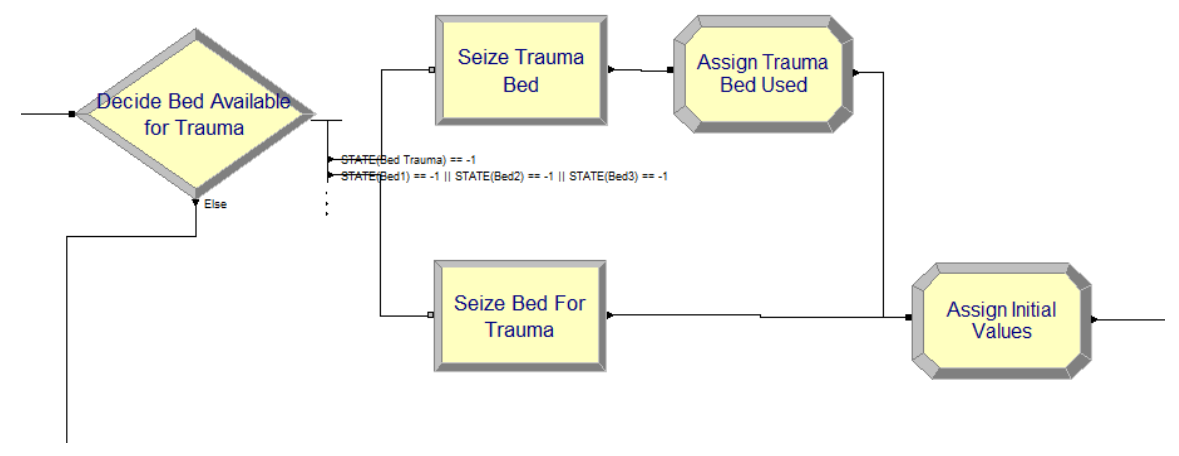

Figure 4.13 - Determining if the Trauma Bed or Other ED Bed is Available

The level 1 entity continues through the simulation model to a processes module for patient triage. This function occurs in the treatment bed as opposed to the trauma 
room. Additionally, the initial physician interaction with the patient is modeled. This sequence is represented in the simulation model using the following modules.

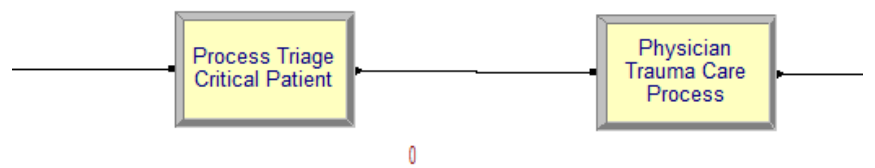

Figure 4.14 - Initial Process Modules Simulating Care of Trauma Patient

At the Decide Module shown in Figure 4.13 above, if a trauma bed or other ED bed is not available at the time a level 1 patient enters the ED, the entity will exit from the bottom of the Decide Module and the follow a process that represents the locating of a bed by moving a less acute patient from an ED bed into the hallway to complete care. This is often called "juggling a patient" from a standard ED treatment bed to the hallway. This "juggling" is accomplished in the simulation module by finding the entity that is currently utilizing an ED bed, and that has the least remaining process steps before exit from the system. This will represent the patient most ready to exit the ED, and thus the patient who will complete the least amount of care in the hallway.

Earlier, it was explained that each entity was assigned an attribute to track the process steps representing the patient care that must still be performed for an entity prior to its exit from the ED. The lower the value is of this attribute, the closer the entity is to exiting the ED. In Arena ${ }^{\circledR}$ it is not possible to search the entire model in order to locate an entity with the lowest value of a particular attribute. However, a queue or a batch can be searched. In the discussion of Figure 4.11 above, it was described that each entity representing a patient in a bed is duplicated, and its duplicate is residing in a "batch". It is possible to search this batch for the patient with the lowest value of a particular 
attribute; in this case the lowest value for the attribute representing the care steps remaining. The steps in Figure 4.15 below depict this process of utilizing the ER technician and a nurse to search the patients in ED beds to find the patient with the least amount of care steps remaining. Each entity in the batch has an attribute that represents the number of care steps remaining until the patient will begin the discharge process. The entity in the batch with the lowest value for this attribute is removed and an entity that has been assigned attributes representing the level 1 entity is returned to the batch. In this way, the system represents that the level 1 entity is occupying a bed, and a entity is in the system and will continue through the process, but without occupying a bed resource.

Figure 4.15 below presents the simulation modules for locating a patient to move to hallway for care, and the assignment of a bed to the level 1 patient.

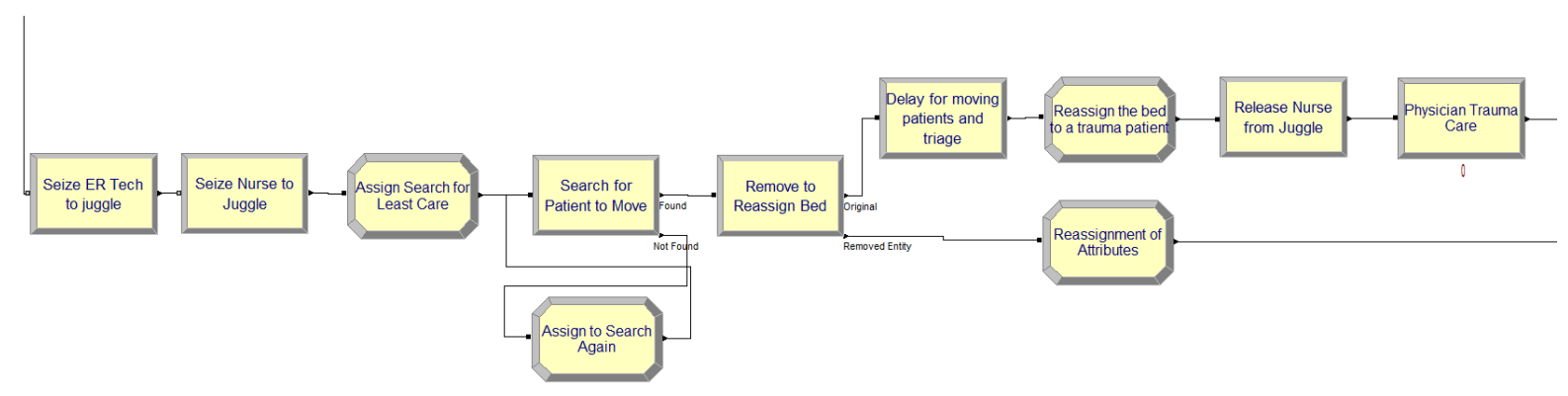

Figure 4.15 - Simulated Process of Moving an ED Patient to Hallway For Completion of ED Care and Assignment of Bed to Level 1 Patient

The patient "juggling" process ends with releasing the nurse and the ED technician, and a physician interaction is performed. The entity then proceeds to the part of the simulation model representing the patient care functions, shown in Figure 4.12 above. 
In order that the searching of the "batch" of entities representing patients in ED beds can be performed accurately to find the entity with the lowest value of an attribute, it is necessary that the attributes for each of the duplicated entities in the batch are updated as the original entity moves through the system and has its attributes updated. Therefore, each time the original entity moves through the process care functions shown in Figure 4.12 above, its duplicated entity must be removed from the batch and the corresponding attributes for the original and the duplicate entity are updated. The duplicate entity is then returned to the batch. This process is shown in Figure 4.16 below.

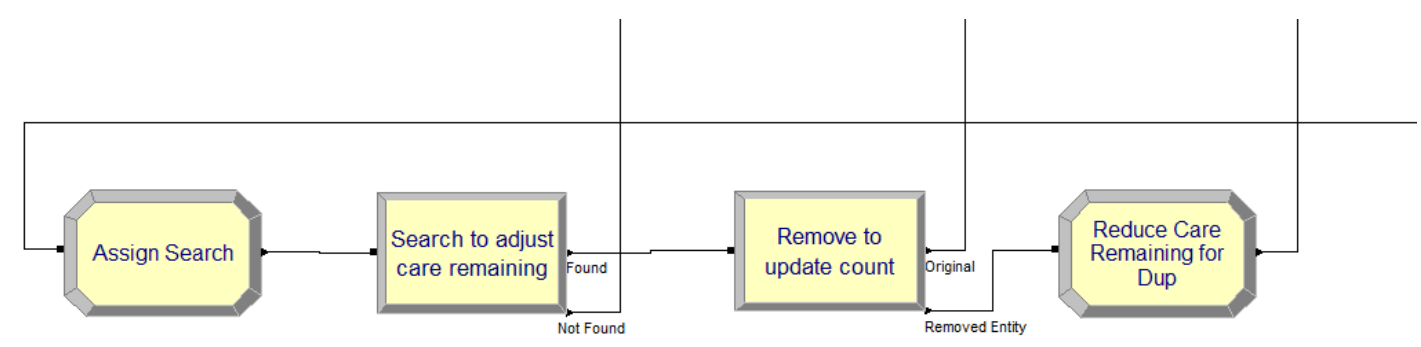

Figure 4.16 - Process to Update Attributes on Duplicate Entity Representing Original Entity in ED Bed

Once it is determined that all ED care has been provided to an entity, that entity will begin the process of exiting the system. As shown in Figure 4.17 below, if care is complete, the patient will either be routed to the "Contact Admitting Physician Module" or immediately to the "Nurse Discharges Patient Module". This decision is made at the "Care Complete" Decide Module in Figure 4.12 above. If the patient will not either be admitted to the Hospital or transferred to another hospital, the entity will proceed to a Process Module representing the nurse discharge function, followed by a Process Module representing the ED technician cleaning the room. If the patient is to be admitted to the Hospital or transferred, a process of contacting the admitting or receiving physician is 
performed by the physician, and the patient then proceeds to the next Module where the patient waits to be transported from the ED, after which the ED nurse completes the discharge paperwork. The length of stay is recorded and the technician cleans the room.

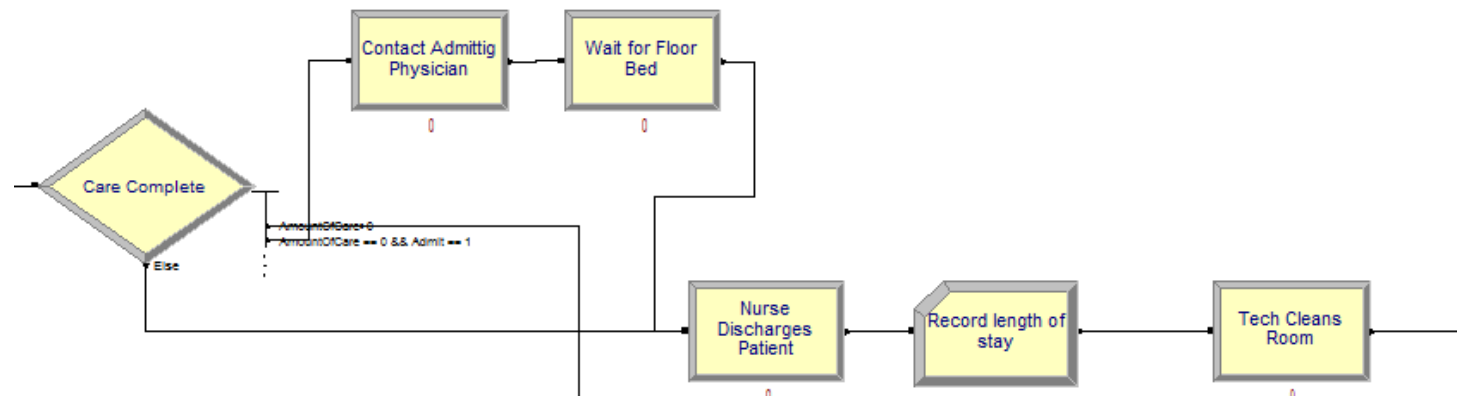

Figure 4.17 - Representation of Nurse Discharge and Room Cleaning

At this point in the model a check is made to determine if a patient has waited too long in the waiting room, and will decide to leave without being seen. Figure 4.18 below presents this process.

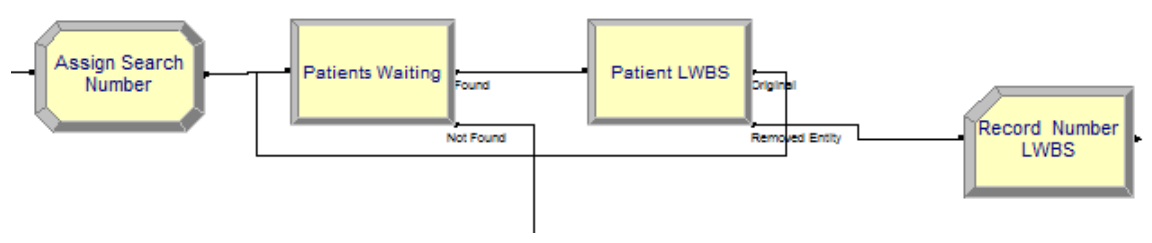

Figure 4.18 - Finding Patients Waiting Too Long For Care

Patients have varying tolerances for how long they will wait in the ED waiting room before physician care begins. This will depend on many factors. The Hospital stakeholders opinion, and supported by Hospital records indicate that the typically a patient is willing to wait two and a half hours. However, some patients will leave after 
no more than an hour and fifteen minute wait, and others may stay as long as five and a half hours. These statistics were used in the Assign Module of Figure 4.18 to assign a variable representing a waiting tolerance value. In the next Module, all patients in the Waiting Room queue are searched to determine if the time they have spent in the waiting room exceeds the waiting tolerance value. If this is the case, the following two Modules shown remove the patient from the waiting room, and record the entity as a LWBS. If or when no patients in the waiting room have waited longer than the tolerance value, the entity proceeds through the "Not Found" route of the "Patients Waiting" Module of Figure 4.18, and enters the first Module shown below in Figure 4.19.

Before the entity can leave the system, it is necessary to determine if a duplicate of the entity is in the Batch module discussed above and shown in Figure 4.11. All entities, with the exception of those representing patients who completed care in the hallway, will have a duplicate in the batch. Finding the duplicate is accomplished through a search of the batch. If a duplicate is found, it is removed and disposed of. This search and dispose process is shown in Figure 4.19 below.

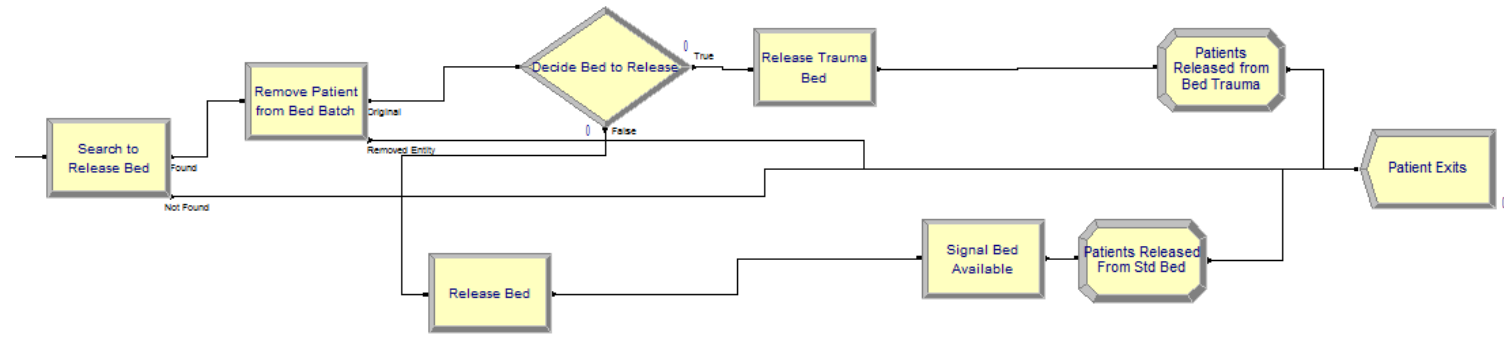

Figure 4.19 - Release of Entity From the Simulation Model

The next step is to determine if the entity was occupying a bed, and if so, whether it was the trauma bed. This is accomplished through the Decide Module in Figure 4.19 
above. If one of the three standard ED beds is released a signal is sent to the Hold Module representing the Waiting Room shown in Figure 4.10 above. This signal will allow the next entity of highest priority to move from the waiting room to seize the bed and begin the care process of Figure 4.12.

The entity is now disposed of from the system.

As stated earlier, this process will run continuously for 768 simulated hours. Statistics will not be collected for the first 48 hours of simulated time to allow the system to warm up, and represent the ongoing nature of an ED. Statistics are collected for the remaining 720 hours, and the model is run for 100 replications in order to increase the statistically accuracy of the results.

\section{Model Verification}

Verification is the process of ensuring that the Arena ${ }^{\circledR}$ model behaves in the way it was intended according to the modeling assumptions made [16]. The model was developed in segments, and as each segment was added, the model was reviewed to verify that it was free of error and that it functioned as intended. Two techniques were utilized in the process or verification.

The first technique was to slow the system and generate input entities such that there was a sufficient delay between each to allow for viewing the activity of all entities in the system. As the model ran, the entities were visually tracked to verify that each traveled through the system as intended. To enhance this visual verification of the model, animation was used in conjunction with a schematic of the hospital ED, thus enabling a clear visualization of the placement of patients in the waiting room, or in a bed. The 
resources representing the physician, nurses, ED technician, registration clerk, the ED beds, and the triage room were animated to show the busy or idle status for each. Figure 4.20 presents an image of the animation of the ED during the running of the simulation model. An understanding of the various components of the image below as they relate to the Hospital ED can be gained through reference to Figure 1.4. A physician, a nurse, and an ED technician are shown standing. The registration clerk is seated at a desk, and there are patients in three of the beds. In addition, there are three people in the waiting room. The nurse and the ED technician are shown red, depicting their busy state. The clerk and the physician are idle.

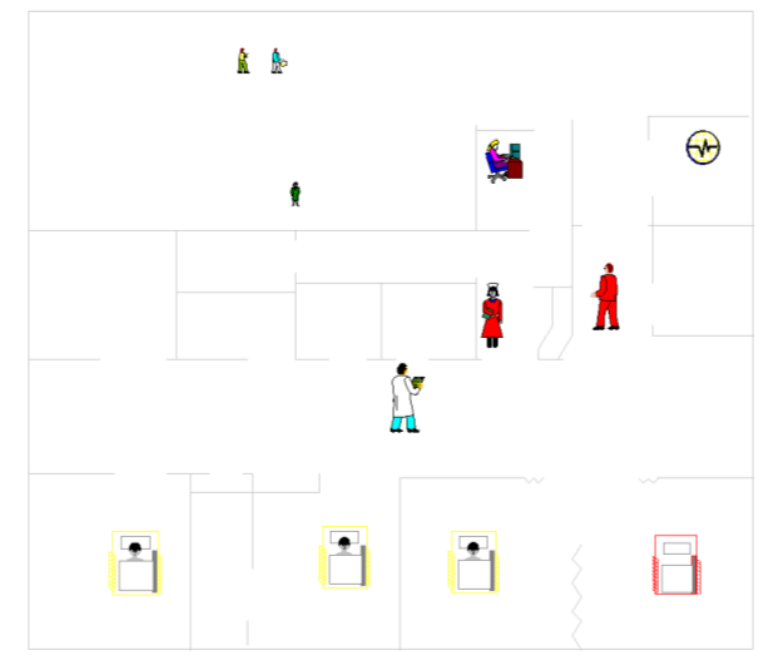

Figure 4.20 - Animation of Hospital ED During Simulation

A second technique used to verify the model was to use functions within Arena ${ }^{\circledR}$ to display system information as the model was running. Using this technique, as the system was running, the user could track the number of patients in the system, the status of each of the patient beds, and the status of the physician and nurses. This was useful in 
demonstrating that priority for bed placement and resource scheduling were functioning as intended.

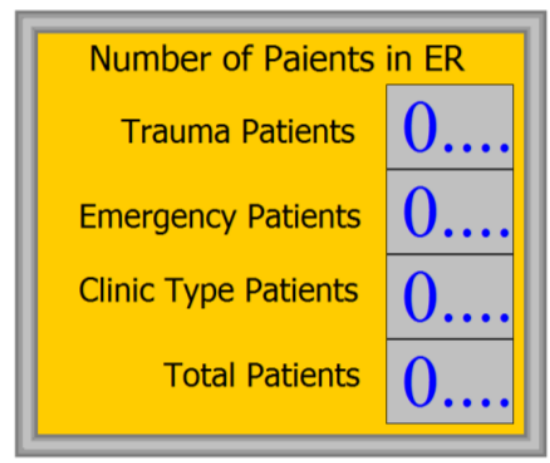

Figure 4.21 - Animation of Patients in Hospital ED During Simulation

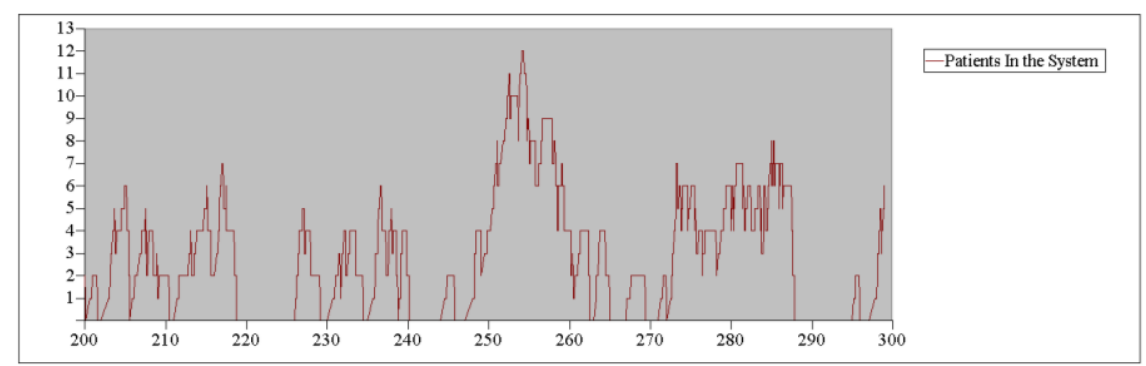

Figure 4.22 - Animation of Patient Arrivals During Simulation
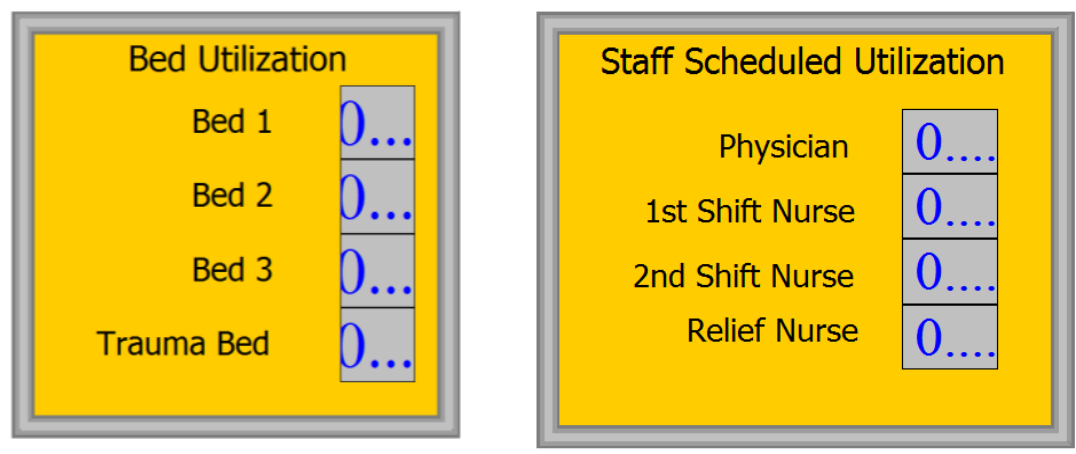

Figure 4.23 - Animation of Bed and Staff Utilization During Simulation 


\section{Model Validation}

Validating a simulation model is the process of ensuring that it behaves the same as the real system [16]. Since this model is an approximation or representation of the real ED system, it can never be absolutely validated. The goal in validation is to ensure the accuracy of the model results and to gain the confidence from the subject matter experts that the model is accurate for decision making purposes. Efforts to ensure validity took place throughout the creation of the model by way of regular meetings with subject matter experts. As the model was modified to reflect input from the experts, the changes in model output were reviewed with the subject matter experts to verify the impact on model results were as expected.

In addition, since the simulation created was developed based on an existing real system, and some output data from the real system was historically recorded, it was possible to compare model results to real system results. The Hospital performs monthly reporting on patient arrival and discharge times. As discussed earlier, the Hospital data relative to patient arrival statistics was used as input data for the simulation model, thus ensuring the simulated patient arrivals accurately reflected the real world patient arrival patterns.

Two measures of interest to the Hospital are the patient's length of stay in the ED, and the number of patients who leave without being seen by the ED physician (LWBS). The patient arrival and discharge times can be used to calculate a length of stay, or the total amount of time a patient is in the ED. Additionally, the Hospital records the number of LWBS each month. Typically, the patient's reason for leaving is due to a long wait 
time in the waiting room before being seen by the physician. Historical values for these two statistics, length of stay and LWBS, were compared to the same statistics generated by the simulation model as a check for validity.

This statistical information for the length of stay is shown in the Table 4-5 below.

\begin{tabular}{|l|l|l|l|l|}
\hline & Average & $\begin{array}{l}\text { Minimum } \\
\text { Value }\end{array}$ & $\begin{array}{l}\text { Maximum } \\
\text { Value }\end{array}$ & Half Width \\
\hline Hospital Data & 2.1 & 0.5 & 11.68 & \\
\hline Model Results & 2.18 & 0.43 & 12.82 & 0.02 \\
\hline
\end{tabular}

Table 4.5 - Comparison of Patient Length of Stay Data Using Hospital Reporting and From Simulation Model Results (Units are in hours)

Comparing the number of LWBS patients between the real world system, and the simulation model, provides a second check on the validity of the model relative to a measure of interest. Hospital data showed that on a monthly average, 25.57 patients LWBS with a minimum monthly LWBS of 22 patients and a maximum monthly LWBS of 34 patients. The simulation model generated a monthly average LWBS of 24.63. This comparison is shown in Table 4.6 below.

\begin{tabular}{|l|l|l|l|l|}
\hline & Average & $\begin{array}{l}\text { Minimum } \\
\text { Value }\end{array}$ & $\begin{array}{l}\text { Maximum } \\
\text { Value }\end{array}$ & Half Width \\
\hline Hospital Data & 25.57 & 22 & 34 & \\
\hline Model Results & 24.63 & & & 1.72 \\
\hline
\end{tabular}

Table 4.6 - LWBS Data Comparison

\section{Designing Experiments}

Having created a valid simulation model of this rural Hospital ED, the stake holders were interested in using the model to test a modification to the ED physical structure and 
modifications to the processes utilized in patient care. Their objective was to identify improvements that would provide for a shorter average length of stay for ED patients, and that would also reduce the LWBS statistic for the ED. Based upon the model's flexibility and discussions of the factors impacting patient throughput, two modifications were chosen to determine the effect on patient throughput times in the ED. Each modification was tested as an independent designed change, and they were tested in The modifications are: 1) add an additional regular patient treatment bed to the ED and, 2) improve the admission process for patients admitted to the Hospital as inpatients.

The first suggested experiment was to convert the break room in the ED to a patient treatment room. The nurses and other ED staff would take their break in a nearby room, but just outside the ED. The model was modified to add a fourth regular treatment bed, providing a total of five treatment beds when the trauma bed is included in the count. This was accomplished by adding a resource titled "Bed4" to the Resource Table as shown in Figure 4.5 above. The expression utilized by the Decide Module of Figure 4.10 above was modified to allow for the use of this new bed if it was not occupied at the time a patient enters the ED. Additionally, the Decide Module of Figures 4.13 above was modified to determine whether this additional bed resource was available for a trauma patient upon arrival to the ED if the trauma bed was occupied. There was no increase in the nurse's break time due to the increased distance from the ED. The increased distance accounted for an expected travel time of 1.5 minutes when going to the break room, or returning from the break room. It was agreed by staff that the time would be a part of their break and not take away from their available time for patient care. The model was 
run using the same patient arrival rates, process distribution times, a warm up period of 48 hours, and it was set for 100 replications, each representing a month of ED operation. The second experiment was to alter the admission process for patients who are admitted from the ED to the Hospital as inpatients for care on the floor. Currently, this can be a time demanding process involving the ED physician contacting the admitting physician to receive consent for the admission, and then waiting for a floor nurse to come to the ED to retrieve the patient. It was suggested that a process be adopted whereby the ED physician writes the admission orders for a patient to be admitted. After the orders are written, the ED nurse contacts the floor nurse to advise that a patient is to be admitted, and the ED nurse contacts the on-call physician or the patient's primary care physician, as appropriate, to advise of the admission. The Hospital should adopt a policy that all patients moving from the ED to the floor are to be so moved within thirty minutes of a call from the ED nurse. As stated earlier, in the event there are no beds in the Hospital, the ED physician must transfer the patient to another hospital for admission. Hospital statistics show that $8.6 \%$ of ED patients are admitted to the Hospital, and the Hospital CEO is desirous for this statistic to increase, making the need for improvement more necessary. In order to represent this process and policy change, two modifications were made to the model. Referring back to the admission process shown above in Figure 4.17, the resource utilized for the process of contacting the admitting physician was changed from the ED physician to the ED nurse. In addition, the delay for waiting for a bed on the floor was set at a constant 30 minutes. It was agreed that if the Nurse is responsible for the task of contacting the admitting physician, she will be able to perform her patient discharge functions commensurate with contacting the admitting physician. 
She will be able to use the time she is waiting for a call back to complete paperwork for the discharge to the floor. Therefore, once the patient is removed to the Hospital floor, there is no additional nursing process and the length of stay is recorded. No other changes were made to the model and it was run with the same input parameters and for 100 replications of a month of ED operations, each with a 48 hour warm up period. 


\section{RESULTS}

This section will deal with the analysis of the results of the simulation and with documenting the findings of the study. In order to properly understand the output from an Arena ${ }^{\circledR}$ model, the results must be analyzed. A typical means of analysis is the Paired-t test for comparing means. This approach tests the null hypothesis that there is no difference between the real world representation in the simulation model, and the modified simulation model. The Paired-t test takes replication-by-replication differences between the results from the two alternatives. The paired-t test is available through Arena ${ }^{\circledR}$ s s Output Analyzer software.

\section{Present Model}

The present model was set to run for 100 replications. Each replication represents one month of ED operations. A month was chosen as the replication length since the Hospital collects statistical data on a monthly basis. The high number or replications provides for more reliable results. Key metrics from the model are shown in Table 5-1 below. 


\begin{tabular}{|l|l|l|l|l|}
\cline { 2 - 5 } \multicolumn{1}{c|}{} & \multicolumn{4}{c|}{ Present ED Model } \\
\cline { 2 - 5 } \multicolumn{1}{c|}{} & Average & $\begin{array}{l}\text { Minimum } \\
\text { Average }\end{array}$ & $\begin{array}{l}\text { Maximum } \\
\text { Average }\end{array}$ & Half Width \\
\hline Patients Per Month & 725 & 615 & 847 & \\
\hline $\begin{array}{l}\text { Average Monthly Number of } \\
\text { Trauma Patients }\end{array}$ & 72 & 52 & 99 & 1.74 \\
\hline $\begin{array}{l}\text { Average Monthly Number of } \\
\text { Level 2 Patients }\end{array}$ & 299 & 260 & 350 & 3.3 \\
\hline $\begin{array}{l}\text { Average Monthly Number of } \\
\text { Level 3 Patients }\end{array}$ & 354 & 303 & 398 & 3.47 \\
\hline \begin{tabular}{l} 
Patient Waiting Room Time \\
\hline Length of Time in the ED
\end{tabular} & 1.05 & 0.8 & 1.3 & 0.02 \\
\hline Patients who LWBS & 2.18 & 2.0 & 2.4 & 0.02 \\
\hline Physician Utilization & 25.9 & 23.8 & 28.6 & 0.0 \\
\hline 7a-7p Nurse Utilization & 48.8 & 44.96 & 54.23 & 0.00 \\
\hline 7p - 7a Nurse Utilization & 37.2 & 33.0 & 42.5 & 0.00 \\
\hline $\begin{array}{l}\text { 3p - 11p Nurse Utilization } \\
\text { (weekends 11a - 11p) }\end{array}$ & 20.06 & 14.97 & 28.11 & 0.01 \\
\hline Bed 1 Utilization & 60.6 & 56.8 & 64.6 & 0.00 \\
\hline Bed 2 Utilization & 47.1 & 42.9 & 55.5 & 0.01 \\
\hline Bed 3 Utilization & 35.6 & 29.2 & 42.1 & 0.01 \\
\hline Trauma Bed Utilization & 29.3 & 20.2 & 36.0 & 0.01 \\
\hline
\end{tabular}

Table 5.1 - Present Model Simulation Output Results

The results of the model provide an expected length of stay for an ED patient at Regional Hospital of 2 hours and 11 minutes. The maximum length of stay encountered was 12 hours and 49 minutes and the minimum length of stay was 26 minutes. The overall average number of patients presenting to the ED for care in a month was 725 . 
The average number of patients coming to the ED for care but who left without being seen was 24.6.

The model shows a utilization rate for the first shift nurse of $48.8 \%$ and a utilization rate for the second shift nurse of $37.2 \%$. This is expected due to the low patient arrival rate in the late night and early morning hours. In addition, the relief nurse who is scheduled on weekends has a utilization rate of only $20.06 \%$. This rate can be expected to be low due to the fact that this nurse is only utilized in the model when the shift nurse is already busy and a nurse resource is needed. In reality, the shift nurse and the relief nurse will share the work load more equally.

The model shows a utilization rate for the physician of $25.9 \%$. This is an average utilization from 6:00 a.m. to 5:59 a.m. the following day. Thus, it encompasses the parts of the late night and early morning when patient volume is low. It also represents the idleness that occurs when the physician is waiting for lab work, $\mathrm{x}$-rays, or for the nurse to perform a procedure.

The model shows an overall utilization of the three regular exam beds of $47.8 \%$, and the utilization of the trauma bed is $29.3 \%$. Statistics were not collected on the number of patients who completed their ED care in the hallway due to crowding. There was a maximum number of 11 patients waiting in the waiting room.

\section{Model Modifications}

As discussed in the previous chapter, the model underwent two modifications. The "Five Bed Model" is the present model with the addition of a regular treatment bed. The "Admit Policy Model" is the present model with the addition of a new policy for 
patient admissions whereby the ED nurse contacts the on-call physician, and the nurse must take the patient from the ED within 30 minutes of notification that the patient is to be admitted. Table 5.2 below presents the measures of greatest importance to the Hospital Administration for each of the models.

\begin{tabular}{|l|l|l|l|l|}
\hline & $\begin{array}{l}\text { Present } \\
\text { Model }\end{array}$ & $\begin{array}{l}\text { Five Bed } \\
\text { Model }\end{array}$ & $\begin{array}{l}\text { Admit } \\
\text { Policy } \\
\text { Model }\end{array}$ & $\begin{array}{l}\text { Add Bed } \\
\text { and } \\
\text { Policy }\end{array}$ \\
\hline Patients Per Month & 725 & 720 & 730 & 727 \\
\hline $\begin{array}{l}\text { Average Monthly Number of } \\
\text { Trauma Patients }\end{array}$ & 72 & 72 & 73 & 72 \\
\hline $\begin{array}{l}\text { Average Monthly Number of } \\
\text { Level 2 Patients }\end{array}$ & 299 & 293 & 301 & 297 \\
\hline $\begin{array}{l}\text { Average Monthly Number of } \\
\text { Level 3 Patients }\end{array}$ & 354 & 355 & 356 & 358 \\
\hline $\begin{array}{l}\text { Patient Waiting Room Time } \\
\text { Length of Time in the ED }\end{array}$ & 1.05 & 0.84 & 0.95 & 0.75 \\
\hline Patients who LWBS & 24.6 & 2.18 & 2.05 & 1.95 \\
\hline Physician Utilization & 25.9 & 26.1 & 24.8 & 24.8 \\
\hline 7a-7p Nurse Utilization & 48.8 & 49.4 & 48.2 & 48.9 \\
\hline 7p - 7a Nurse Utilization & 37.2 & 37.1 & 35.5 & 35.2 \\
\hline $\begin{array}{l}\text { 3p - 11p Nurse Utilization } \\
\text { (weekends 11a - 11p) }\end{array}$ & 20.06 & 21.4 & 19.3 & 20.6 \\
\hline Bed 1 Utilization & 60.6 & 57.5 & 60.0 & 56.7 \\
\hline Bed 2 Utilization & 47.1 & 42.8 & 45.3 & 41.1 \\
\hline Bed 3 Utilization & 35.6 & 30.0 & 33.7 & 28.5 \\
\hline Bed 4 Utilization & 29.3 & 28.4 & 26.6 & 25.6 \\
\hline Trauma Bed Utilization & 20.1 & & 18.8 \\
\hline
\end{tabular}

Table 5.2 - Comparison of Model Results 
By altering the model to add an additional regular exam bed, the utilization rate for each of the shift nurses and the physician showed only a slight change.

The patient's expected length of stay was reduced by an expected amount of 5.4 minutes. However, adding this additional treatment bed did provide a significant improvement on one measure of interest. The expected number of LWBS was reduced by over $63 \%$. This improvement is understandable when one considers that since LWBS is based upon patients waiting an extended period in the waiting room before being seen by a physician, and to be seen by a physician the patient must first be placed in a treatment bed.

By altering the model to require that patients who are to be admitted to the Hospital as inpatients are moved to the floor within 30 minutes of the physician ordering the admission, and further that the duty to contact the admitting physician and advise him or her of the admission is the responsibility of the ED nurse, slightly more mprovement is achieved in the expected average length of stay, however less improvement is achieved in the LWBS levels.

The patient's expected length of stay was reduced by approximately 8 minutes. However, the effect on LWBS was only an expected reduction of $20.3 \%$ to an expected level of 19.6 patients.

Implementing both modifications provided the most improvement on the patient's waiting room time reducing it to an expected time of 45 minutes. In addition, the overall time in the ED was reduced by 14 minutes and the LWBS was reduced to an expected level of 5.6 patients. This represents an improvement in this quality measure of $77 \%$. 


\section{Analysis of Models Using the Paired-t Test}

The Paired-t test, comparing the means of the Present Model and the Five Bed Model, was performed using Arena ${ }^{\circledR}$ 's Output Analyzer. Figure 5.1 below presents the results of the Paired-t test.

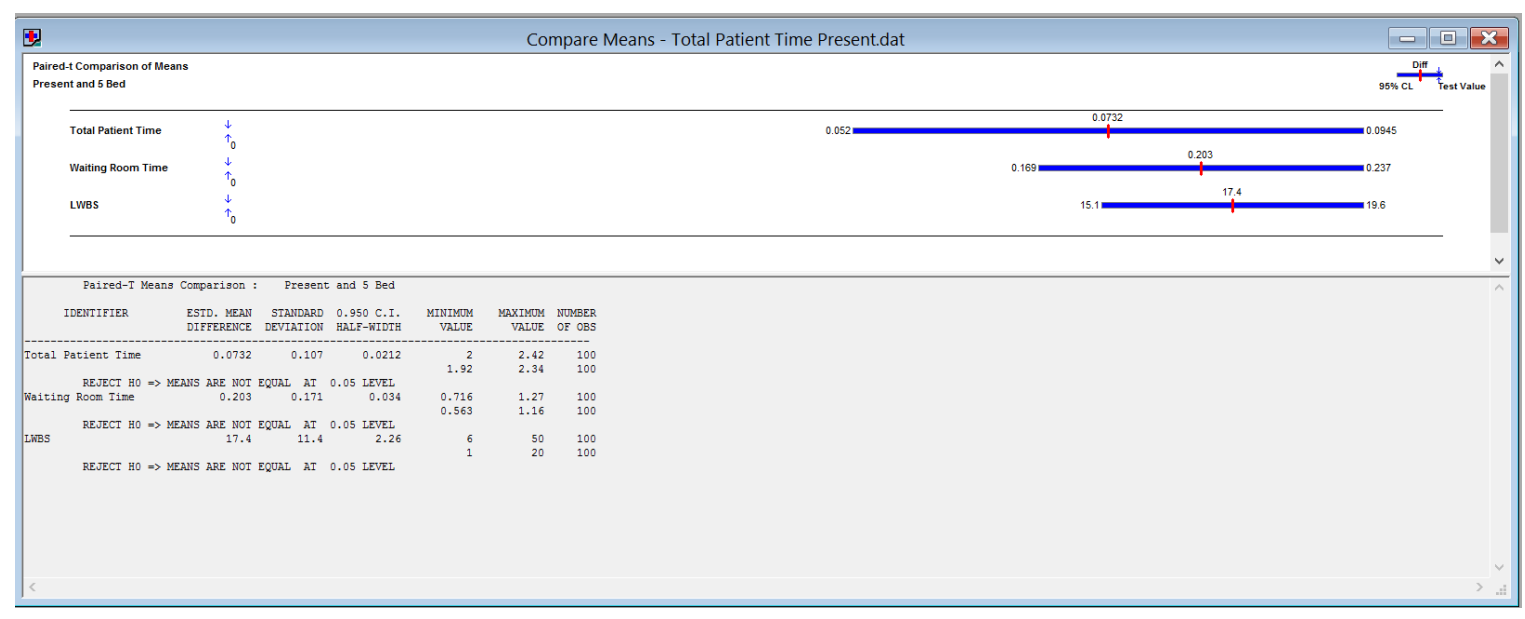

Figure 5.1 - Paired-t Test of Present Model and Five Bed Model

By adding an additional treatment bed, there is a significant difference in the total length of time a patient can expect to be in the ED for care. In addition, there is a significant difference in the amount of time a patient can expect to wait in the waiting room before being called to a treatment room. And this second factor results in a significant reduction in the number of patients who leave the ED without being seen by the ED physician. Thus the addition of an ED bed provides improvement on two quality measures of importance to the Hospital. Adding this additional ED bed will not result in significant cost to the Hospital since it will be placed in an existing room with all necessary electrical and water facilities currently available. The nursing staff will be adversely impacted by the change in their break room, however this negative impact is, in 
their opinion, offset by an improvement in patient care. Table 5-3 below provides a comparison of the quality measures for the Present Model versus the Five Bed Model.

\begin{tabular}{|l|l|l|l|c|}
\cline { 2 - 5 } \multicolumn{1}{c|}{} & \multicolumn{4}{c|}{ Comparison of Present Model to Five Bed Model } \\
\hline Variable & $\begin{array}{c}\text { Present } \\
\text { Model }\end{array}$ & $\begin{array}{c}\text { Five Bed } \\
\text { Model }\end{array}$ & $\%$ Change & $\begin{array}{c}\text { Significant } \\
\text { Difference }\end{array}$ \\
\hline Length of Time in the ED & 2.18 & 2.09 & $4.13 \%$ & Yes \\
\hline Patient Waiting Room Time & 1.05 & 0.84 & $20 \%$ & Yes \\
\hline Patients who LWBS & 24.6 & 9.0 & $63.4 \%$ & Yes \\
\hline
\end{tabular}

Table 5.3 - Comparison of Quality Measures for Present Model and Five Bed Model

The Paired-t test, comparing the means of the Present Model and the Admit Policy Model was performed using Arena ${ }^{\circledR}$, s Output Analyzer. Figure 5.2 below presents the results of the Paired-t test.

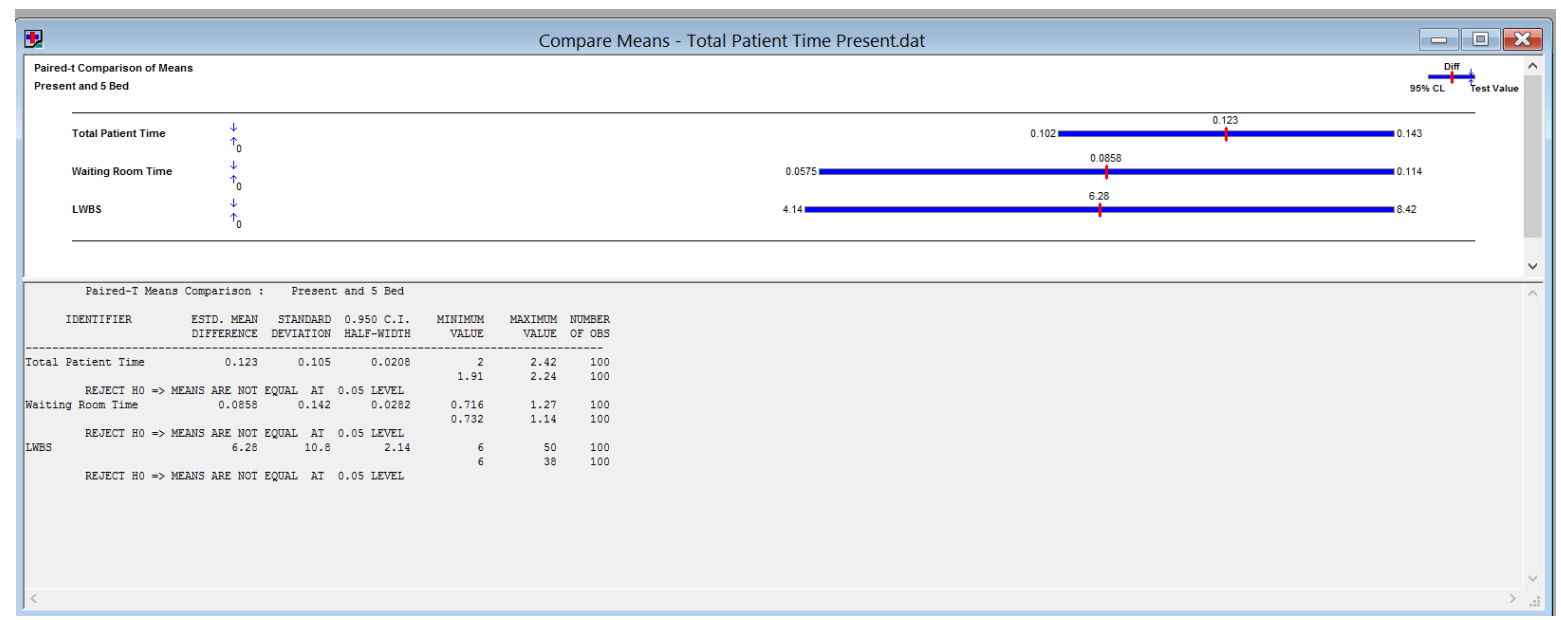

Figure 5.2 - Paired-t Test of Present Model and Admit Policy Model

By changing the admission policy for the Hospital such that patients to be admitted to the floor are transported from the ED to the Floor within 30 minutes of the 
call to the Floor for admission, there is an increased difference in the expected total length of time a patient may expect to be in the ED for care as compared to the 5 Bed Model. However, the patients can expect to wait longer in the waiting room before being called to a treatment room than in the 5 Bed Model, but less than under the Present Model. This second factor results in the LWBS quality measure being improved by $20.3 \%$ if the new policy on admission is adopted.

Adopting this change in policy may have a significant impact on the Hospital staff outside the ED. Streamlining the admission process from within the ED would allow ED beds to become more quickly available for waiting ED patients and enable the admitted patients' care to begin on the floor rather cause the patients and the patient's family to continue to wait for the next step in hospital care. Table 5.4 below provides a comparison of the quality measures for the Present Model versus the Admit Policy Model.

\begin{tabular}{|l|l|l|l|l|}
\cline { 2 - 5 } \multicolumn{1}{c|}{} & \multicolumn{4}{c|}{ Comparison of Present Model to New Admit } \\
Policy Model
\end{tabular}

Table 5.4 - Comparison of Quality Measures for Present Model and Admit Policy Model

Both of the above changes to the Hospital ED can be implemented, thus it was decided to look at the expected benefit of adopting both concepts. The Paired-t test 
comparing the means of the Present Model and the Five Bed Plus Admit Policy Model was performed using Arena ${ }^{\circledR}$ 's Output Analyzer. Figure 5.3 below presents the results of the Paired-t test.

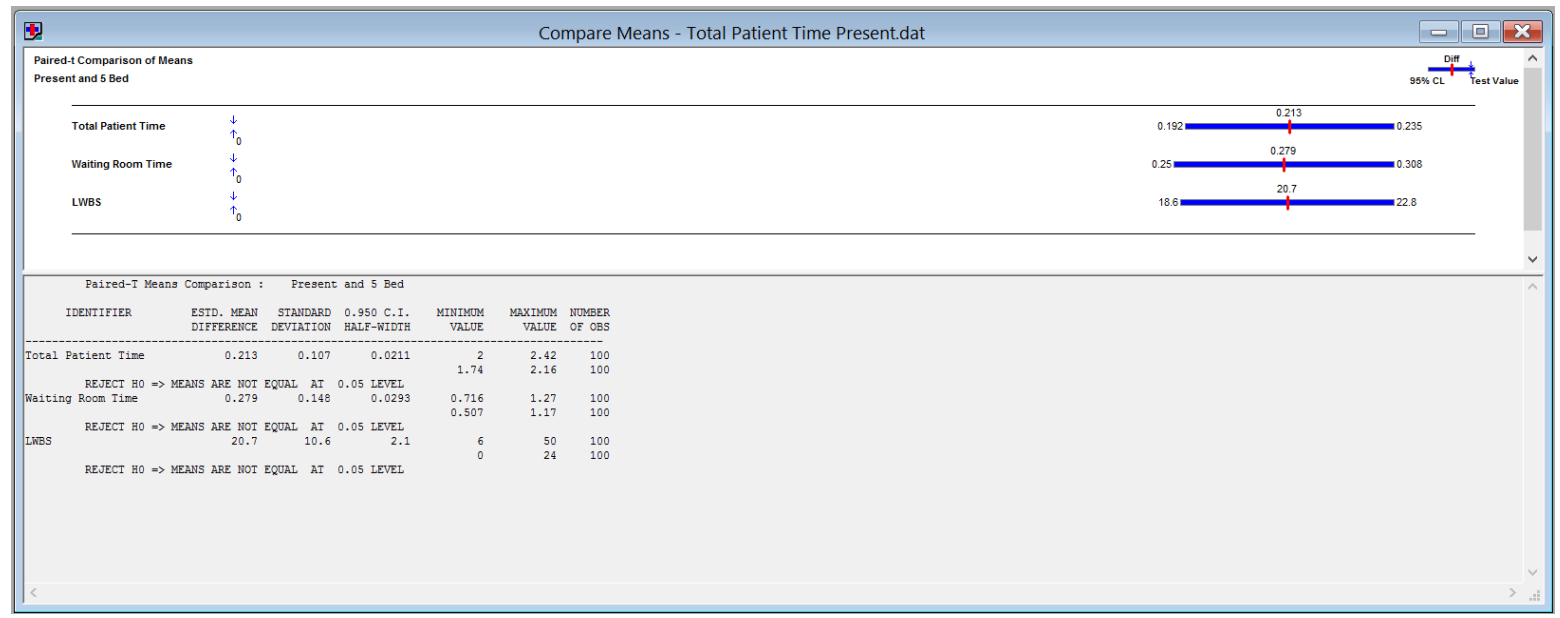

Figure 5.3 - Paired-t Test of Present Model and Five Bed Plus Admit Policy Model

By adopting both changes, the greatest improvements in all three quality measures are achieved. Table 5.5 below provides a comparison of the quality measures for the Present Model versus the Five Bed Plus Admit Policy Model.

\begin{tabular}{|l|l|l|l|l|}
\cline { 2 - 5 } \multicolumn{1}{c|}{} & \multicolumn{4}{c|}{ Comparison of Present Model to 5 Bed and New } \\
\multicolumn{1}{c|}{} & \multicolumn{4}{c|}{ Admit Policy Model } \\
\hline Variable & $\begin{array}{l}\text { Present } \\
\text { Model }\end{array}$ & $\begin{array}{l}\text { Add Bed } \\
\text { and Policy }\end{array}$ & $\begin{array}{l}\% \\
\text { Change }\end{array}$ & $\begin{array}{l}\text { Significant } \\
\text { Difference }\end{array}$ \\
\hline Length of Time in the ED & 2.18 & 1.95 & $10.5 \%$ & Yes \\
\hline Patient Waiting Room Time & 1.05 & 0.75 & $28.6 \%$ & Yes \\
\hline Patients who LWBS & 24.6 & 9.0 & $63.4 \%$ & Yes \\
\hline
\end{tabular}

Table 5.5 - Comparison of Quality Measures for Present Model and Five Bed Plus Admit Policy Model 
The impact to the inpatient areas of the Hospital if the proposed admission policy is adopted was not investigated as a part of this research. The gain in improved waiting times and length of ED stay would need to be offset against the burden to the Hospital inpatient area staff. 


\section{CONCLUSIONS}

The current model demonstrates that ED patients, on average often must deal with an ED visit of 2 hours and 11 minutes, and that approximately half of the time is spent in the waiting room prior to the first contact with the ED physician. This long wait is more than some patients are willing to accept and therefore on average, each month, nearly 25 patients leaving the ED without being seen by the ED physician. If current patient trends continue, the expected length of the ED visit will increase and more time will be spent waiting to be seen by the physician, likely causing the number of patients who leave without being seen to increase.

Two proposed changes to the Hospital ED were the addition of a patient treatment bed, and the adoption of a policy whereby the floor nurses would come to the ED and transport a patient for admission to the floor within 30 minutes of the ED physicians order to admit the patient. Adding a patient bed resulted in a significant reduction in the waiting room time, with a corresponding significant greatest reduction in LWBS. Changing the admission policy had less of an impact in reducing both waiting room time, and LWBS.

Adopting both of the modifications provides the greatest reductions in waiting room time, LWBS and the total length of time a patient can expect to be in the ED before discharge. 


\section{RECOMMENDATIONS}

In many instances in the patient care process, the physician is the critical path, or the bottleneck. This designation is based upon the fact that in a rural ED there is one physician and any task that must be performed by the physician or must be approved or ordered by the physician utilizes this one resource. In addition, the physician only addresses the needs of the patients residing in an exam bed. Regardless of the true number of patients that have arrived at the ED and are waiting for care, only those who have been placed in a bed will receive available attention from the physician. This need to have a patient in a bed in order to receive physician care places a constraint on the efficiency of the physician, thus compounding the significance of the physician bottleneck. The physician can be idle while at the same time numerous patients can be in the waiting room.

Improvements in the ED should be focused on placing more patients in the care process, and removing waiting time, or idle time, for the physician. This waiting time can be waiting for labs to return, or waiting for x-ray results, or for a medication to take effect, or many other events that occur in the ED and are not performed by the physician.

After this project was begun, President Obama signed the Patient Protection and Affordable Care Act (ACA) into Law. This legislation will bring about sweeping changes in the healthcare landscape, many of which will affect the delivery of emergency care. A significant change will be the inclusion of many more people who will become insured either through health insurance exchanges, or on the expanded rolls of Medicaid. A second significant change will occur in the way payment for patient care will be 
calculated. The Center for Medicare \& Medicaid Services, along with private insurers will shift away from the current payment model of pay-for-volume, where an agreed upon payment amount is paid to a physician or hospital each time a particular type of care is provided. They will shift to a model based upon pay-for-performance, or pay-forvalue. In a pay-for-performance model, the amount paid for patient care will be directly tied to efficiency measures, and poor efficiency measures will result in reductions in payment [26], [27]. In emergency medicine, these efficiency measures include:

- the number of patients who left without being seen;

- the median time from entry into the emergency department to physician evaluation;

- the median time from entry into the emergency department to discharge from the emergency department;

- the median time from entry into the emergency department to hospital admission for patients admitted to the hospital;

- the median time from the physician's decision to admit a patient to the time the patient is admitted into the hospital

Optimizing the ED performance based upon the efficiency measures identified in the pay-for-performance models should be the objective of any improvement effort in the rural hospital ED. The rural ED should be reviewed to identify the improvements which will provide the greatest impact to these measures. Each efficiency measure should be analyzed to identify the factors that effect its outcome, and then system modifications should be studied to identify the most efficient, cost effective way to achieve the greatest improvement. As an example, with respect to the efficiency measure of median time 
from entry into the emergency department to physician evaluation: Currently this measure is impacted by the availability of a nurse to perform the triage function, by the availability of a bed for the patient, and by the physician's availability. Each of these constraints occurs in series, having a potential for a compounding effect. Rather than take these constraints as a given, a review should look at how the process of patient care delivery in the rural hospital ED can be modified to achieve the greatest efficiency, and quality, thus improving the payment model performance measure.

Simulation offered significant insight into the ED functionality, and enabled stakeholders to understand the inter-relationship of the various components of the ED process. However, a simulation model that represents the 24 hour day will generate results that are impacted by the very slow times of the day, such as the overnight hours when the patient volume is very slow. If the objective is to improve performance on efficiency measures, it may be more appropriate for the simulation model to be focused on those hours of the day where meeting quality measures is most difficult due to the patient volume. This would enable decision making to be more targeted and the impact of the results of modifications to be better measured. 


\section{APPENDIX I}

KENTUCKY POPULATION DENSITY MAP 

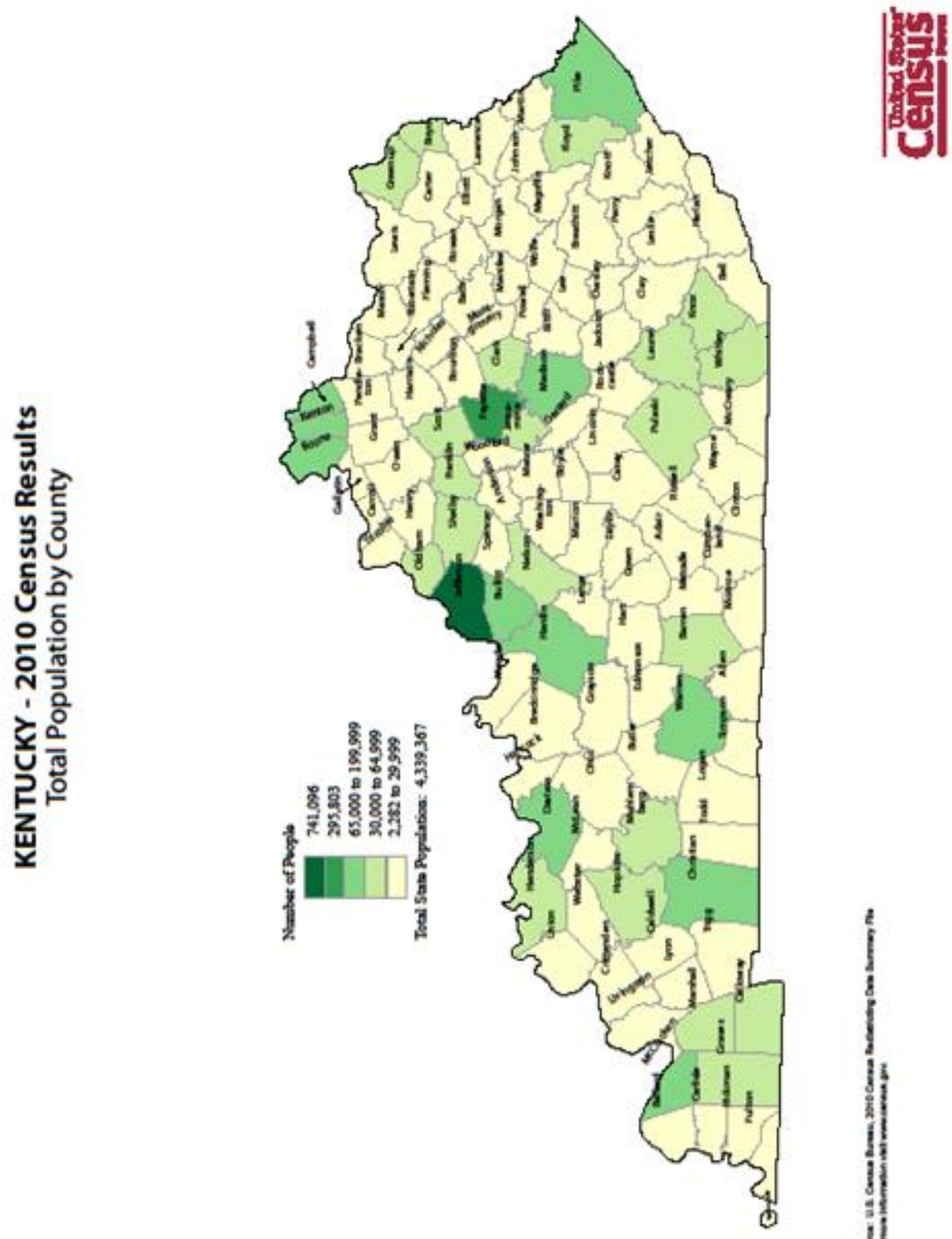

Total Population by County [28] 


\section{APPENDIX II}

KENTUCKY METROPOLITAN STATISTICAL AREA WTH POPULATION

AND

ED PATIENT VISITS 


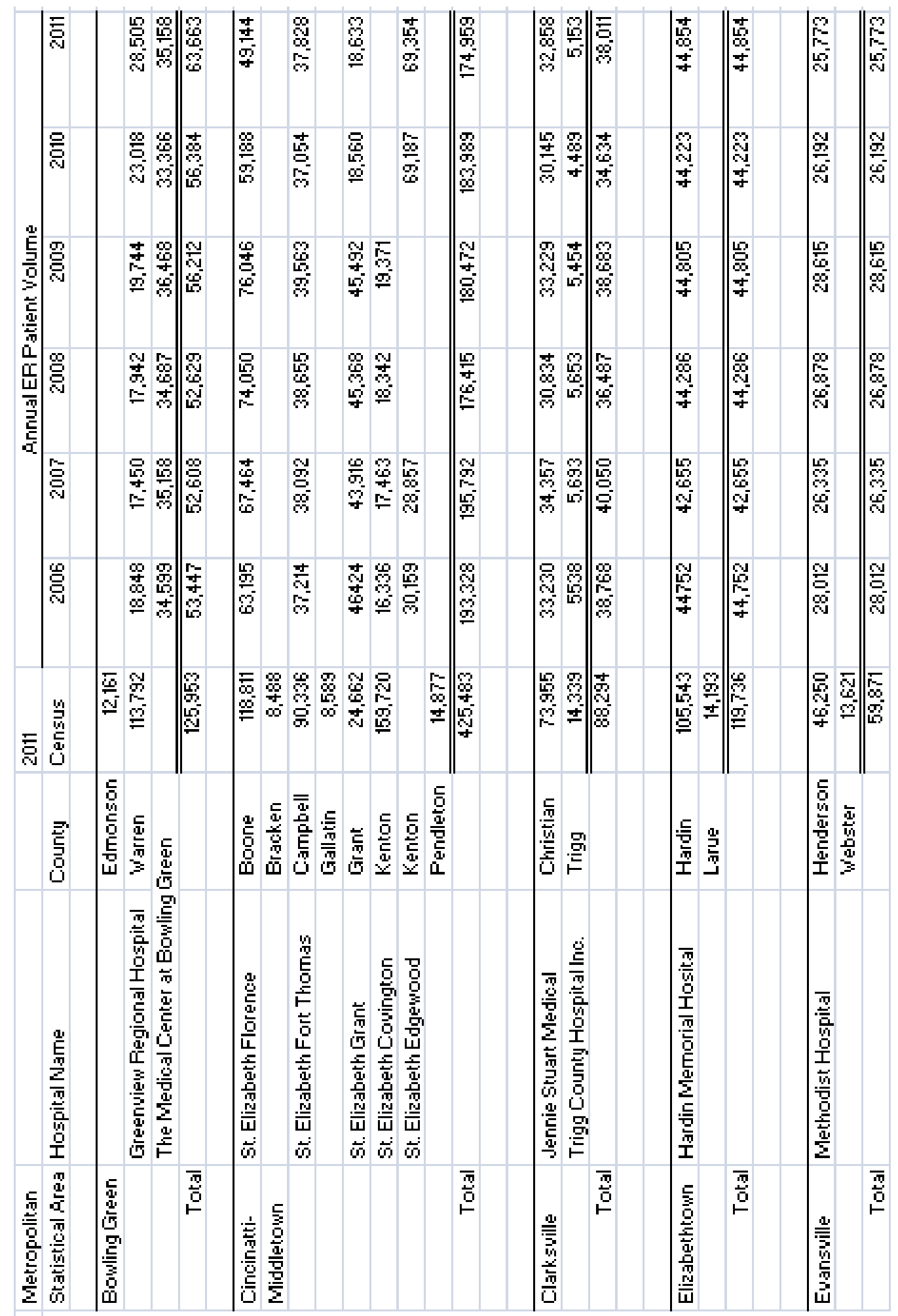

Table A.2- Metropolitan Statistical Areawith Population and ED Patient Visits 


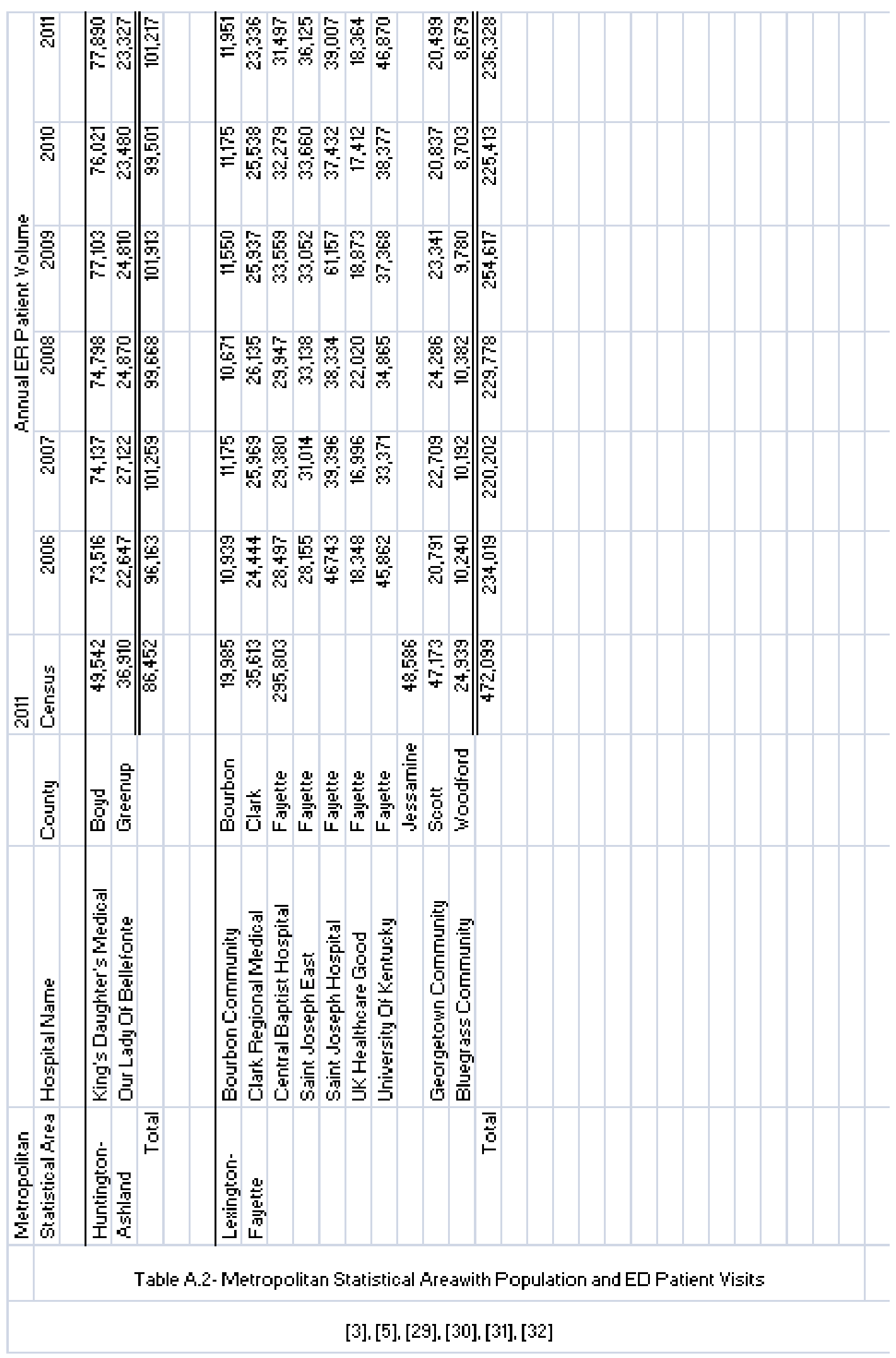




\begin{tabular}{|c|c|c|c|c|c|c|c|c|c|c|c|c|c|c|c|c|}
\hline$\overline{\bar{\nu}}$ & & 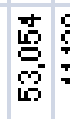 & $\frac{2}{8}$ & $\stackrel{\mathrm{N}}{\mathrm{N}}$ & $\frac{\mathrm{m}}{\bar{\sigma}}$ & $\begin{array}{l}8 \\
8 \\
8 \\
8 \\
8\end{array}$ & $\frac{\omega}{8}$ & & $\bar{s}$ & 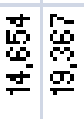 & & $\mid \begin{array}{l}\text { 眷 } \\
\stackrel{\circ}{8} \\
\stackrel{8}{\circ}\end{array}$ & 受 & & 㽚 & 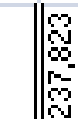 \\
\hline 言 & & $\begin{array}{l}\text { 愛 } \\
\text { 点 }\end{array}$ & 爱总总 & $\begin{array}{l}\infty \\
\neq \\
\neq\end{array}$ & $\frac{\mathrm{g}}{\mathrm{g}}$ & $\underset{8}{8}$ & $\stackrel{\mathbb{N}}{\mathrm{B}}$ & $\begin{array}{l}\mathscr{9} \\
\stackrel{8}{\circ} \\
\infty \\
\infty\end{array}$ & $\begin{array}{l}\text { के } \\
\stackrel{5}{9}\end{array}$ & 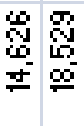 & & 商 & 冚 & & $\stackrel{+}{\stackrel{5}{0}}$ & 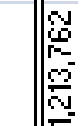 \\
\hline 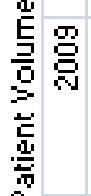 & & 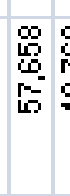 & $\frac{8}{8}$ & 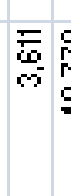 & 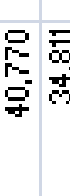 & 离 & $\begin{array}{l}\% \\
\% \\
\%\end{array}$ & & 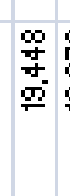 & 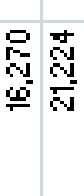 & & 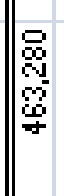 & $\begin{array}{l}3 \\
\overline{8} \\
\overline{8} \\
\overline{8}\end{array}$ & & $\begin{array}{l}5 \\
0 \\
\mathscr{8} \\
\mathcal{B}\end{array}$ & 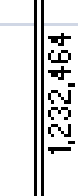 \\
\hline 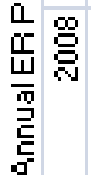 & & 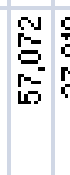 & 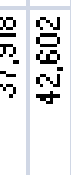 & & 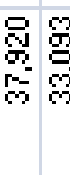 & $\begin{array}{l}\stackrel{8}{8} \\
\stackrel{8}{8} \\
8 \\
8\end{array}$ & $\frac{9}{3}$ & & 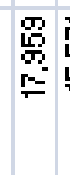 & 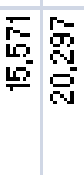 & & 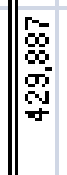 & \begin{tabular}{l}
- \\
\hdashline \\
$\mathscr{8}$
\end{tabular} & & 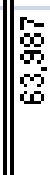 & $\mid$ \\
\hline 愛 & & $\begin{array}{l}9 \\
\frac{9}{5} \\
6 \\
6\end{array}$ & 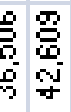 & & 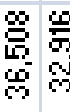 & 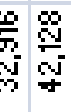 & $\frac{5}{9}$ & 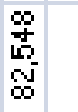 & 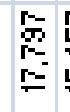 & 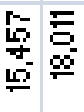 & & $\frac{\infty}{2}$ & 鱼 & & 孚 & 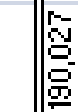 \\
\hline 吉 & & $\frac{\mathbf{W}}{\mathbf{5}}$ & 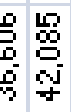 & & 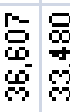 & $\begin{array}{l}\frac{5}{8} \\
\frac{5}{8} \\
\frac{5}{9}\end{array}$ & $\stackrel{\infty}{\circ}$ & $\underset{\mathrm{N}}{\stackrel{\mathrm{N}}{\circ}}$ & + & 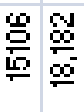 & & 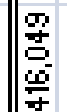 & 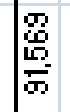 & & \begin{tabular}{|l}
$\Phi$ \\
$\frac{8}{5}$ \\
$\overline{5}$
\end{tabular} & 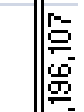 \\
\hline 言离 & 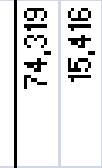 & $\frac{\mathscr{O}}{\frac{9}{2}}$ & & & & & & $\begin{array}{l}\text { g } \\
9 \\
9 \\
9\end{array}$ & $\frac{5}{3}$ & 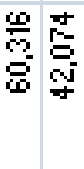 & 愛苾 & 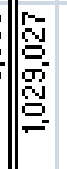 & 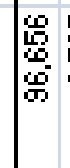 & & $\stackrel{N}{N}$ & . \\
\hline 龸 & 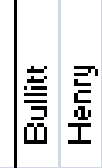 & $\begin{array}{l}\text { c } \\
\text { 竞 } \\
\text { 竞 }\end{array}$ & 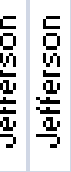 & 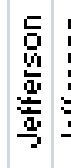 & 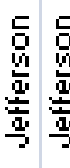 & 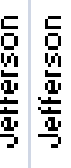 & 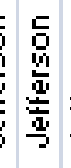 & 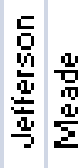 & $\frac{5}{\frac{c}{3}}$ & 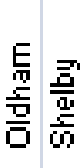 & 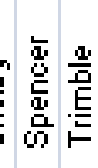 & & $\mid$ & & & \\
\hline 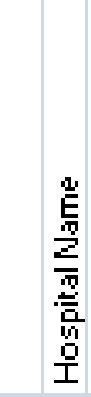 & & 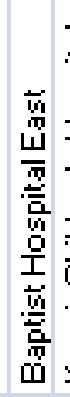 & 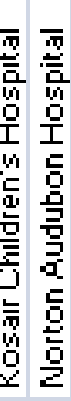 & 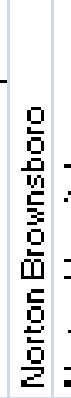 & 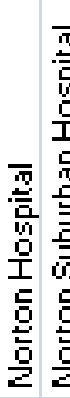 & 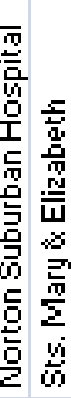 & 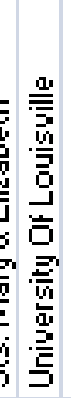 & 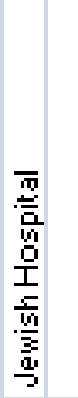 & 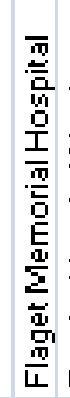 & 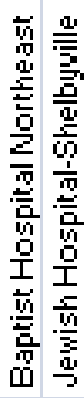 & & & 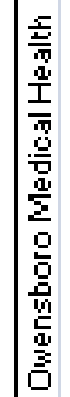 & & & $\frac{\alpha}{2}$ \\
\hline 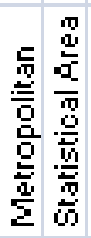 & & & & & & & & & & & & 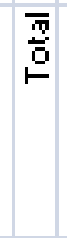 & 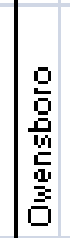 & & $\begin{array}{l}\overline{0} \\
\text { 自 }\end{array}$ & 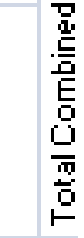 \\
\hline
\end{tabular}

Table A.2- Metropolitan Statistical Areawith Population and ED Patient Visits

[3], [5], [29], [30], [31], [32] 


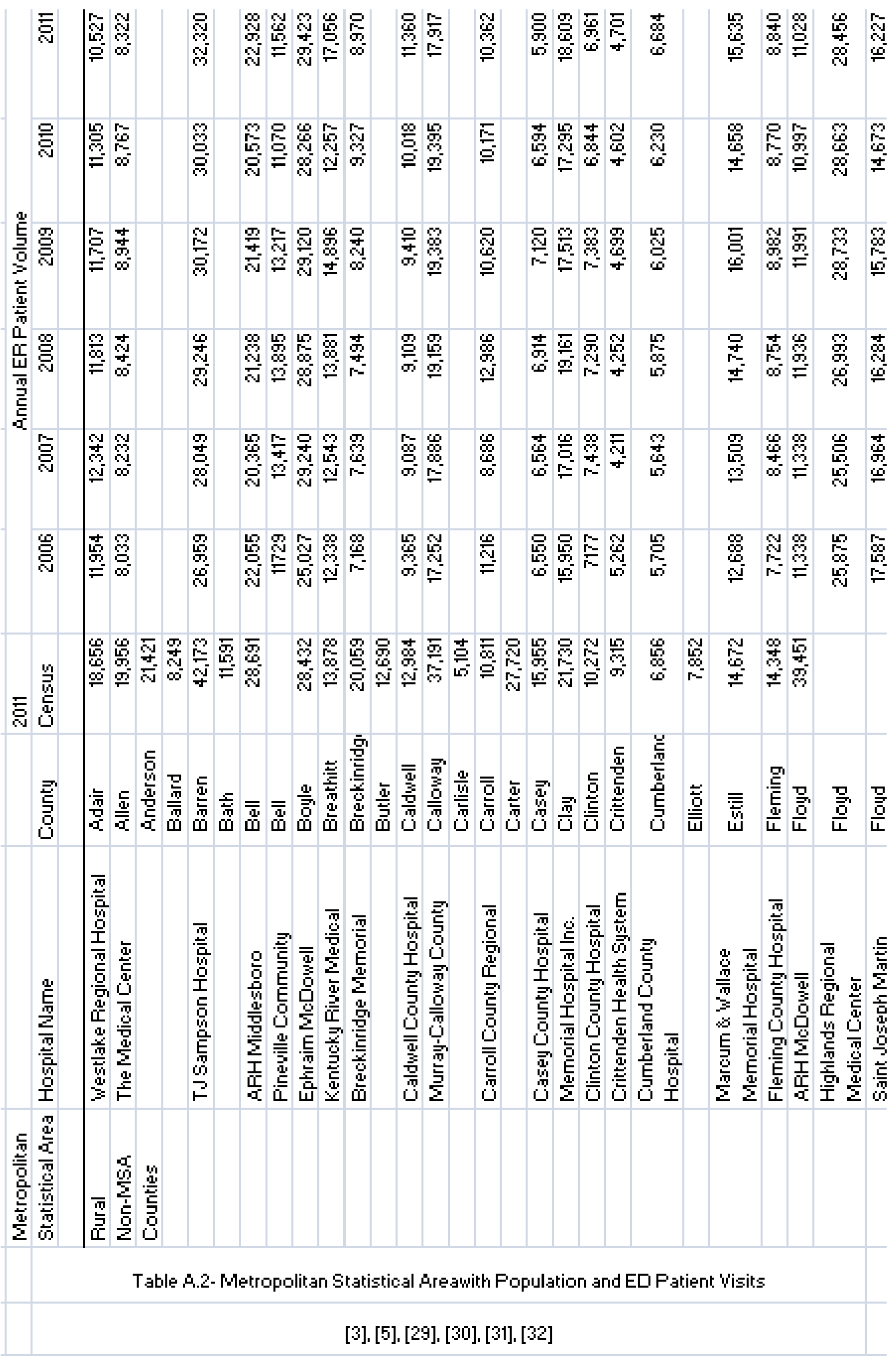




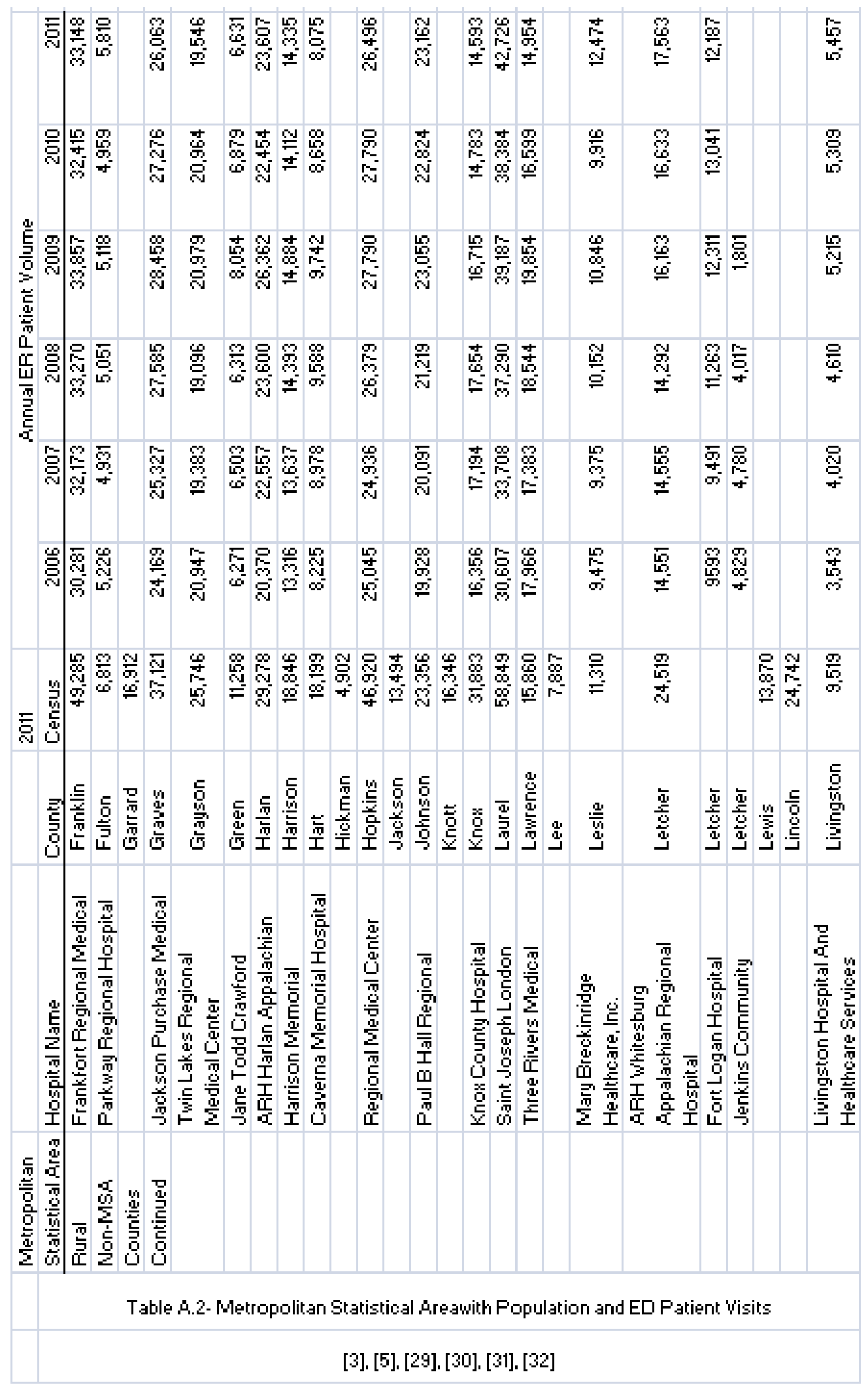




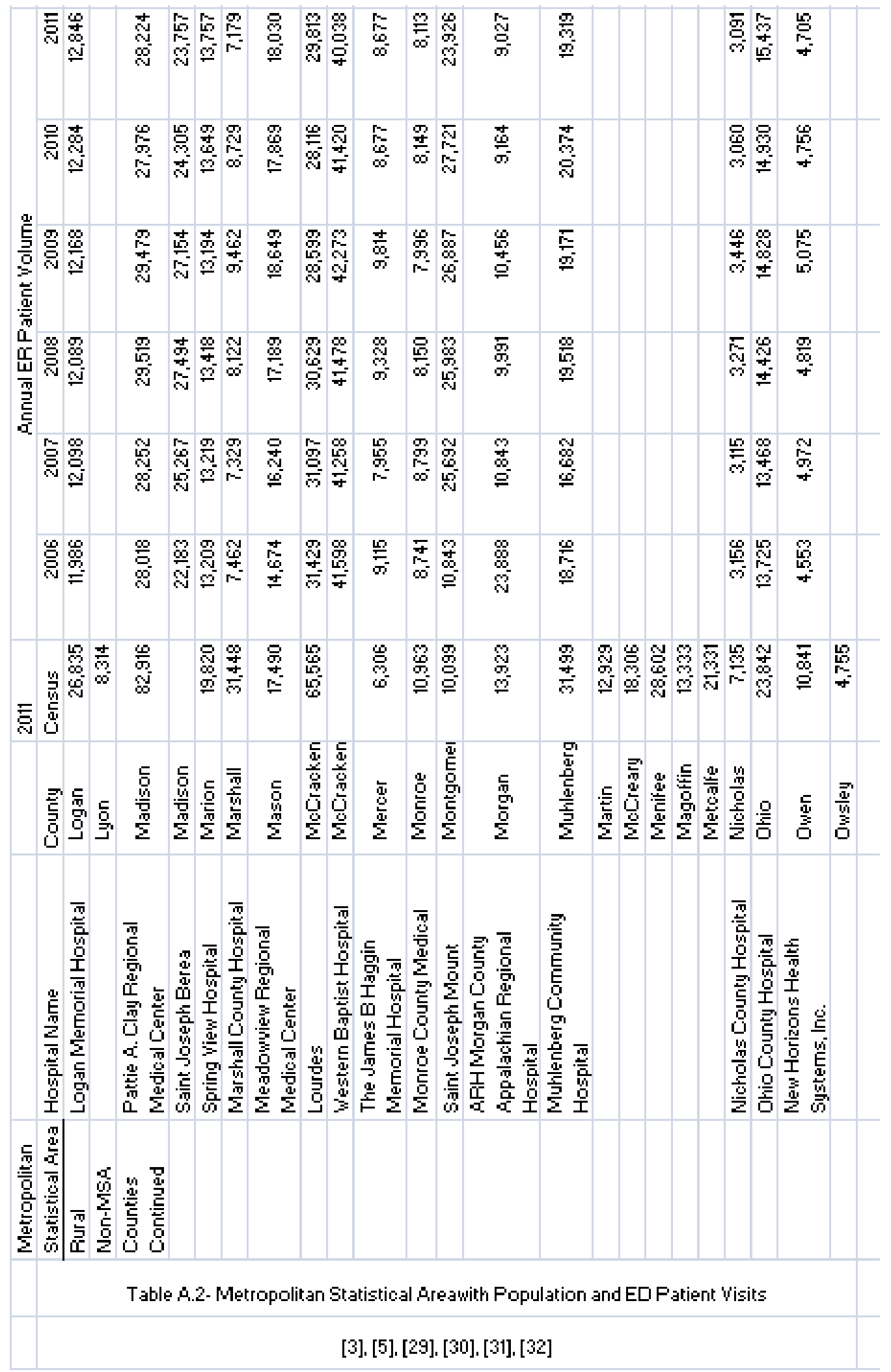




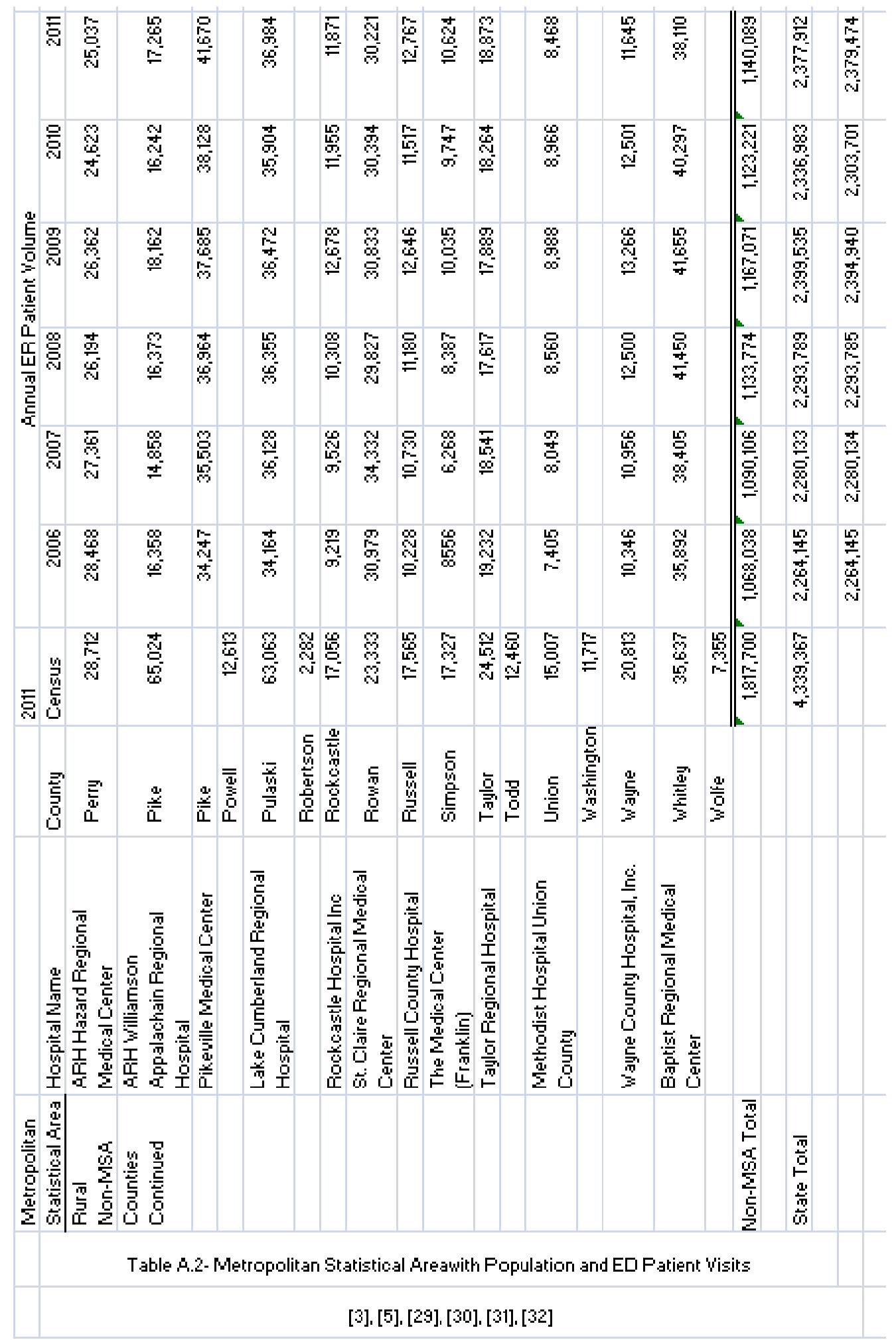


APPENDIX III

ED PATIENT CARE TASK LISTING 


\begin{tabular}{|c|c|c|c|c|c|c|c|}
\hline \multicolumn{3}{|c|}{ Procedure } & \multicolumn{5}{|c|}{ Resource Utilized } \\
\hline Abbreviation & Full Name & Description & $\begin{array}{l}\text { Write } \\
\text { Order }\end{array}$ & $\begin{array}{l}\text { Enter } \\
\text { Order }\end{array}$ & $\begin{array}{l}\text { Phone } \\
\text { Call }\end{array}$ & Procedure & Other \\
\hline Blood & Blood Work & $\begin{array}{l}\text { Drawing Blood to } \\
\text { analyze in the lab }\end{array}$ & MD & $\mathrm{N}$ or $\mathrm{T}$ & & $\mathrm{N}$ & $\mathrm{L}$ \\
\hline Swab & Swab & $\begin{array}{l}\text { Nasal, throat, or wound } \\
\text { swab for certain tests } \\
\text { (Strep, flu, culture, etc) }\end{array}$ & MD & $\mathrm{N}$ or $\mathrm{T}$ & & $\mathrm{N}$ or $\mathrm{T}$ & $\mathrm{L}$ \\
\hline UA & Urinalysis & $\begin{array}{l}\text { Collection of Urine for } \\
\text { analysis (either from } \\
\text { Cath or Clean Catch) }\end{array}$ & MD & $\mathrm{N}$ or $\mathrm{T}$ & & $\mathrm{N}$ or $\mathrm{T}$ & $\mathrm{L}$ \\
\hline $\mathrm{ABG}$ & $\begin{array}{l}\text { Arterial } \\
\text { Blood Gas }\end{array}$ & $\begin{array}{l}\text { Collection of blood from } \\
\text { an artery }\end{array}$ & MD & $\mathrm{N}$ or $\mathrm{T}$ & $\mathrm{N}$ or $\mathrm{T}$ & & $\mathrm{RE}$ \\
\hline EKG & $\begin{array}{l}\text { Electro- } \\
\text { Cardiogram }\end{array}$ & $\begin{array}{l}\text { placing electrodes and } \\
\text { running EKG on patient }\end{array}$ & MD & $\mathrm{N}$ or $\mathrm{T}$ & $\mathrm{N}$ or $\mathrm{T}$ & & $\mathrm{RE}$ \\
\hline NEBS & $\begin{array}{l}\text { Nebulizer } \\
\text { Treatment }\end{array}$ & $\begin{array}{l}\text { Giving medications by } \\
\text { inhalation nebulizers }\end{array}$ & MD & $\mathrm{N}$ or $\mathrm{T}$ & $\mathrm{N}$ or $\mathrm{T}$ & $\mathrm{N}$ & $\mathrm{RE}$ \\
\hline Xray & X-Ray & $\begin{array}{l}\text { Portable (machine to ER) } \\
\text { or Department (sending } \\
\text { pt to xray dept) }\end{array}$ & MD & $\mathrm{N}$ or $\mathrm{T}$ & & & RA \\
\hline CT w/o & $\begin{array}{l}\text { CT scan No } \\
\text { contrast }\end{array}$ & Cat Scan with no contrast & MD & $\mathrm{N}$ or $\mathrm{T}$ & & & RA \\
\hline CT with & $\begin{array}{l}\text { CT scan } \\
\text { with contrast }\end{array}$ & $\begin{array}{l}\text { Cat Scan with IV } \\
\text { contrast, oral contrast, or } \\
\text { both }\end{array}$ & MD & $\mathrm{N}$ or $\mathrm{T}$ & & & RA \\
\hline IV & IV & $\begin{array}{l}\text { Consists of a Sal-lock or } \\
\text { IV drip }\end{array}$ & MD & & & $\mathrm{N}$ & RA \\
\hline IV med & $\begin{array}{l}\text { IV } \\
\text { medications }\end{array}$ & $\begin{array}{l}\text { injecting meds via the IV } \\
\text { (either drip or push) }\end{array}$ & MD & & & $\mathrm{N}$ & \\
\hline
\end{tabular}

Abbreviations: $\mathrm{MD}=$ Doctor, $\mathrm{N}=$ Nurse, $\mathrm{T}=\mathrm{ED}$ Technician, $\mathrm{RE}=$ Respiratory Department, $\mathrm{RA}=$ Radiology Department, L=Laboratory Department, UT=Ultrasound Technician

Table A.3 - ED Patient Care Tasks 


\begin{tabular}{|c|c|c|c|c|c|c|c|}
\hline \multicolumn{3}{|c|}{ Procedure } & \multicolumn{5}{|c|}{ Resource Utilized } \\
\hline Abbreviation & Full Name & Description & $\begin{array}{l}\text { write } \\
\text { order }\end{array}$ & $\begin{array}{l}\text { enter } \\
\text { order }\end{array}$ & $\begin{array}{l}\text { phone } \\
\text { call }\end{array}$ & Procedure & Other \\
\hline IV $a b x$ & $\begin{array}{l}\text { IV } \\
\text { antibiotics }\end{array}$ & $\begin{array}{l}\text { Injecting antibiotics via } \\
\text { IV (always a drip) }\end{array}$ & MD & & & $\mathrm{N}$ & \\
\hline IM meds & $\begin{array}{l}\text { IM } \\
\text { medications }\end{array}$ & $\begin{array}{l}\text { Injecting medication via } \\
\text { the intramuscular route }\end{array}$ & MD & & & $\mathrm{N}$ & \\
\hline PO med & $\begin{array}{l}\mathrm{PO} \\
\text { medications }\end{array}$ & $\begin{array}{l}\text { Giving medications by } \\
\text { mouth (tablets, capsules, } \\
\text { liquid) }\end{array}$ & MD & & & $\mathrm{N}$ & \\
\hline Nsg Prcd & $\begin{array}{l}\text { Nursing } \\
\text { Procedure }\end{array}$ & $\begin{array}{l}\text { Placing pt on a monitor, } \\
\text { checking blood pressure, } \\
\text { etc. }\end{array}$ & MD & & & $\mathrm{N}$ & \\
\hline Foley & $\begin{array}{l}\text { Foley } \\
\text { Catheter }\end{array}$ & $\begin{array}{l}\text { Placing a catheter in the } \\
\text { bladder }\end{array}$ & MD & & & $\mathrm{N}$ & \\
\hline Sutures & Sutures & $\begin{array}{l}\text { Doctor preparing, } \\
\text { cleaning, and sewing up a } \\
\text { wound }\end{array}$ & & & & $\mathrm{N}, \mathrm{T} \& \mathrm{MD}$ & \\
\hline MD Major & $\begin{array}{l}\text { MD Major } \\
\text { Procedure }\end{array}$ & $\begin{array}{l}\text { Intubation, Chest Tube, } \\
\text { Central Line, large } \\
\text { wounds, large abscesses }\end{array}$ & & & & MD & \\
\hline MD middle & $\begin{array}{l}\text { MD Middle } \\
\text { Procedure }\end{array}$ & $\begin{array}{l}\text { Most sutures, small } \\
\text { abscesses, dermabond, }\end{array}$ & & & & MD & \\
\hline MD minor & $\begin{array}{l}\text { MD Minor } \\
\text { Procedure }\end{array}$ & $\begin{array}{l}\text { Splinting extremity, } \\
\text { foreign body removal } \\
\text { from eye or ear }\end{array}$ & & & & MD & \\
\hline Exm only & Exam Only & $\begin{array}{l}\text { Physician peforms an } \\
\text { exam no other procedures } \\
\text { or tests are preformed }\end{array}$ & & & & MD & \\
\hline Ultrasou & Ultrasound & $\begin{array}{l}\text { An Ultrasound test is } \\
\text { performed }\end{array}$ & MD & $\mathrm{N}$ or $\mathrm{T}$ & $\mathrm{N}$ or $\mathrm{T}$ & & UT \\
\hline Oxyg & $\begin{array}{l}\text { Oxygen } \\
\text { Therapy }\end{array}$ & $\begin{array}{l}\text { The patient is given an } \\
\text { oxygen treatment }\end{array}$ & MD & & $\mathrm{N}$ or $\mathrm{T}$ & $\mathrm{N}$ & $\mathrm{RE}$ \\
\hline Transfer & $\begin{array}{l}\text { Transfer of a } \\
\text { patient }\end{array}$ & $\begin{array}{l}\text { Patient is transferred to a } \\
\text { higher level hospital }\end{array}$ & MD & $\mathrm{N}$ or $\mathrm{T}$ & $\mathrm{N}$ or $\mathrm{T}$ & $\mathrm{N}, \mathrm{T} \& \mathrm{MD}$ & \\
\hline Admit & $\begin{array}{l}\text { Admission } \\
\text { of a patient }\end{array}$ & $\begin{array}{l}\text { Patient is admitted to the } \\
\text { Hospital }\end{array}$ & MD & $\mathrm{N}$ or $\mathrm{T}$ & Yes & $\mathrm{N}, \mathrm{T} \& \mathrm{MD}$ & \\
\hline
\end{tabular}

Abbreviations: $\mathrm{MD}=$ Doctor, $\mathrm{N}=$ Nurse, $\mathrm{T}=\mathrm{ED}$ Technician, $\mathrm{RE}=$ Respiratory Department,

RA=Radiology Department, L=Laboratory Department, UT=Ultrasound Technician

Table A.3 - ED Patient Care Tasks 


\section{APPENDIX IV}

TIME STUDY DATA COLLECTION TEMPLATE 


\begin{tabular}{|c|c|c|c|c|c|c|c|c|c|c|c|c|c|c|c|c|c|c|c|c|c|c|c|}
\hline Time & 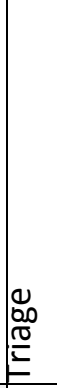 & 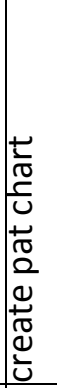 & 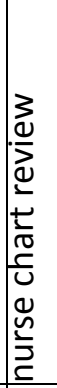 & 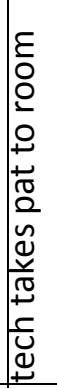 & 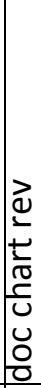 & 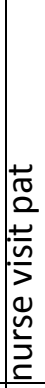 & 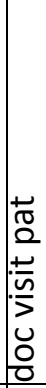 & 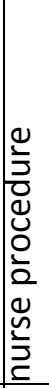 & 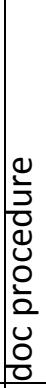 & 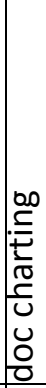 & 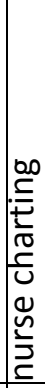 & 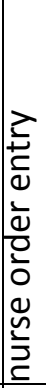 & 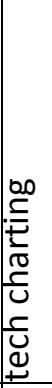 & 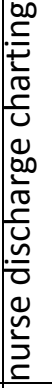 & 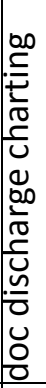 & 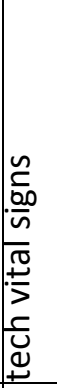 & \begin{tabular}{|l} 
\\
Do \\
0 \\
\end{tabular} & 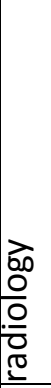 & 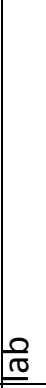 & 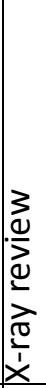 & 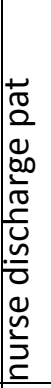 & 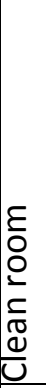 & Time \\
\hline & & & & & & & & & & & & & & & & & & & & & & & \\
\hline & & & & & & & & & & & & & & & & & & & & & & & \\
\hline & & & & & & & & & & & & & & & & & & & & & & & \\
\hline & & & & & & & & & & & & & & & & & & & & & & & \\
\hline & & & & & & & & & & & & & & & & & & & & & & & \\
\hline & & & & & & & & & & & & & & & & & & & & & & & \\
\hline & & & & & & & & & & & & & & & & & & & & & & & \\
\hline & & & & & & & & & & & & & & & & & & & & & & & \\
\hline & & & & & & & & & & & & & & & & & & & & & & & \\
\hline & & & & & & & & & & & & & & & & & & & & & & & \\
\hline & & & & & & & & & & & & & & & & & & & & & & & \\
\hline & & & & & & & & & & & & & & & & & & & & & & & \\
\hline & & & & & & & & & & & & & & & & & & & & & & & \\
\hline & & & & & & & & & & & & & & & & & & & & & & & \\
\hline & & & & & & & & & & & & & & & & & & & & & & & \\
\hline & & & & & & & & & & & & & & & & & & & & & & & \\
\hline & & & & & & & & & & & & & & & & & & & & & & & \\
\hline & & & & & & & & & & & & & & & & & & & & & & & \\
\hline & & & & & & & & & & & & & & & & & & & & & & & \\
\hline & & & & & & & & & & & & & & & & & & & & & & & \\
\hline
\end{tabular}

Table A.4 - Time Study Data Collection Template 


\section{APPENDIX V}

COMPLETED

TIME STUDY DATA COLLECTION FORM 


\begin{tabular}{|c|c|c|c|c|c|c|c|c|c|c|c|c|c|c|c|c|c|c|c|c|c|c|c|}
\hline Time & 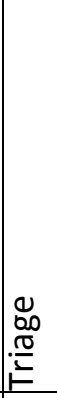 & 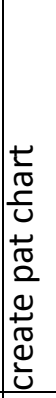 & 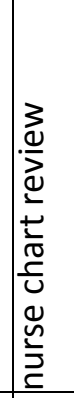 & 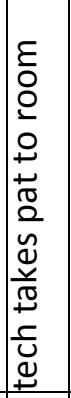 & 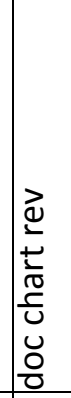 & 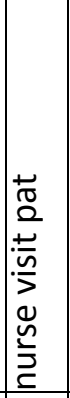 & 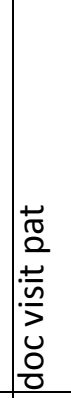 & 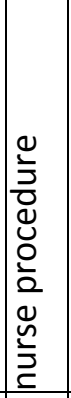 & 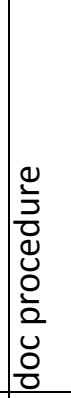 & 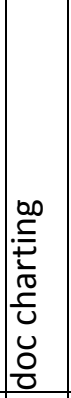 & 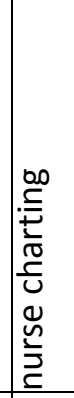 & 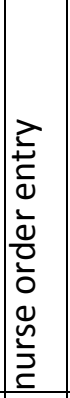 & 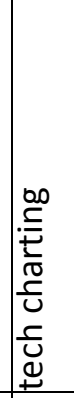 & 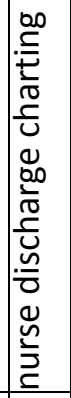 & 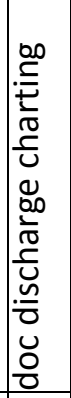 & 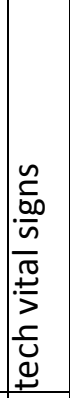 & $\frac{20}{0}$ & 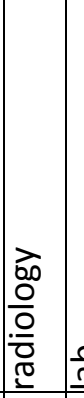 & $\frac{0}{\underline{\underline{O}}}$ & 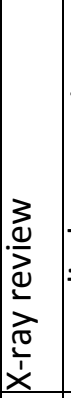 & 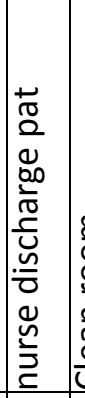 & 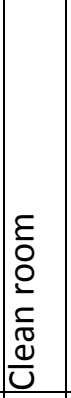 & Time \\
\hline $1: 54$ & & & & $x$ & & & & & & & & & & & & & & & & & & & 1:54:15 \\
\hline 1:54:15 & & $x$ & & & & & & & & & & & & & & & & & & & & & 1:56:00 \\
\hline $2: 35: 25$ & & & & & & & $x$ & & & & & & & & & & & & & & & & 2:37:27 \\
\hline $2: 37: 27$ & & & & & & & & & & & & & & & & & & & & $x$ & & & 2:41:00 \\
\hline 2:41:00 & & & & & & & $x$ & & & & & & & & & & & & & & & & 2:50:49 \\
\hline 2:51:08 & & & & & & & & & & & & $x$ & & & & & & & & & & & 2:53:25 \\
\hline $3: 14: 07$ & & & & & & & & & & & & & & & & & & $x$ & & & & & $3: 31: 54$ \\
\hline $3: 14: 07$ & & & & & & & & & & & & & $x$ & & & & & & & & & & $3: 14: 15$ \\
\hline $3: 31: 54$ & & & & & & $x$ & & & & & & & & & & & & & & & & & $3: 33: 18$ \\
\hline $3: 33: 18$ & & & & & & & $x$ & & & & & & & & & & & & & & & & $3: 34: 00$ \\
\hline & & & & & & & & & & & & & & & & $x$ & & & & & & & \\
\hline $3: 50: 00$ & & & & & & & & & & & & & & & & & & & & $x$ & & & 4:01:15 \\
\hline 4:01:15 & & & & & & & $x$ & & & & & & & & & & & & & & & & 4:07:30 \\
\hline 4:07:30 & & & & & & & & & & & & & & & $x$ & & & & & & & & 4:11:35 \\
\hline 4:11:35 & & & & & & & & & & & & & & $x$ & & & & & & & & & 4:17:45 \\
\hline $4: 17: 45$ & & & & & & & & & & & & & & & & & & & & & $x$ & & $4: 20: 50$ \\
\hline 4:20:50 & & & & & & & & & & & & & & $x$ & & & & & & & & & 4:22:27 \\
\hline 4:21:10 & & & & & & & & & & & & & & & & & & & & & & $x$ & 4:22:50 \\
\hline 5:14:57 & $x$ & & & & & & & & & & & & & & & & & & & & & & $5: 20: 23$ \\
\hline 5:24:00 & & & & $x$ & & & & & & & & & & & & & & & & & & & 5:25:15 \\
\hline $5: 20: 23$ & & & & & & & & & & & $x$ & & & & & & & & & & & & $5: 26: 30$ \\
\hline 5:39:47 & & & & & $x$ & & & & & & & & & & & & & & & & & & 5:41:00 \\
\hline 5:41:00 & & & & & & $x$ & & & & & & & & & & & & & & & & & $5: 44: 32$ \\
\hline 5:44:32 & & & & & & & & & & $x$ & & & & & & & & & & & & & 5:51:33 \\
\hline 5:51:30 & & & & & & & & $x$ & & & & & & & & & & & & & & & 6:01:13 \\
\hline 5:53:00 & & & & & & & & & & & & & & $x$ & & & & & & & & & 5:59:46 \\
\hline
\end{tabular}

Table A.5 - Completed Time Study Data Collection Form 


\section{APPENDIX VI}

DESCRIPTION OF PATIENT ACUITY LEVELS 


\begin{tabular}{|c|c|c|c|}
\hline Level II & Level III & Level IV & Level V \\
\hline Ace wrap application & AMA* & Admit/OBS - reg. Room & Admit OR. \\
\hline Ear exam & B/P Monitor-auto & Cardiac monitor appli. & Admit ICU \\
\hline Emotional support-pt & $\begin{array}{l}\text { Care related to device } \\
\text { (not } \\
\text { insertion/reinsertion) }\end{array}$ & Charcoal administration & Admit Telemetry \\
\hline Enemas 1-2 & Consents & Combative/belliger. pt* & Antivenin monitoring \\
\hline Eye exam & C-spine precautions* & Legal spec. collections & $\begin{array}{c}\text { Behavioral issues- } \\
\text { psych* }\end{array}$ \\
\hline Eye patch application & Doppler pulses* & Non-inject meds $>6$ & $\begin{array}{l}\text { Core temperature } \\
\text { interventions }\end{array}$ \\
\hline FSBS 1-2 & Elimination needs & $\begin{array}{l}\text { Non-invasive airway } \\
\text { mgmt* }\end{array}$ & $\begin{array}{l}\text { Decontamination of } \\
\text { hazardous material }\end{array}$ \\
\hline First aid procedures & $\begin{array}{l}\text { Emotion support- } \\
\text { pt/fam* }\end{array}$ & $\begin{array}{l}\text { Notify outside agency }>3 \\
\text { calls }\end{array}$ & Rape/assault exam \\
\hline $\begin{array}{l}\text { Inst. on prescription } \\
\text { meds }\end{array}$ & Enema $>2$ & Patient Teaching* & ReassessmentNS>4 \\
\hline Med. record retrieval & Eye irrigation & Pelvic Exam-OB* & $\begin{array}{l}\text { Restraint appli. \& } \\
\text { monitor }\end{array}$ \\
\hline Nasal exam & Fecal disimpaction & Post mortem care & Transfer - ground EMS \\
\hline $\begin{array}{l}\text { Non-injectable meds } 1 \text { - } \\
3 "\end{array}$ & Fetal heart tones* & $\begin{array}{l}\text { Pt. Accompany- } \\
\text { diagnostic* }\end{array}$ & Transfer - air EMS \\
\hline $\begin{array}{l}\text { Notify outside agency } \\
<3 \text { calls }\end{array}$ & FSBS $>2$ & Re-assessmentNS $\times 4^{*}$ & $\begin{array}{l}\text { Transfer - Nsg. } \\
\text { Accompany }\end{array}$ \\
\hline $\begin{array}{l}\text { Order entry for } \\
\text { diagnostic test results } \\
\text { (lab or } x \text {-ray) }\end{array}$ & $\begin{array}{l}\text { Med. Rec. retrieval after } \\
\text { hrs }\end{array}$ & Take home meds $>3$ & \\
\hline Ortho device, simple*" & $\begin{array}{l}\text { NIG tube insertion-no } \\
\text { lavage }\end{array}$ & Transfer - POV & \\
\hline Oxygen application & Neuro exam & & \\
\hline $\begin{array}{l}\text { Pelvic exam, simple, } \\
\text { non- OB }\end{array}$ & Non-inject meds 4-6" & & \\
\hline Procedure scheduling & $\begin{array}{l}\text { Ortho device, } \\
\text { complex*** }\end{array}$ & & \\
\hline Pulse oximetry & \multirow{2}{*}{$\begin{array}{l}\text { Order entry for } \\
\text { diagnostic test results } \\
\text { (lab and } x \text {-ray) }\end{array}$} & & \\
\hline & & & \\
\hline Re-assessmentNS x $2 *$ & Pelvic exam w/specimen & & \\
\hline $\begin{array}{l}\text { Ring removal, } \\
\text { simp/single }\end{array}$ & Phone orders from MD & & \\
\hline Specimen collection & ReassessmentNS $\times 3^{*}$ & & \\
\hline Steri strip applic. & $\begin{array}{l}\text { Ring removal, } \\
\text { compli/multi }\end{array}$ & & \\
\hline Strain urine & Suctioning & & \\
\hline Tilt test (orthostatic VS) & Superficial FB Removal & & \\
\hline U bag placement & Take home meds $1-3$ & & \\
\hline \multicolumn{4}{|l|}{ Visual acuity } \\
\hline $\begin{array}{l}\text { Wound cleaning (no } \\
\text { suture) }\end{array}$ & & & \\
\hline
\end{tabular}

If no items are checked in the above charge levels, the charge is assumed to be a Level 1.

Critical Care Charge: This charge can only be taken if more than

Reference [33]

Table A.6 - Acuity Level Descriptions 
APPENDIX VII

HOSPITAL ED PATIENT DATA FOR 2011 


\begin{tabular}{|c|c|c|c|c|}
\hline Month & $\begin{array}{l}\text { ED } \\
\text { Census }\end{array}$ & $\begin{array}{l}\text { X-Ray } \\
\text { Orders }\end{array}$ & $\begin{array}{l}\text { Patients } \\
\text { Admitted }\end{array}$ & Transferred \\
\hline January & 683 & 206 & 59 & 40 \\
\hline February & 712 & 311 & 64 & 41 \\
\hline March & 810 & 411 & 60 & 44 \\
\hline April & 748 & 376 & 64 & 50 \\
\hline May & 751 & 336 & 50 & 49 \\
\hline June & 687 & 320 & 67 & 49 \\
\hline July & 687 & 329 & 71 & 43 \\
\hline August & 898 & 408 & 62 & 55 \\
\hline September & 725 & 312 & 64 & 45 \\
\hline October & 724 & 328 & 62 & 44 \\
\hline November & 668 & 300 & 59 & 42 \\
\hline December & 673 & 315 & 60 & 43 \\
\hline Total & 8766 & 3952 & 742 & 545 \\
\hline \multicolumn{2}{|c|}{$\%$ of Total Patients } & $45 \%$ & $8 \%$ & $6 \%$ \\
\hline
\end{tabular}

Table A.7 - Monthly ED Census, X-Rays, and Admitted Patients Counts 


\section{APPENDIX VIII}

LARGER IMAGE OF HOSPITAL ARENA SIMULATION MODEL 


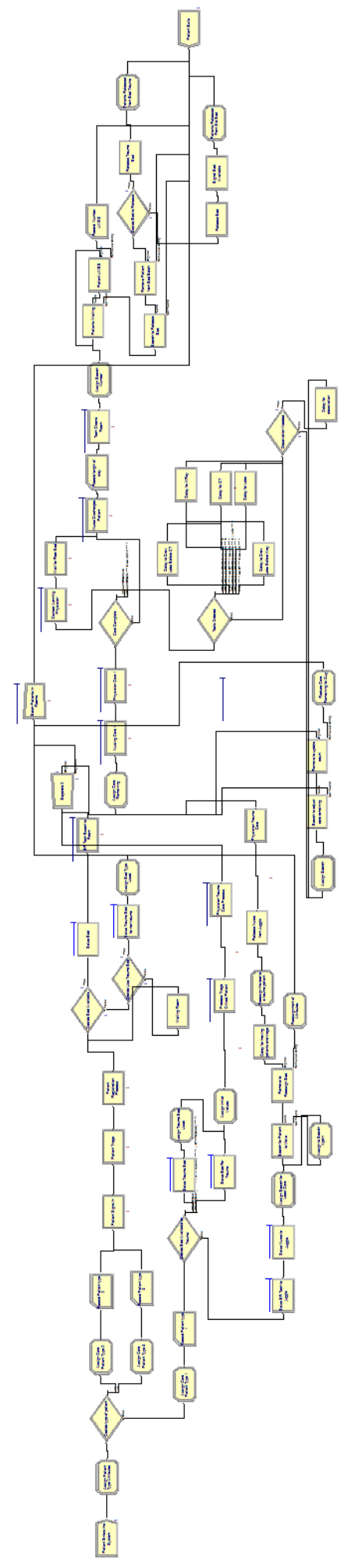

Figure A.8 - Larger Image of Hospital Simulation Model 


\section{REFERENCES}

1. Moskop, J.C., PhD, Sklar, D.P., MD, Geiderman, J.M., MD., Bookman, K.J., MD (2009) Emergency dEpartrment Crowding, Part 1 - Concept, Causes, and Moral Consequences. Annuals of Emergency Medicine, Vol 53, no. 5 p 605.

2. Kentucky Office of Rural Health, Kentucky Rural Health Works, Kentucky Hospital Association. 2008. Kentucky Rural health Plan. Medicare Rural Hospital Flexibility, (24 November).

3. Commonwealth of Kentucky Cabinet for Health and Family Services Office of Health Policy 2011 KY Annual Hospital Utilization Services Report (September 2012).

4. 42 U.S. code Section 1395dd.

5. Commonwealth of Kentucky Cabinet for Health and Family Services Office of Health Policy. 2010 KY Annual Hospital Utilization Services Report (August 2011).

6. McNulty, J.E., MD, Hampers, L.C., MD, Krug, S.E., MD, (2001) "Primary Care and Emergency Department Decision Making", Archives of Pediatrics \& Adolescent Medicine, Vol. 155, pp. 1266-1270.

7. Washington DC: National Academies Press, Committee on Quality of Healthcare in America. 2000. To Err is Human: Building a Safer Health System.

8. Washington DC: National Academies Press, Committee on Quality of Healthcare in America. 2001. Crossing the Quality Chasm: A New Health System for the $21^{\text {st }}$ Century.

9. Reid, P.P., Compton, W.D., Grossmen, J.H. 2005. Building a Better Delivery System: A New Engineering/Health Care Partnership. Washington, DC: National Academies Press.

10. Paul, S.A., Reddy, M.C., DeFlitch, C.J. 2010. A systematic Review of Simulation studies Investigating Emergency Department Overcrowding. Simulation 86:559-571. 
11. Han,J.H., Zhou, C., France, D.J., Zhong, S., Jones, I., Storrow, A.B., \& Aronsky, D. 2007. The Effect of Emergency Department Expansion on Emergency Department Overcrowding. Academic Emergency Medicine 14(4): 338-343.

12. Beck, E., Balasubramanian, H., Henneman, P.L. 2009. Resource Management and Process Change in a Simplified Model of the Emergency Department. Proceedings of 2009 Winter Simulation Conference (Austin, Texas), 1887-1895.

13. Holm, L.B., Dahl, F.A. 2009. Simulating the Effect of Physician Triage on the Emergency Department of Akershus University Hospital. Proceedings of 2009 Winter Simulation Conference (Austin, Texas), 1896-1905.

14. Khare, R.K., Powell, E.S., Reinhardt, G., Lucenti, M. 2009. Adding More Beds to the Emergency Department or Reducing Admitted Patient Boarding Times: Which Has a More Significant Influence on Emergency Department Congestion? Annals of Emergency Medicine 53(5): 575-585.

15. Babool K., Griffiths J.D., Knight V.A., Nelson A.V., Voake C., Williams J.E. 2012. How efficient can an Emergency Unit Be? A Perfect World Model. Emergency Medicine Journal 10:1136-1142.

16. Kelton,W. David, Sadowski, Randall P., Swets, Nancy B. 2010. Simulation With Arena Fifth Addition. New Yory: McGraw-Hill.

17. Ceglowske, R., Churilov, L. \& Wasserthiel, J. 2007. Combining Data Mining and Discrete Event Simulation for a Value-Added View of a Hospital Emergency Department. Journal of the Operational Research Society 58: 246-254.

18. Miller, M., Ferrin, D., \& Shahi, N. 2009. Estimating Patient Surge Impact on Boarding Time in Several Regional Emergency Departments. Proceedings of 2009 Winter Simulation Conference (Austin, Texas) 1906-1915.

19. Connelly, L.G., Bair, A.E. 2004 Discrete Event Simulation of Emergency Department Activity: A Platform for System-Level Operations Research. Academic Emergency Medicine 11:1177-1185. 
20. McGuire, F. 1994. Using Simulation to Reduce Length of Stay in Emergency Departments. Proceedings of the 1994 Winter Simulation Conference (Orlando, Florida) 861-867.

21. Ismail, K., Waleed, A., Arisha, A. 2010. Integrating Balanced Scorecard and Simulation Modeling to Improve Emergency Department Performance in Irish Hospitals. Proceedings of the 2010 Winter Simulation Conference (Baltimore, Maryland) 2340-2351.

22. Nafarrate, Adrain R., Fowler, John W., Wu, Teresa (2010). Bi-Criteria Analysis of Ambulance Diversion Policies. Proceedings of the 2010 Winter Simulation Conference (Baltimore, Maryland) 2315-2326.

23. Gilboy N, Tanabe P, Travers DA, Rosenau AM, Eitel DR. Emergency Severity Index, Version 4: Implementation Handbook. Rockville, MD: Agency for Healthcare Research and Quality; 2005. AHRQ Publication No. 05-0046-2 Available at http://www.ahrq.gov/research/esi.

24. Fries B.E. (1976). Bibliography of Operations Research in Health-Care Systems. Operations Research 24(5): 801-814.

25. VanVonderen, M.L. 2008. Managing Rural Emergency Department Overcrowding. Journal of Trauma Nursing 15(3): 113-117.

26. Sasson C., Wiler J.L., Haukoos J.S., Sklar D., Kellermann A.L., Beck D., Urbina C., Heilpern K. ,Magid D.J. 2012. The Changing Landscape of America's Health Care system and the Value of Emergency Medicine. Academic Emergency Medicine. 10: 1204-1211.

27. Department of Health and Human Services. "Medicare and Medicaid Programs: Hospital Outpatient Prospective Payment; Ambulatory Surgical Center Payment; Hospital Value-Based Purchasing Program; Physician SelfReferral; and Patient Notification Requirements in Provider Agreements." Internet Source, 9 October 2012, available at: http://www.regulations.gov/\#!documentDetail;D=CMS-2011-0130-0537; accessed October 9, 2012.

28. United States Census Bureau, "Kentucky- 2010 Census Results total Population by County" Internet Source, available from http://www.census.gov/geo/www/maps/2010pop/ky_totalpop_2010map.pdf; accessed 8 October 2012. 
29. Commonwealth of Kentucky Cabinet for Health and Family Services Office of Health Policy. 2006 KY Annual Hospital Utilization Services Report (July 2007).

30. Commonwealth of Kentucky Cabinet for Health and Family Services Office of Health Policy. 2007 KY Annual Hospital Utilization Services Report (August 2008).

31. Commonwealth of Kentucky Cabinet for Health and Family Services Office of Health Policy. 2008 KY Annual Hospital Utilization Services Report (July 2009).

32. Commonwealth of Kentucky Cabinet for Health and Family Services Office of Health Policy. 2009 KY Annual Hospital Utilization Services Report (June 2010).

33. U.S. Department of Health and Human Services, Agency for Healthcare Research and Quality. 2011. Emergency Severity Index, Version 4:

Implementation Handbook. AHRQ Publication No. 05-0046-2 (December). 